University of Louisville

ThinkIR: The University of Louisville's Institutional Repository

$5-2013$

\title{
Production of high yield gold/gold-sulfide nanoparticles via cellulose membrane.
}

Kurtis T. James

University of Louisville

Follow this and additional works at: https://ir.library.louisville.edu/etd

\section{Recommended Citation}

James, Kurtis T., "Production of high yield gold/gold-sulfide nanoparticles via cellulose membrane." (2013). Electronic Theses and Dissertations. Paper 678.

https://doi.org/10.18297/etd/678

This Master's Thesis is brought to you for free and open access by ThinkIR: The University of Louisville's Institutional Repository. It has been accepted for inclusion in Electronic Theses and Dissertations by an authorized administrator of ThinkIR: The University of Louisville's Institutional Repository. This title appears here courtesy of the author, who has retained all other copyrights. For more information, please contact thinkir@louisville.edu. 
PRODUCTION OF HIGH YIELD GOLD/GOLD-SULFIDE NANOPARTICLES VIA CELLULOSE MEMBRANE

By

Kurtis T. James

B.S., University of Louisville, 2012

\author{
A Thesis \\ Submitted to the Faculty of the \\ University of Louisville \\ J.B. Speed School of Engineering \\ as Partial Fulfillment of the Requirements \\ for the Professional Degree
}

MASTER OF ENGINEERING

Department of Bioengineering

May 2013 


\section{PRODUCTION OF HIGH YIELD GOLD/GOLD-SULFIDE NANOPARTICLES VIA CELLULOSE MEMBRANE}

Submitted by:

Kurtis T. James

A Thesis Approved on

(Date)

by the Following Reading and Examination Committee:

Robert S. Keynton, Thesis Director

Andrea S. Gobin

Stuart J. Williams

Andre M. Gobin 


\section{ACKNOWLEDGMENTS}

The author would like to thank everyone who has helped in one way or another through undergraduate and graduate school at the University of Louisville.

Dr. Andre M. Gobin

Dr. Guandong Zhang

Dr. Xinghua Sun

Dr. Robert Keynton

Dr. Martin O'Toole

Dhruvinkumar Patel

Alex Keynton

Tom Priest

Dennis Stephens

I would also like thank my family and friends who have given me enormous support throughout my academic career. 


\begin{abstract}
The properties of gold nanoparticles (GNP) holds promising potential for drug delivery, diagnostics, plasmonic photothermal therapy of diseases, electronics, catalysis, and photovoltaics (Liu et al., 2006; Huang et al., 2003; Thompson, 2007; Atwater and Polman, 2010). This field is growing at a fast pace with the demand for GNPs ever increasing with slow progress on development of synthesis techniques. The objective of this study was to develop a new synthesis technique that produces gold/gold sulfide (GGS) nanoparticles with a high yield. This process can control the equilibrium shift of the surface plasmon resonance (SPR) of the nanoparticles (Patel, 2012). The goal of this research is to increase the total volume of GGS nanoparticles to be synthesized while keeping their tunability for the SPR absorption peak. This research has demonstrated the ability of cellulose membrane to reduce the need for purification steps, which are associated with traditional synthesis techniques for removing small colloidal gold $(<10$ $\mathrm{nm})$. It was found that controlling the surface area to volume ratio (SA/Vol) of the cellulose to GGS solution and temperature of the synthesis process, would provide, greater control over the SPR peak. Using these principles allows for larger volume synthesis to be performed while still retaining the ability to tune the SPR peak. It was also discovered that dialyzing out ions during the synthesis process makes bare GGS nanoparticles more stable over time. The time for the reaction to reach equilibrium was observed and showed an increase in temperature and/or SA/Vol reduces the reaction time. In conclusion, this study demonstrated how increasing the temperature and SA/Vol shifts the SPR peak and reduces the time for the reaction to reach equilibrium.
\end{abstract}




\section{TABLE OF CONTENTS}

Approval Page

Acknowledgments............................................................................................ ii

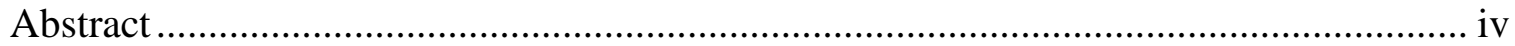

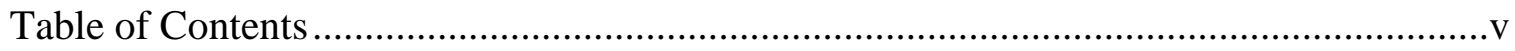

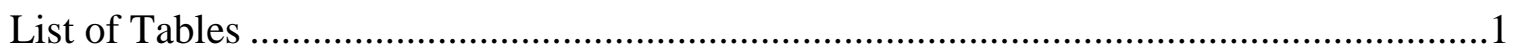

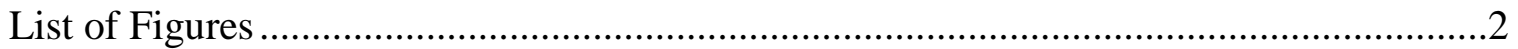

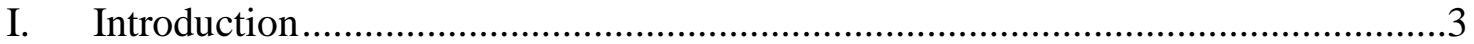

A. Problem Statement …………………………………...............................

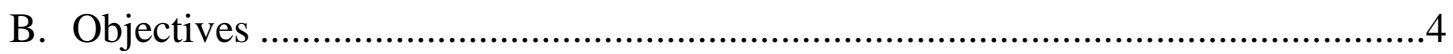

C. Therapeutic Applications ..............................................................................

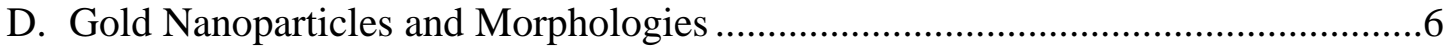

1. Surface Plasmon Resonance ………………………...........................

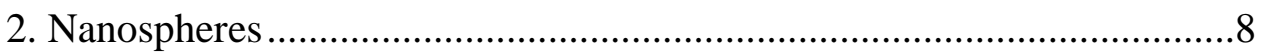

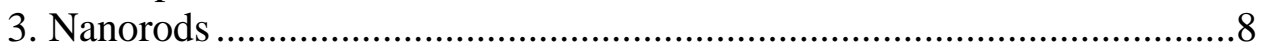

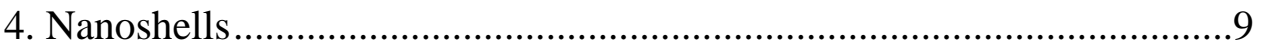

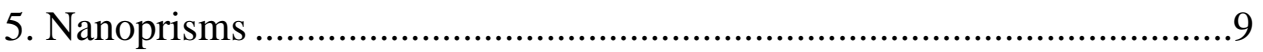

6. Gold/Gold Sulfide Nanoparticles.......................................................12

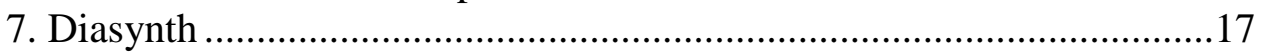

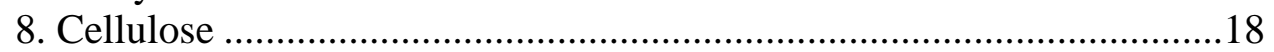

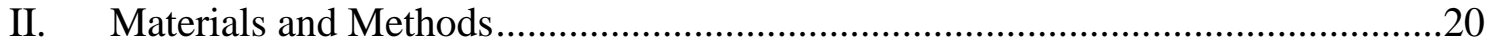

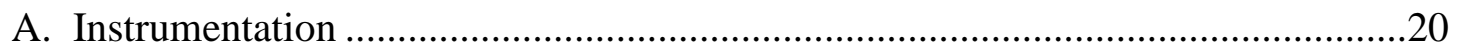

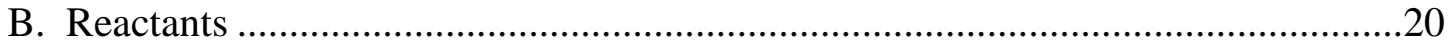

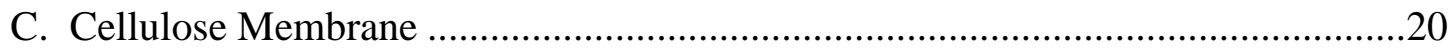

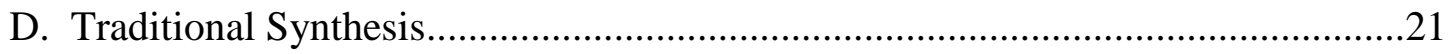

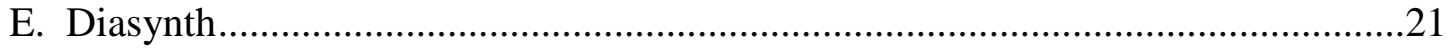

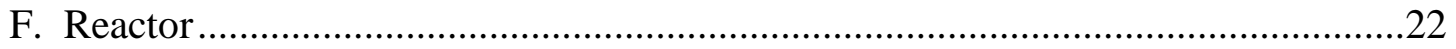

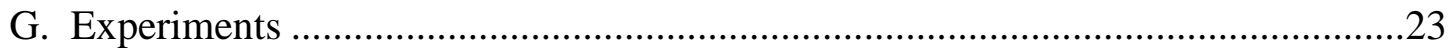

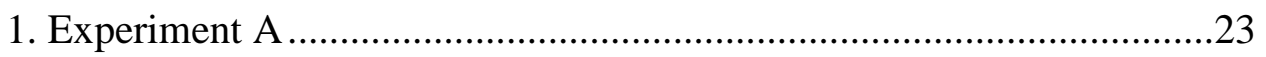

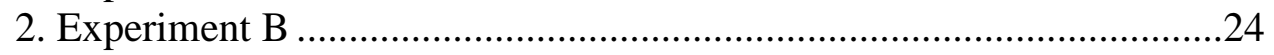

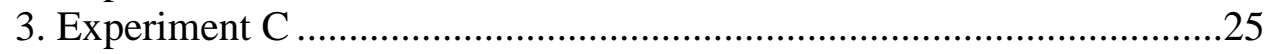

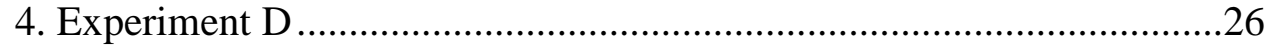

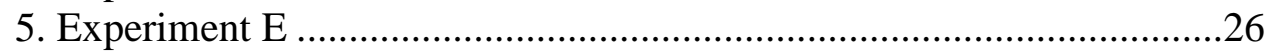

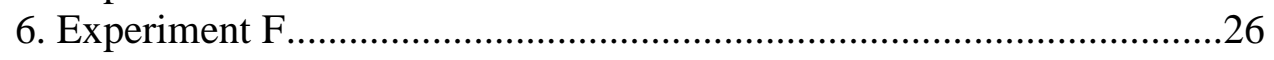

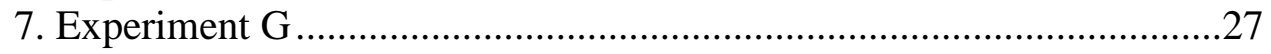

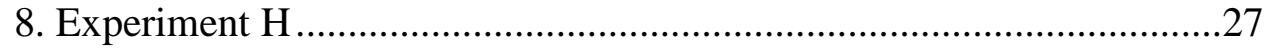

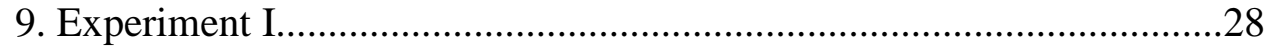

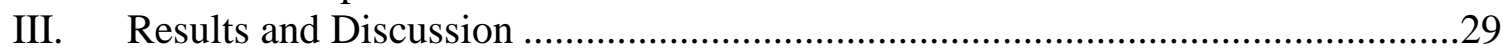

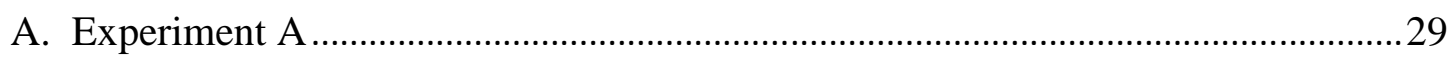

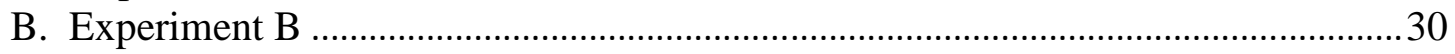

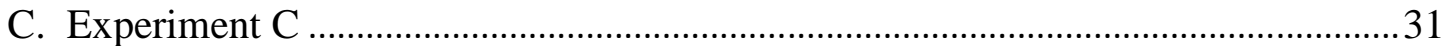

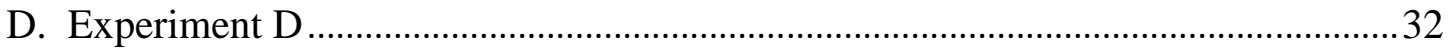

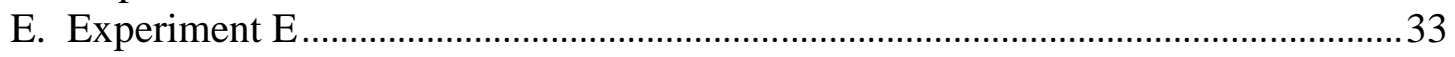

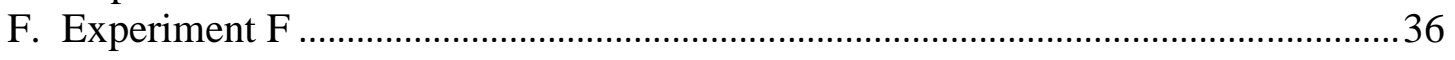

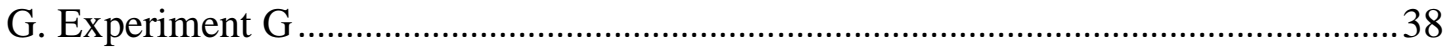




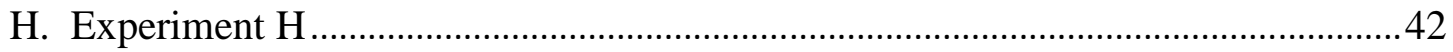

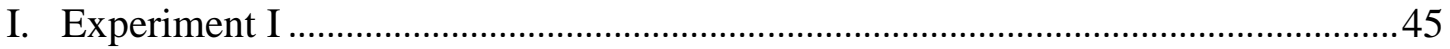

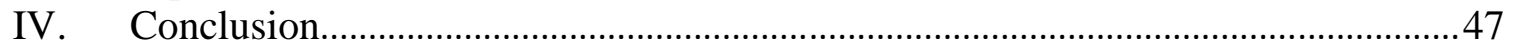

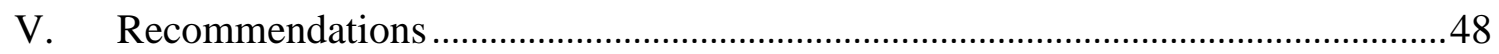

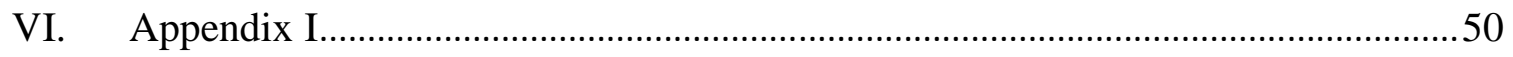

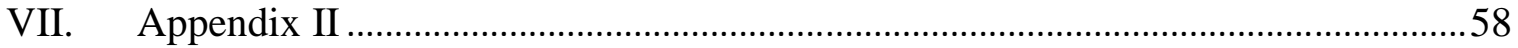

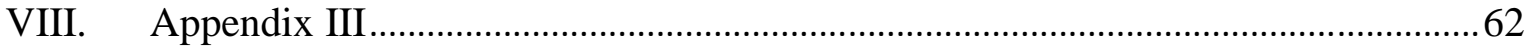

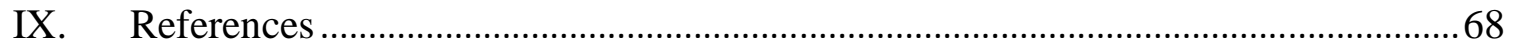




\section{LIST OF TABLES}

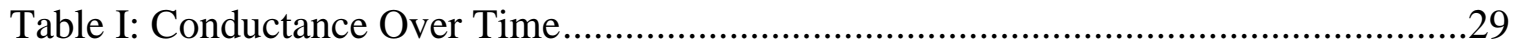

Table II: Experiment B GGS Sample Properties ...........................................................30

Table III: Experiment C GGS Sample Properties...............................................................32

Table IV: Experiment E GGS Sample Properties ..............................................................35

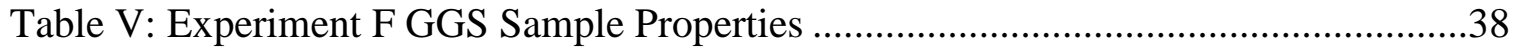

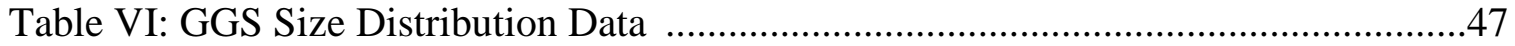

Table VII: Experiment G GGS Sample Properties ........................................................58

Table VIII: Experiment H GGS Sample Properties ………………………......................59 


\section{LIST OF FIGURES}

Figure 1: Graph depicting the nIR window …………...........................................

Figure 2: Illustration showing a localized surface plasmon ...........................................

Figure 3: Various Gold Nanoparticles of shapes and sizes..............................................11

Figure 4: Optical spectra of GGS nanoparticles ..............................................................13

Figure 5: UV-vis-NIR spectra of GGS nanoparticles before and after purification ..........14

Figure 6: TEM image of GGS nanoparticles with traditional synthesis .............................15

Figure 7: TEM image of GGS nanoparticles after purification .........................................16

Figure 8: Image of Non-Dialysis synthesis and dialyzed synthesis over $1 \mathrm{hr}$ time ..........17

Figure 9: TEM images of traditional synthesis and Diasynth..........................................18

Figure 10: TEM image and histogram of Au nanoparticles in cellulose fiber...................19

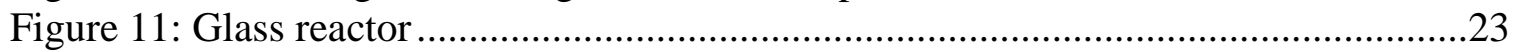

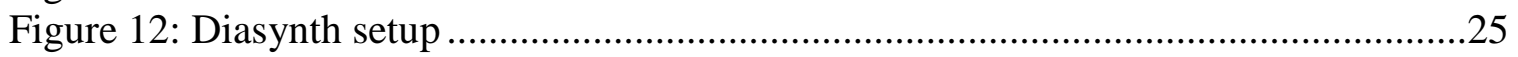

Figure 13: Conductance vs. time for GGS sample dialysate and DI water ......................22

Figure 14: The UV-spectra of Diasynth GGS nanoparticles with various surface areas...31

Figure 15: Reactor synthesis .......................................................................................

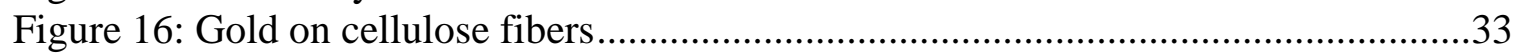

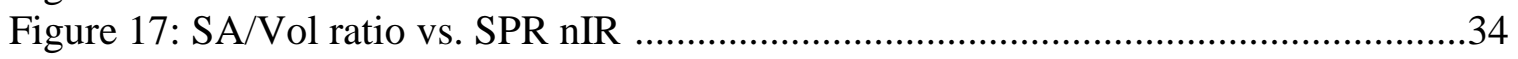

Figure 18: The UV-spectra SA/Vol ratio vs. SPR nIR GGS particles ................................35

Figure 19: The UV-spectra of GGS nanoparticles synthesized with dry Diasynth ...........37

Figure 20: The UV-spectra of GGS nanoparticles synthesized with dry Diasynth ............37

Figure 21: Temperature vs. SPR nIR peak placement ......................................................39

Figure 22: An example showing the equilibrium shift during a Diasynth reaction............40

Figure 23: An example showing the equilibrium point for a Diasynth sample .................40

Figure 24: Time of equilibrium vs Temperature ………….........................................41

Figure 25: Stability of the GGS nanoparticles after 14 days ...........................................42

Figure 26: Temperature vs. SPR nIR peak placement ......................................................43

Figure 27: Time of equilibrium vs Temperature …………………………………........4

Figure 28: Stability of the GGS nanoparticles after 14 days ............................................45

Figure 29: The UV-spectra of GGS nanoparticles at 800nm and 900nm.........................46

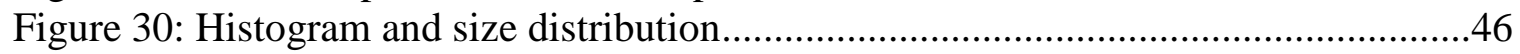

Figure 31: Residual plots for Experiment E …………............................................51

Figure 32: Residual plots for Experiment G …………...........................................53

Figure 33: Main effects plots for Experiment G …………...........................................54

Figure 34: Interaction plot for Experiment G ……………........................................54

Figure 35: Residual plots for Experiment $\mathrm{H}$............................................................56

Figure 36 Main effects plots for Experiment $\mathrm{H}$.......................................................57

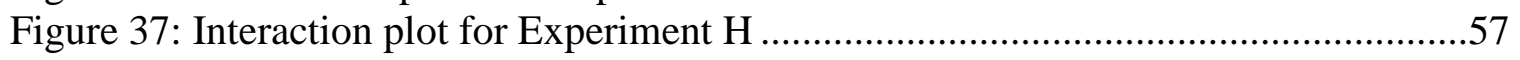

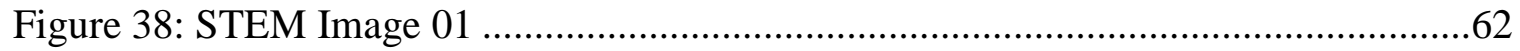

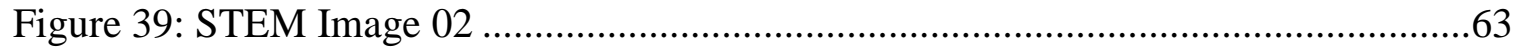

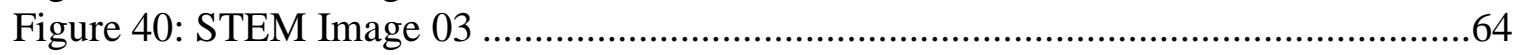

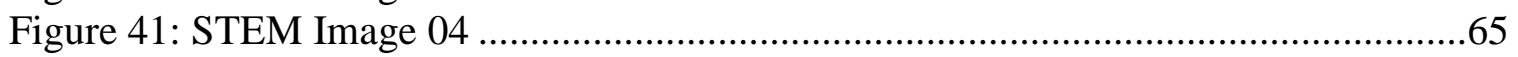

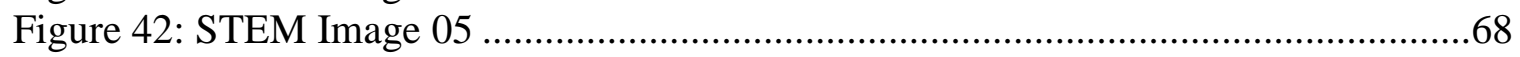

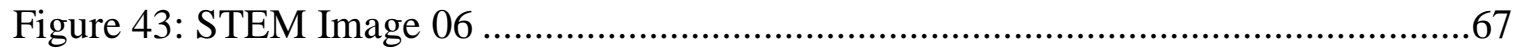




\section{INTRODUCTION}

\section{A. Problem Statement}

Over the past two decades, gold nanoparticles (GNPs) have been of great interest due to their unique physical and optical properties. The properties of GNPs hold promising potential for drug delivery, diagnostics, plasmonic photothermal therapy of diseases, electronics, catalysis, and photovoltaics (Liu et al., 2006; Huang et al., 2003; Thompson, 2007; Atwater and Polman, 2010). To date, research has focused on the application of GNPs, with slow progress on the development of new synthesis techniques, leaving a gap between research and applied technology. The desired goal for gold nanotechnology is the controlled growth of the size and shape, making GNPs robust tools. Many of the current synthesis techniques are intended for research purposes instead of industrial manufacturing. Most synthesis techniques require $24 \mathrm{hrs}$ to weeks to synthesize GNPs. Faster synthesis techniques have been shown to utilize a fast selfassembly process that reduces a gold salt with a sulfur group. Recently, Patel et al. (Patel, 2012) have demonstrated a new high yield synthesis process, known as "Diasynth", which uses a cellulose dialysis membrane as a reaction vessel to control the equilibrium shift favoring the growth of the gold/gold sulfide nanoparticles (GGS). Diasynth has a reaction time of less than an hour and removes the need for purification steps (Patel, 2012). This process, however, has difficulty in scaling up with volume while keeping the tunability of the surface plasmon resonance and repeatability constant. Therefore, finer control is needed with the Diasynth process to control the growth of the particles and retain the ability to increase the total volume of the reaction. 


\section{B. $\underline{\text { Objectives }}$}

The objective of this study is to develop a new synthesis technique that produces gold/gold sulfide (GGS) nanoparticles with a high yield by evaluating the effect of temperature and surface area to volume ratio $(\mathrm{SA} / \mathrm{Vol})$ of the cellulose membrane to nanoparticle solution on the surface plasmon resonance (SPR) peak, time it takes for equilibrium to occur, the reaction environment, and GGS nanoparticle yield. The hypothesis of this study is that as the surface area to volume ratio increases, the SPR absorption peak will have a blue shift and the SPR tunability approaches a constant. Four corollaries to this hypothesis are: 1) as the reaction temperature increases the SPR absorption peak will have a blue shift; 2) as the SA/Vol ratio of cellulose membrane to nanoparticles solution increases the reaction time will decrease; 3) as the reaction temperature increases the reaction time will decrease; and, 4) the exchange of ions will affect the stability of the GGS nanoparticles.

\section{Therapeutic Applications}

Gold nanoparticles of are great interest in biomedicine due to their biocompatibility, ease of functionalization, stability under atmospheric conditions, and photothermal abilities (Zharov, 2006; Ghosh and Pal, 2007). Another important aspect of GNPs is their large surface to volume ratio and close size to biomolecules which allow for great opportunities in medical applications (Azzazy and Mansour, 2009). Photothermal therapy has emerged in the past decade as a promising treatment against cancer and bacteria cells. Cancer is one of the leading causes of death worldwide; in 2007, accounting for nearly 8 million deaths, and in 2030 it is projected to increase to 12 million (Bode and Dong, 2009). The need for better treatments at lower cost is in need. 
Photothermal therapeutics have shown to hold promising potential in this field (Jain, Hirst, and O’Sullivan, 2012).

There is a narrow near infrared wavelength range (also known as optic or therapeutic window) from 650-900 $\mathrm{nm}$ where light penetrating tissue is scattered and with little absorption shown in Fig. 1. Within this window, a laser can pass through tissue with little temperature change to the surrounding tissue leaving it unharmed (Ito et al., 2000). Applying this principle with the photothermal properties of GNPs, one could heat up GNPs within the body while preventing unnecessary damage to other areas.

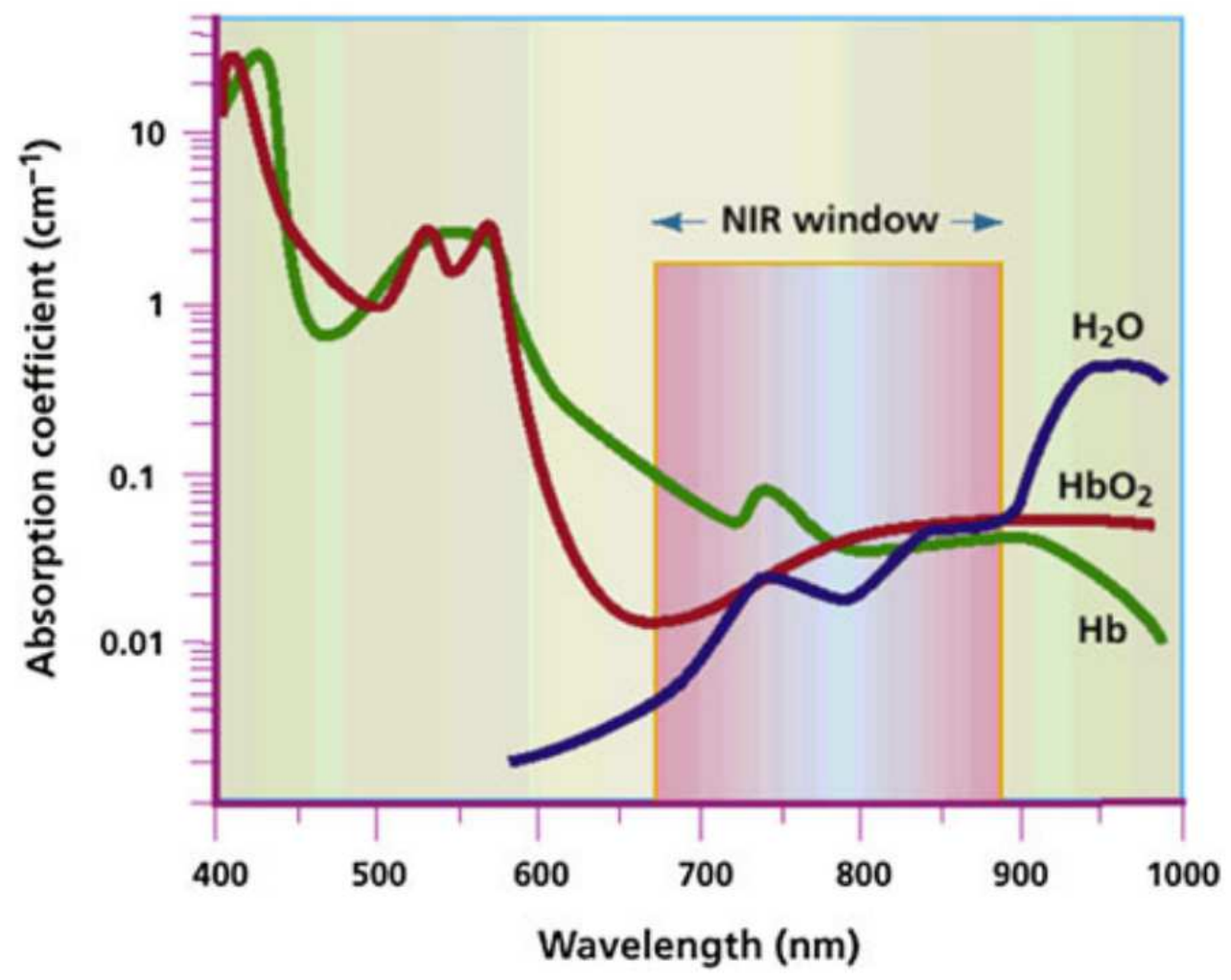

FIGURE 1 - Graph depicting the nIR window $(650-900 \mathrm{~nm})$ that light can pass through tissue with minimal damage at high intensities. (Weissleder, 2001).

One of the first in vivo studies to demonstrate this was by Hirsch et al. where 100 $\mathrm{nm}$ gold nanoshells was injected into mice tumors and a laser tuned to the SPR was 
applied where the average tumor temperatures increased by $9^{\circ} \mathrm{C}$ in control mice and $37^{\circ} \mathrm{C}$ in nanoshell treated mice with irreversible tissue damage. All mice in the nanoshell group survived 90 days with no evidence of tumor recurrence whereas all mice in the control group were euthanized by 20 days from uncontrolled tumor growth (Hirsch et al., 2003).

Another study conducted by Gobin et al. repeated Hirschs's study with gold/gold sulfide nanoparticles. It was found that there was no difference between the two types of particles with respect to mice survival. However, the size of the gold/gold sulfide particles was 30-36 nm vs. the silica/gold nanoshell particles at $110 \mathrm{~nm}$. The smaller size means that the particle has a higher absorbing cross-sectional area ratio than the gold/silica nanoshell. Also the Mie scattering theory calculations predict that the gold/gold sulfide nanoparticles will absorb 98-99\% of the incident energy compared to $67-85 \%$ for the gold/silica nanoshells currently being used. The implications for these smaller, more highly energy-absorbing nanoshells for therapy are that fewer particles could be used during treatment or alternatively a lower laser power or time could be utilized during therapeutic laser administration (Gobin et al.,2010).

\section{Gold Nanoparticle Morphologies}

Nanoparticles are usually under $100 \mathrm{~nm}$ (1000 angstroms) in size and have unique properties at this dimension. Gold nanoparticles (GNPs) were first used during ancient Roman times to stain glass to various colors. The first scientific report on them wasn't observed until the 1850's by Michael Faraday (Faraday, 1857). It was not until this past century that the optical principles were understood in more detail. It is now known that nanoparticles are larger than individual atoms but are smaller than the bulk solid, making 
materials at the nanoscale exhibit behavior intermediate between a macroscopic solid and an atomic system (Gosh and Pal, 2007). This allows for GNPs to have unique optical and electronic properties capable of being determined by their size and shape (Link and ElSayed, 1999b). Some of the optical properties for GNPs include surface plasmon resonance (SPR), surface enhanced Raman scattering (SERS), nonlinear optical properties (NLO), and luminescence making GNPs a robust tool (Klar et al. 1998; Averitt et al. 1999; Cao et al. 2002). Along with its optical properties, GNPs can be irradiated by a laser at a wavelength around the SPR band which can efficiently convert the photon energy to thermal energy (Zharov, 2006).

\section{Surface Plasmon Resonance}

A unique optical characteristic of gold nanoparticles, which is an important topic within this study, is surface plasmon resonance (SPR). This phenomenon is present within many metal nanoparticles, including the GNPs described herein. Figure 2 illustrates the principles behind SPR with light (Willets and Van Duyne, 2007). SPR is created in metallic nanoparticles from the interaction of electromagnetic radiation with the metal sphere. A dipole is induced, which oscillates in phase with the electric field of the incident electromagnetic radiation. This causes the conduction electrons in the particle to act like an oscillator system (Ghosh and Pal, 2007). 

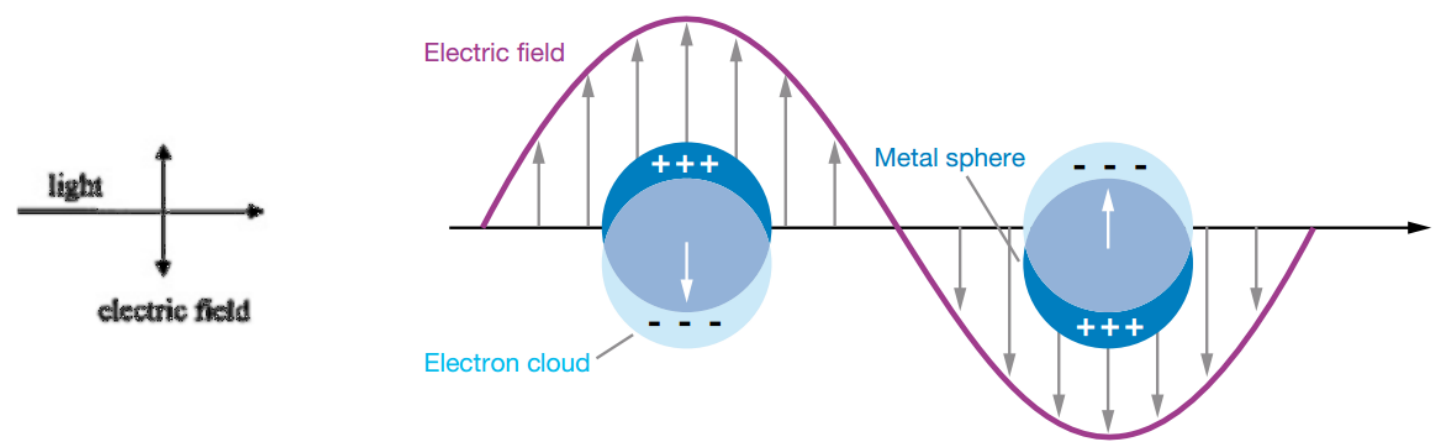

FIGURE 2 - Illustration showing a localized surface plasmon. (Willets and Van Duyne, 2007).

\section{Nanospheres}

Gold nanospheres (also known as gold colloids) range from less than a nanometer to over $100 \mathrm{~nm}$ in diameter and are synthesized by a controlled reduction of an aqueous $\mathrm{HAuCl}_{4}$ solution with a reducing agent. One of the most commonly used reducing agents is citrate, which can produce nearly monodisperse gold nanospheres (Turkevich et al 1951; Frens 1973). The size of the nanospheres can be controlled by varying the citrate/gold ratio. Generally, a smaller amount of citrate will yield larger nanospheres. These particles have a strong absorbance peak in the visible range typically from 520 to $540 \mathrm{~nm}$ as shown in Figure 3a (Link and El-Sayed, 1999b). The major limitations of this method are the low yield and the restriction of using water as the solvent (Cai et al., 2008).

\section{Nanorods}

In preparing gold nanorods (GNRs) there are two different approaches available: 1) electrochemical; and, 2) seed-mediated (Yu et al., 1997; Nikoobakht and El-Sayed, 2003). When the shape of the gold nanoparticles is changed from sphere to rod, the SPR spectrum splits into two peaks; a stronger, long-wavelength band in the nIR region is due to the longitudinal oscillation of electrons while a weaker short-wavelength band in the 
visible region (around $520 \mathrm{~nm}$ ) is due to the transverse electronic oscillation (Link and El-Sayed, 1999a). Unlike gold nanospheres, the absorption spectrum of the gold nanorods is very sensitive to the aspect ratio (length/width). With an increase in the nanorod aspect ratio, the SPR absorption peak of the longitudinal band significantly shifts redshifts to the red region of the spectrum (Huang et al., 2008). Figure 3b shows a TEM of GNRs and their spectra profile.

\section{Nanoshells}

Oldenburg et al. (Oldenburg et al., 1999) developed a gold nanoshell structure, which is composed of a silica dielectric core (100-200 nm in diameter) surrounded by a thin layer of gold shell $(5-20 \mathrm{~nm})$. The nanoshells absorb and scatter strongly in the nIR region. The SPR of the nanoshells can be tuned by adjusting the ratio of the thickness of the gold shell to the diameter of the silica core. A redshift of the SPR wavelength occurs with a decrease in the thickness to diameter ratio (Loo et al., 2004; Huang et al. 2008). Mie theory uses Maxwell's equations that can be used to estimate the nIR spectra profile of gold nanoshells (Mie, 1908; Gosh and Pal, 2007). These particles require a multiple step synthesis process, but result in a monodispersed homogenous population. Figure $3 \mathrm{c}$, shows a TEM of gold nanoshells and their respective spectra as well.

\section{Nanoprisms}

A variety of synthesis routes have been used to generate triangular, plate-like nanostructures (also referred to as nanoprisms, nanotriangles, nanoplates, or nanodisks) (Millstone et al., 2009). In particular, these prisms have SPRs that are tunable throughout the visible and nIR regions of the spectrum by controlling the nanoprism's edge length, 
thickness, and tip morphology (Young et al., 2012). Gold nanoprism synthesis typically generates gold colloid and requires purification steps to acquire a homogenous solution (Young et al. 2012). Figure 3d shows a TEM image and spectra profile of gold nanoprisms. 

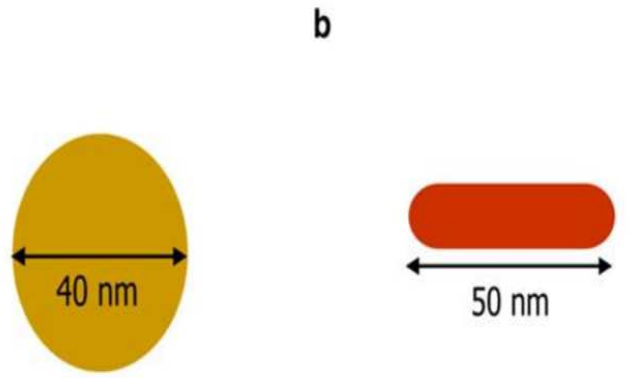

C
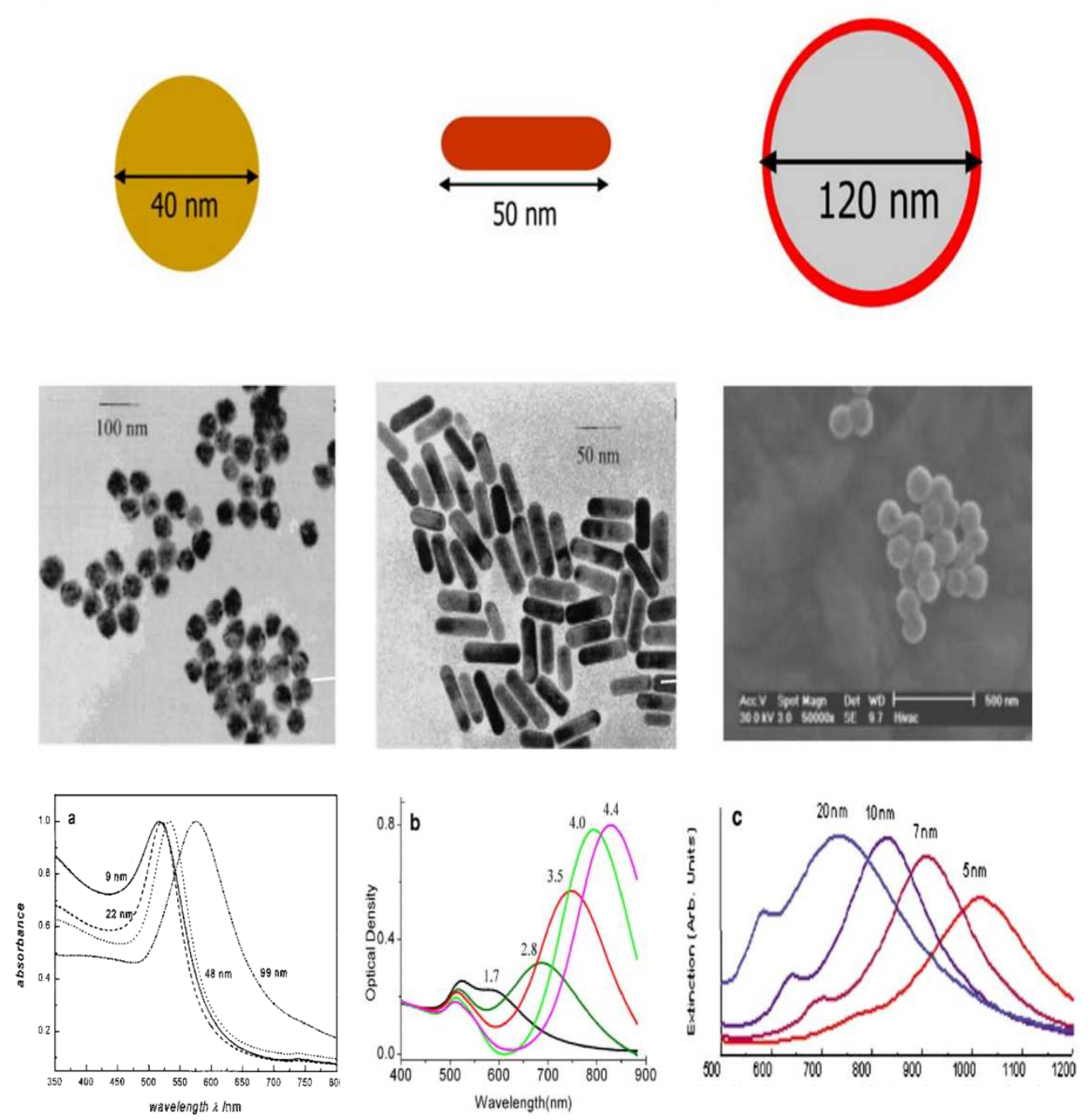
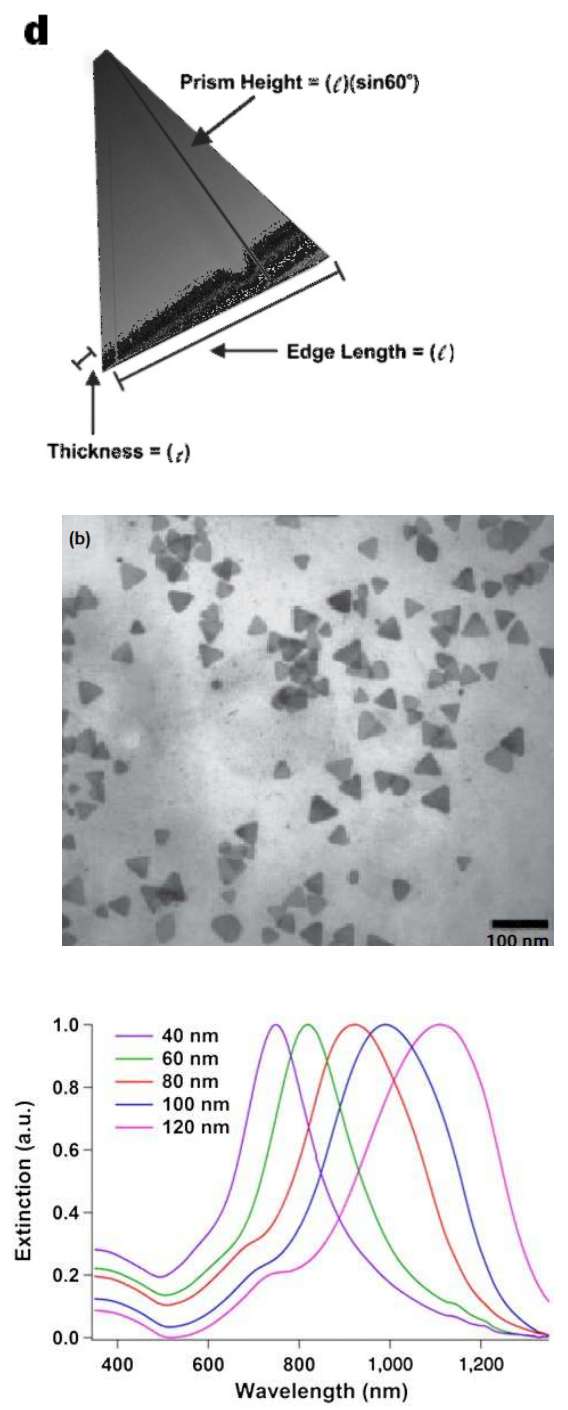

FIGURE 3 - (a) Top - Illustration of colloidal gold nanoparticle (Huang et al., 2008), Middle - TEM image of $99 \mathrm{~nm}$ gold nanoparticles (Link and El-Sayed, 1999b), Bottom UV-vis absorption spectra of various diameter gold nanospheres (Link and El-Sayed, 1999b). (b) Top - Illustration of gold nanorod (Huang et al., 2008), Middle - TEM image of $50 \mathrm{~nm}$ gold nanorods (Link and El-Sayed, 1999a), Bottom - UV-vis optical density spectra of gold nanorods of various lengths (Nikoobakht and El-Sayed, 2003; Huang et al., 2008), (c) Top - Illustration of silica core/gold nanoshell (Huang et al., 2008), Middle - TEM image of silica core/gold nanoshell particle (Loo et al., 2004),

Bottom - UV-vis extinction spectra of various shell thickness of silica core/gold nanoshell (Oldenburg et al., 1999; Huang et al. 2008), (d) Top-Illustration of gold nanoprism (Millstone et al., 2009), Middle - TEM image of gold nanoprisms (Tréguer-

Delapierre et al., 2008) Bottom-UV-vis extinction spectra for gold nanoprisms of varying edge lengths (Young et al. 2012). 


\section{Gold/Gold Sulfide Nanoparticles}

Gold/Gold nanoparticles (GGS) are synthesized by reacting sodium sulfide $\left(\mathrm{Na}_{2} \mathrm{~S}\right)$ or sodium thiosulfate $\left(\mathrm{Na}_{2} \mathrm{~S}_{2} \mathrm{O}_{3}\right)$ with a gold salt, tetrachloroauric acid $\left(\mathrm{HAuCl}_{4}\right)$, in a traditional one-step or two-step method. Below, Eq. 1 and 2 shows the reaction for both $\mathrm{Na}_{2} \mathrm{~S}$ and $\mathrm{Na}_{2} \mathrm{~S}_{2} \mathrm{O}_{3}$ respectively (Averitt, Sarkar, and Halas, 1997; Schwartzberg, 2007; Patel, 2012).

$\mathrm{HAuCl}_{4} * 4 \mathrm{H}_{2} \mathrm{O}+\mathrm{Na}_{2} \mathrm{~S} * 9 \mathrm{H}_{2} \mathrm{O}=\mathrm{Au}_{2} \mathrm{~S}+\mathrm{Au}+\mathrm{Au}_{2} \mathrm{~S} / \mathrm{Au}$ (nanoshell) $+\mathrm{S}^{+}$

$\mathrm{HAuCl}_{4} * 3 \mathrm{H}_{2} \mathrm{O}+\mathrm{Na}_{2} \mathrm{~S}_{2} \mathrm{O}_{3} * 5 \mathrm{H}_{2} \mathrm{O}=\mathrm{Au}_{2} \mathrm{~S}+\mathrm{Au}+\mathrm{Au}_{2} \mathrm{~S} / \mathrm{Au}$ (nanoshell) $+\mathrm{S}^{+}+\mathrm{H}^{+}+$

$\mathrm{SO}_{4}{ }^{2-}+\mathrm{NaCl}+\mathrm{SO}_{3}{ }^{2-}+\mathrm{S}_{2} \mathrm{O}_{6}{ }^{2-}+\mathrm{Cl}^{-}+\mathrm{Na}^{+}$

The advantage of these particles is their ability to be synthesized without the assistance of additional templates, capping reagents, or seeds in addition to having a strong tunable SPR absorption peak in the nIR range (Zhang et al., 2012). These selfassembling particles require one or two steps and can be synthesized in less than an hour. This synthesis process also has associated issues, mainly the control over the formation of the particle structure and a high concentration of small colloidal gold $(<10 \mathrm{~nm}$ nanospheres) formed as a result of the self-assembly process (Schwartzberg et al. 2007). The traditional one-step reaction calls for the mixing of $2 \mathrm{mM} \mathrm{HAuCl}_{4}$ with $1 \mathrm{mM} \mathrm{Na}_{2} \mathrm{~S}$ 
solution at a volumetric ratio of 1:2, while stirring at room temperature (Diao and Chen, 2006). For the two-step method, $\mathrm{Na}_{2} \mathrm{~S}$ is mixed with $\mathrm{HAuCl}_{4}$ for a few minutes and then an additional amount of $\mathrm{Na}_{2} \mathrm{~S}$ is added (Zhou, Honma, and Komiyama, 1994). The twostep becomes more difficult to repeat with increasing the total volume of the reaction. This study will focus on the one-step method over the two-step to ensure repeatability. Both methods produce a heterogeneous mixture of nanoparticles containing gold colloid, spheroids, triangular plates, and rods. Mie theory cannot be applied to these particles since they are not homogenous spherical particles (Gosh and Pal, 2007). The SPR peak can be tuned to a certain wavelength by adjusting the molar ratio of $\mathrm{Na}_{2} \mathrm{~S}$ or $\mathrm{Na}_{2} \mathrm{~S}_{2} \mathrm{O}_{3}$ and $\mathrm{HAuCl}_{4}$ (Zhou, Honma, and Komiyama, 1994; Zhang et al., 2012; Diao and Chen, 2006; Schwartzberg et al. 2007). Fig. 4 shows the tunability of the SPR peak in a one-step process by varying the molar ratio (Zhang et al., 2012).

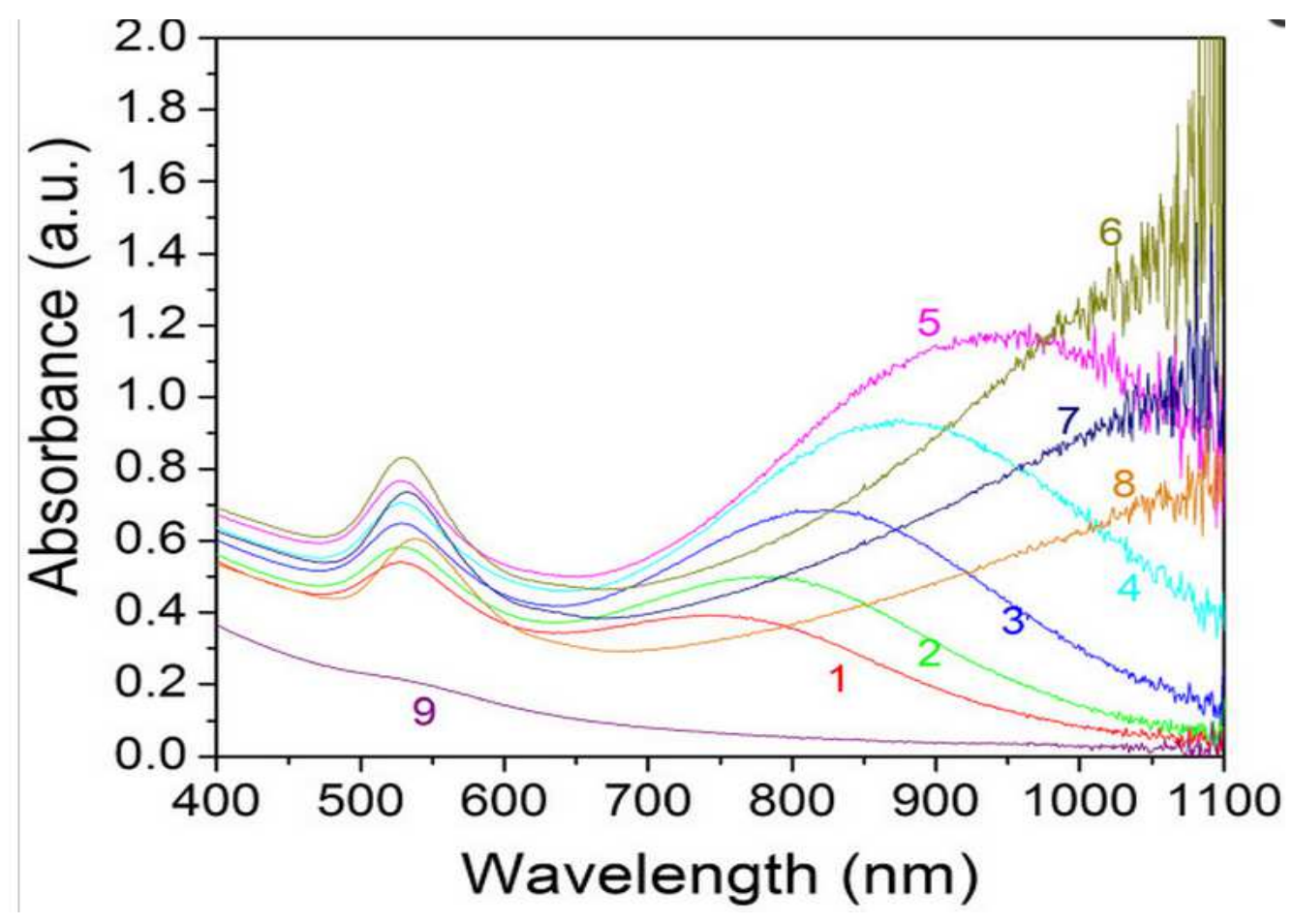

FIGURE 4 - Optical spectra of GGS nanoparticles from a traditional one step method with different molar ratios, $\mathrm{Na}_{2} \mathrm{~S}_{2} \mathrm{O}_{3}: \mathrm{HAuCl}_{4}$. (Zhang et al., 2012) 
The traditional one-step synthesis process forms a high concentration of small colloidal gold particles $(<10 \mathrm{~nm})$ as evidenced by the $530 \mathrm{~nm}$ peak absorption and the nIR peak varies depending on the molar ratio. Fig. 5 shows the UV-vis-nIR spectra of GGS manufactured via traditional one-step synthesis (black) and purified (blue) (Zhang et al., 2012). After purification from centrifugation, the resulting solution's nIR SPR redshifts and reduces the colloidal gold as illustrated by the reduction in peak absorbance at $530 \mathrm{~nm}$ (Figure 5 blue). The removal of the small colloidal gold was not only evident from the $530 \mathrm{~nm}$ absorbance peak drop in Fig. 5, but can also be seen from transmission electron microscopy (TEM) image shown in Figs. 6 and 7 (Patel, 2012; Zhang et al., 2012).

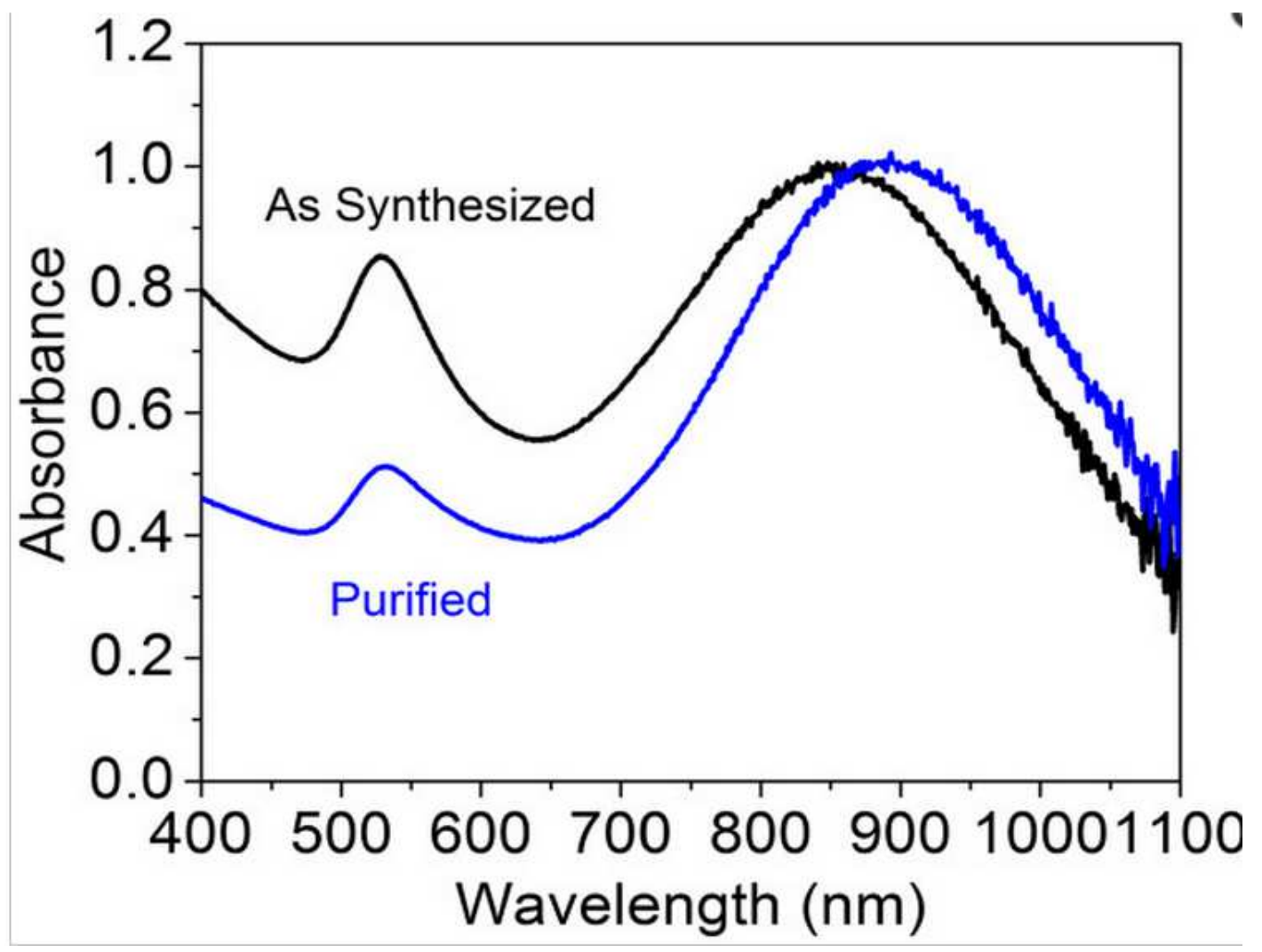

FIGURE 5 - UV-vis-nIR spectra of GGS nanoparticles shown before and after purification via centrifugation. The sample is separated at $1,000 \times \mathrm{g}$ for $20 \mathrm{~min}$. (Zhang et al., 2012) 


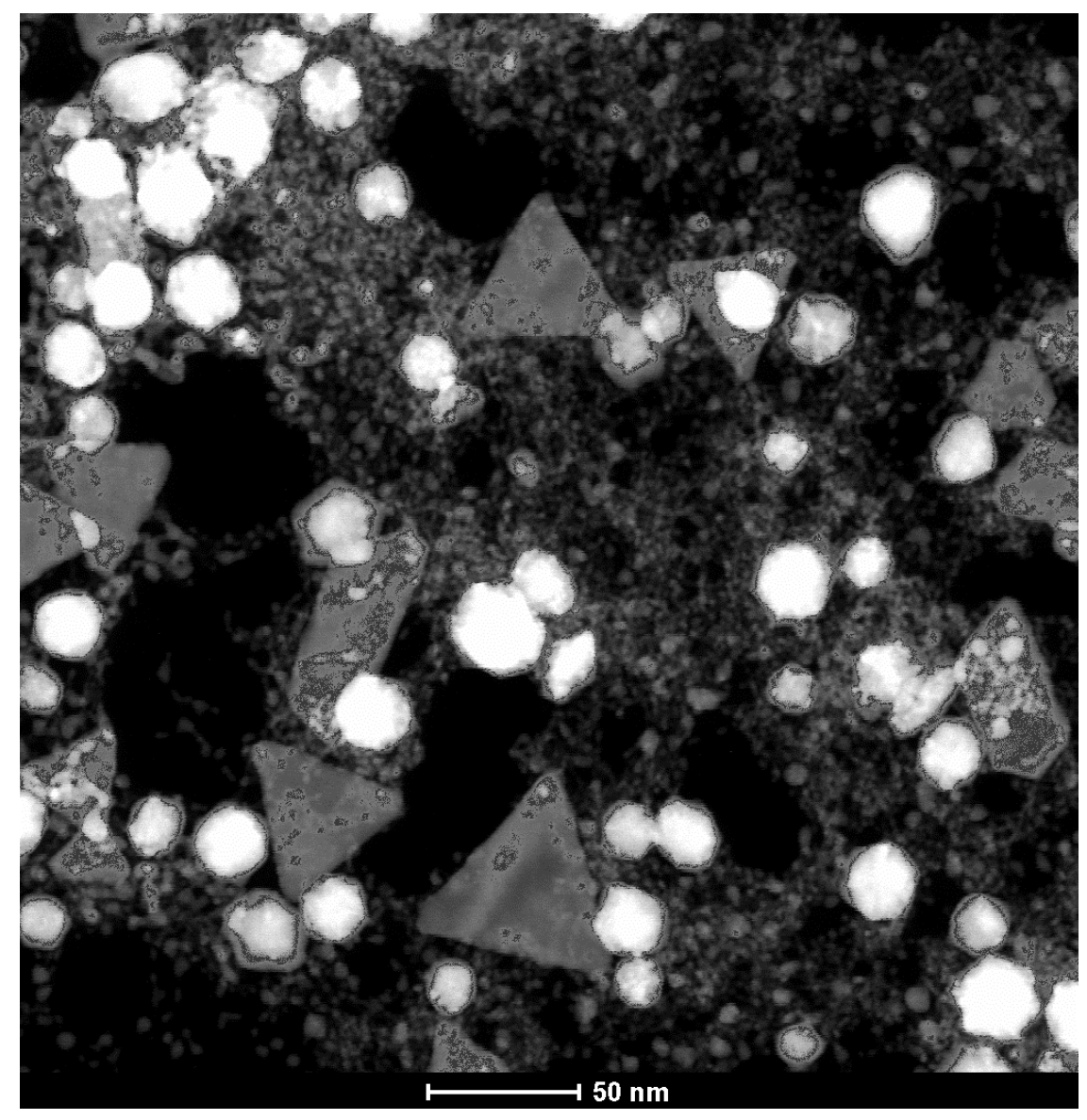

FIGURE 6 - TEM image of gold/gold sulfide nanoparticles made with traditional one step synthesis. (Patel, 2012) 


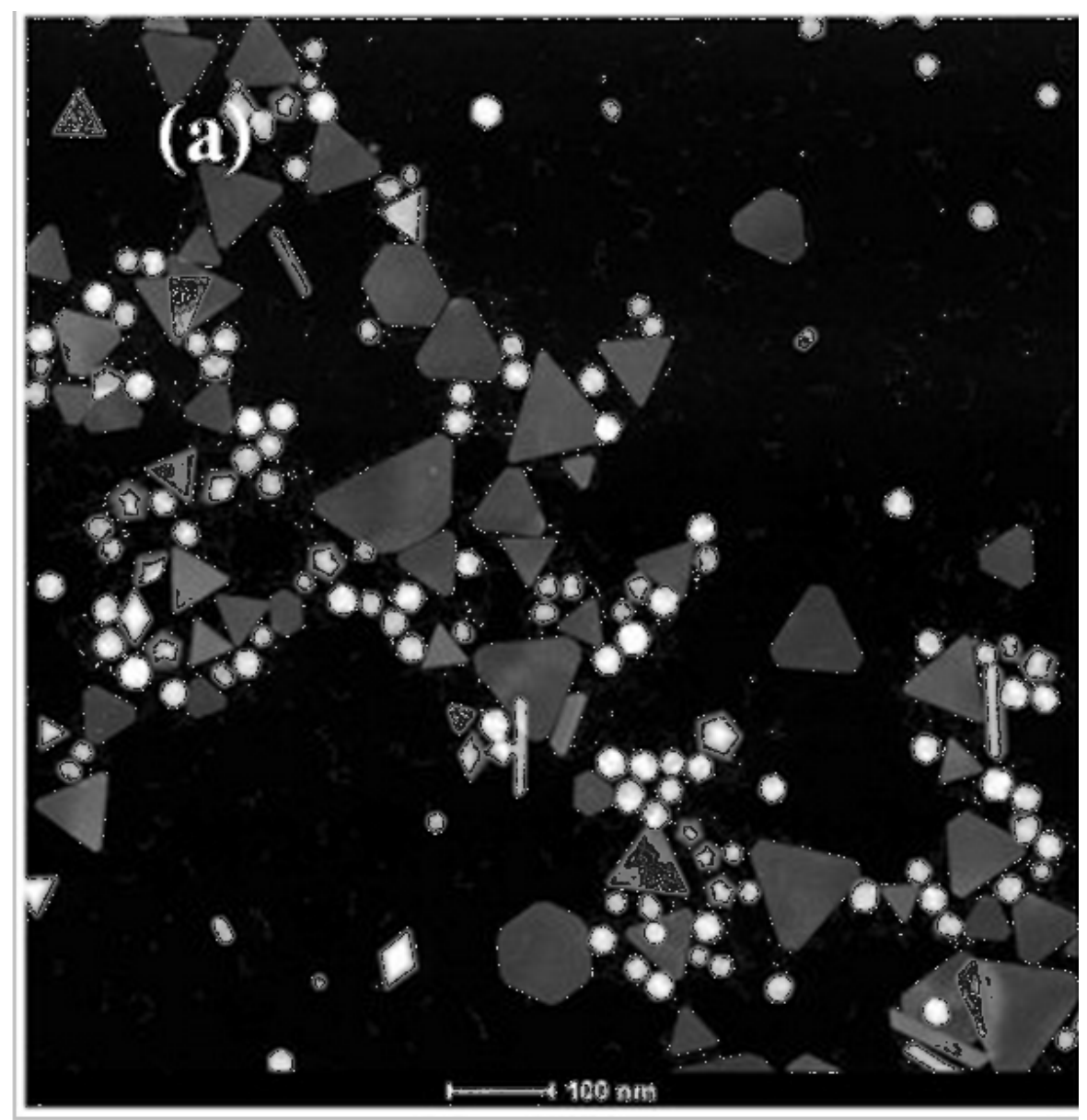

FIGURE 7 - TEM image of GGS nanoparticles after centrifugation to remove gold colloid. (Zhang et al., 2012) 


\section{Diasynth}

The Diasynth process was described by Patel (Patel et al., 2012) as an exchange of ions and GNPs which occurs between the GGS solution and surrounding deionized (DI) water via a cellulose membrane resulting in an equilibrium shift that changes the SPR nIR peak position. From Eq. (2), there are many ions present from the reaction that can affect the growth of the GGS particles, thereby altering the SPR peak equilibrium shift. Patel (Patel et al., 2012) tested different molecular weight cutoffs (MWCO) and various molar ratios of reactants to determine the optimal conditions for a high absorbance peak centered on $820 \mathrm{~nm}$, while minimizing the colloidal gold concentration (530 nm peak). It was seen that different MWCOs would alter the equilibrium shift due to the different rates of diffusion for the exchange ions and GNPs. Fig. 8 shows the change in colors in the traditional synthesis (A-D) vs. Diasynth (E-H) over an hour time span.

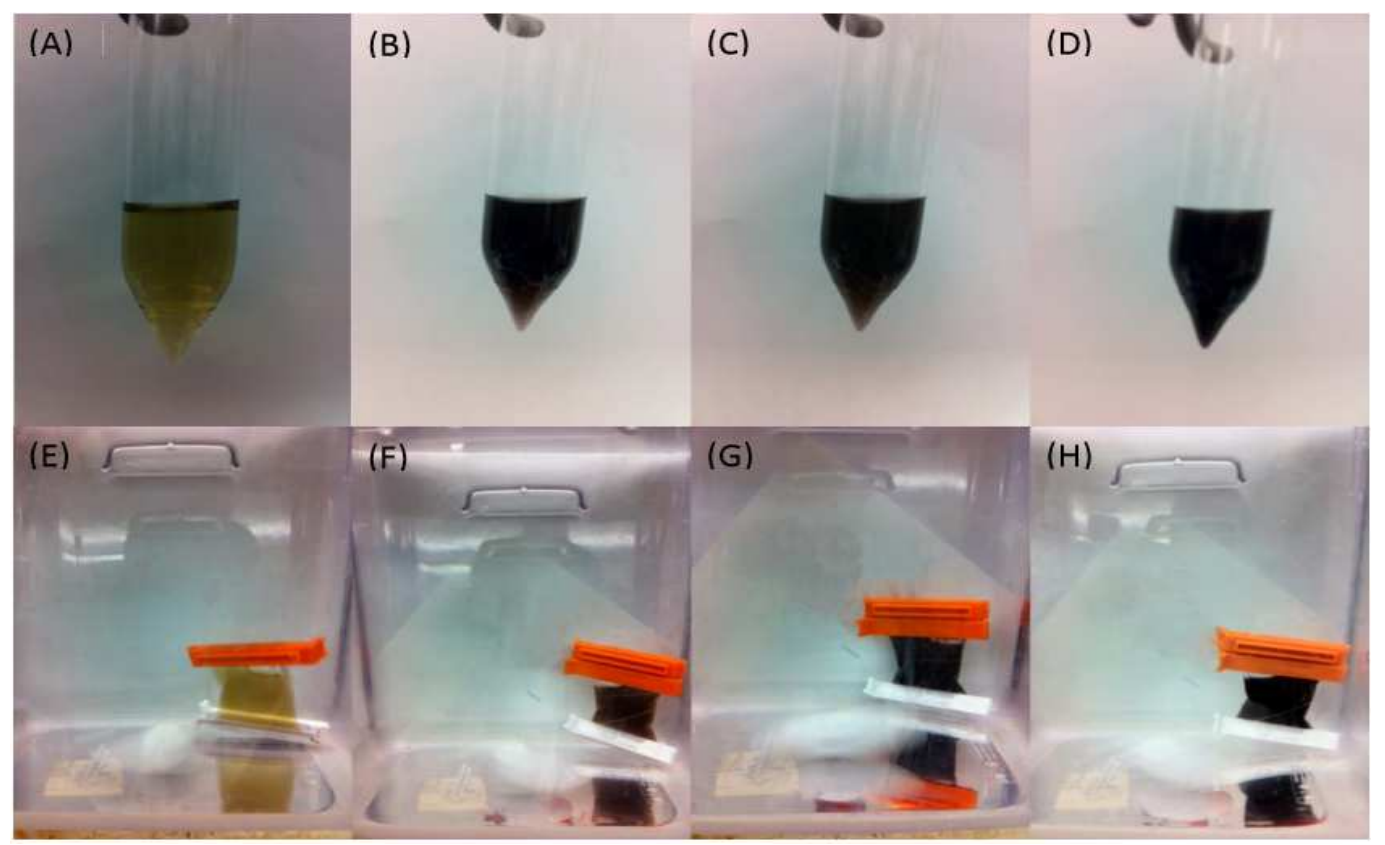

FIGURE 8 - Image of Non-Dialysis synthesis and dialyzed synthesis over $1 \mathrm{hr}$ time period: (A) 30sec, (B) 5 mins, (C) 30mins, (D) 1hr. Image of Diaylzed sample over $1 \mathrm{hr}$ time period: (E) 30sec, (F) 5 mins, (G) 30mins, (H) 1hr. (Patel, 2012) 

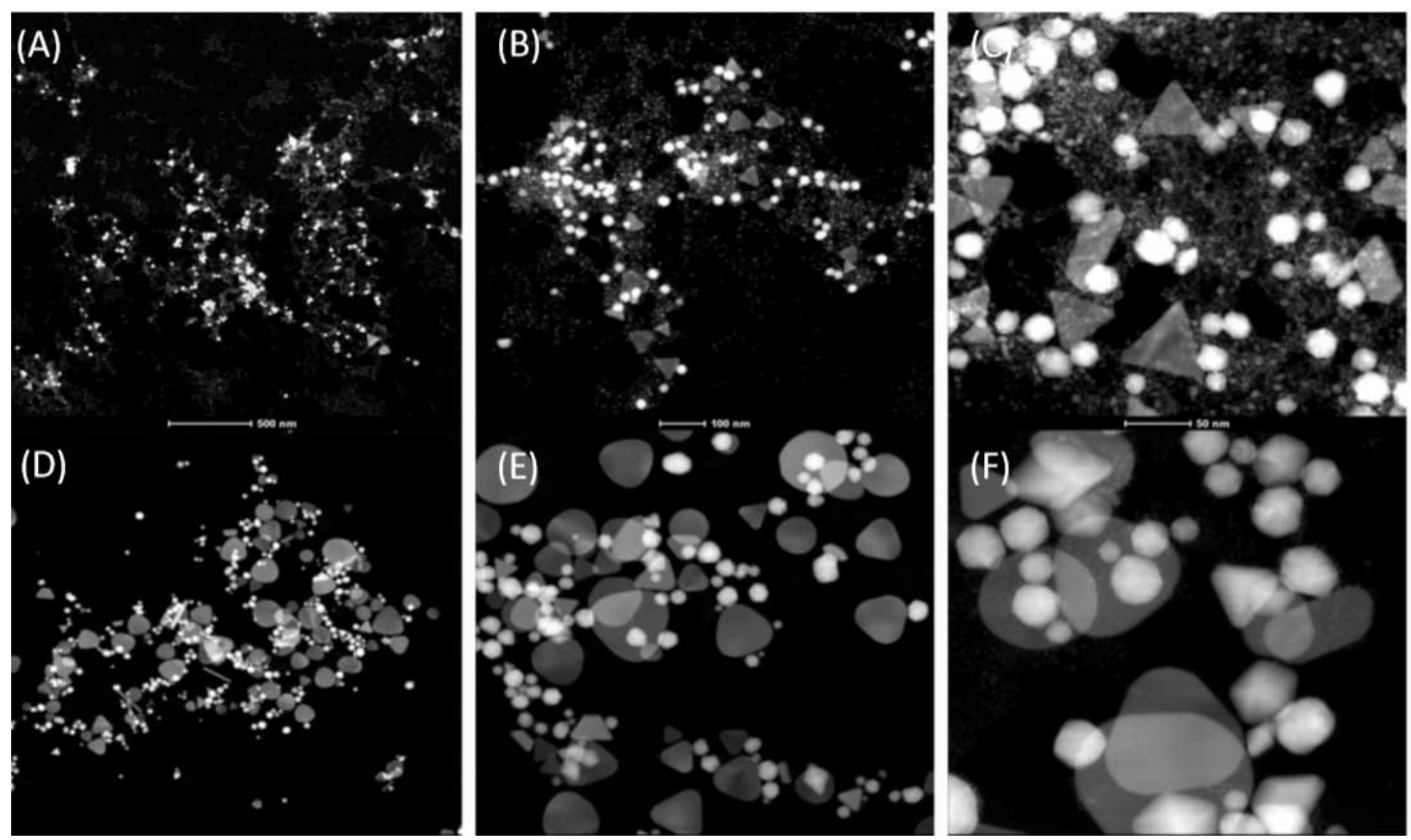

FIGURE 9 - TEM images of traditional synthesis (A-C) and Diasynth (D-F).

(Patel, 2012)

The Diasynth process (Fig. 9) was shown to be just as effective at removing colloidal gold as the centrifugation method of the traditional GGS synthesis process (Fig. 7). From Patel, it was seen that the Diasynth is a high yield synthesis process for GGS nanoparticles.

\section{Cellulose}

Porous materials have been used as nanoreactors for metal nanoparticle synthesis. Specifically $\mathrm{Ag}, \mathrm{Au}, \mathrm{Pt}$, and $\mathrm{P}$ nanoparticles have been synthesized in porous cellulose (He, Kunitake, and Nakao, 2003). He et al. (2003) submerged porous cellulose fibers in $10 \mathrm{mM} \mathrm{AuCl}$, then added $\mathrm{NaBH}_{4}$ (reducing agent) and saw the clear membrane change color to a light pink. Fig. 10 shows a TEM image and size distribution histogram from their findings. 

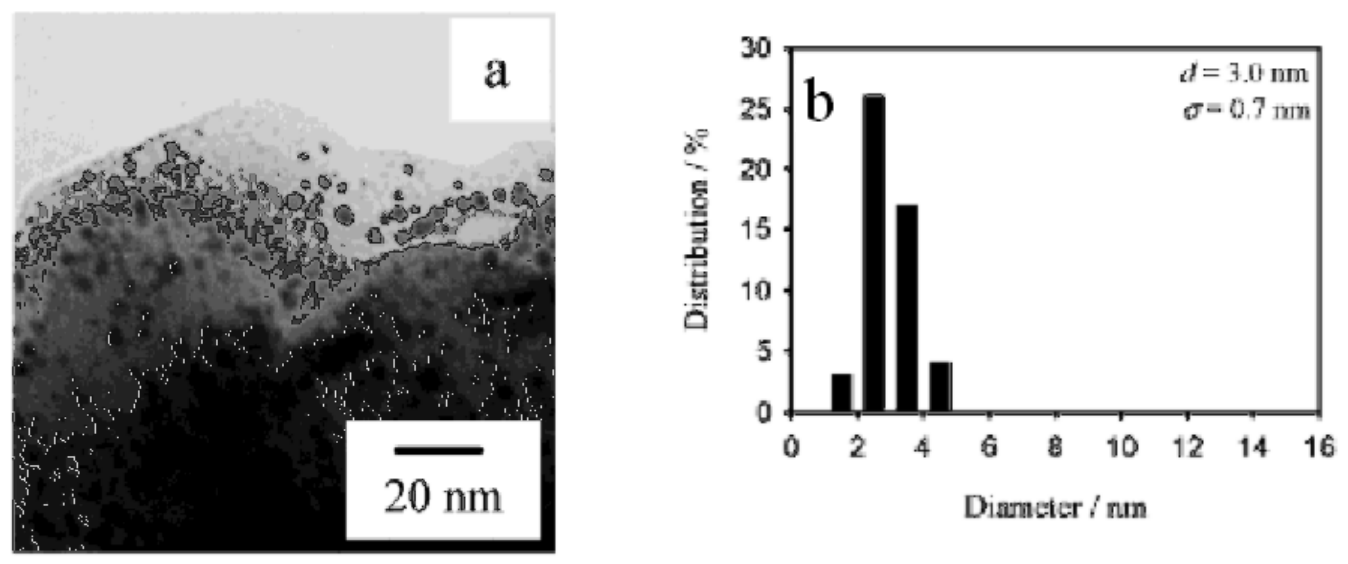

FIGURE 10 - (a) TEM image and (b) histogram of Au nanoparticles in cellulose fiber. (He, Kunitake, and Nakao, 2003)

The metal ions are impregnated into and reduced onto the cellulose fibers in the presence of a reducing agent. This method can be employed without the addition of a reducing agent, because adsorption of metal ions on the cellulose fibers may be reduced to metal nanoparticles by organic moieties such as terminal aldehyde or carboxylic groups. The structure and the presence of ether and hydroxyl groups in cellulose fibers create an effective nanoreactor for synthesis of the metal nanoparticles. The ether oxygen and the hydroxyl group not only anchor metal ions tightly onto cellulose fibers via iondipole interactions, but also stabilize metal nanoparticles by strong bonding interaction with their surface interactions (He, Kunitake, and Nakao, 2003; Pinto and Neves, 2012, 77). 


\section{MATERIALS AND METHODS}

\section{A. Instrumentation}

UV absorption spectrum was measured on all samples at a 10x dilution in water with the Varian Cary 50 BIO UV Visible Spectrometer. The size and zeta potential measurements were measured at a 10x dilution in DI water on the Malvern Zetasizer Nano ZS90. It is important to note that the size measured is the hydrodynamic radius with the Malvern Zetasizer. The conductance measurements were performed with the Brookhaven Zeta Pals instrument. The scanning tunneling electron microscopy (STEM) was performed on the Zeiss SUPRA FE-SEM. The statistical analysis was performed with Minitab software. Image $\mathrm{j}$ software was used to measure the size and counts for the size distribution analysis.

\section{B. Reactants}

The gold salt used for all experiments was hydrogen tetrachloroaurate(III) trihydrate $\left(\mathrm{HAuCl}_{4} * 3 \mathrm{H}_{2} \mathrm{O}\right)$ purchased from Alfa Aesar. A $2 \mathrm{mM}$ solution is prepared with DI water and protected from light with aluminum foil. The sulfur used in all experiments was sodium thiosulfate pentahydrate $\left(\mathrm{Na}_{2} \mathrm{~S}_{2} \mathrm{O}_{3} * 5 \mathrm{H}_{2} \mathrm{O}\right)$ purchased from Sigma-Aldrich.

\section{Cellulose Membrane}

The cellulose dialysis tubing was stored at $4^{\circ} \mathrm{C}$ and pretreated by soaking in $2 \mathrm{~L}$ of DI water for 4 days while changing the water every day to remove preservatives (glycerol, sodium azide, and/or sulfur in trace amounts). Once hydrated, the membrane was kept in 2L of DI water. Before use, the membrane was cut to desired lengths and rinsed thoroughly inside and out with running DI for 3-5 minutes. The 8 (FW 50mm; 
Spectra/Por 7), 15 (FW 45mm; Spectra/Por 7), and 12-14kDa (FW 120mm; Spectra/Por 2) molecular weight cutoff (MWCO) cellulose membranes were purchased from Spectrum Labs and 12kDa (FW 43 and 76mm) from Sigma-Aldrich.

\section{Traditional Synthesis}

For the traditional synthesis procedure, $3 \mathrm{mM} \mathrm{Na} \mathrm{S}_{2} \mathrm{O}_{3}$ was added to $2 \mathrm{mM}$ $\mathrm{HAuCl}_{4}$. The molar ratio of the two reactants controlled the size and placement of the SPR nIR peak. Traditional synthesis protocol consisted of measuring $150 \mathrm{ml}$ of $2 \mathrm{mM}$ $\mathrm{HAuCl}_{4}$ into a $250 \mathrm{ml}$ polystyrene $75 \mathrm{~cm}^{2}$ canted neck flask (Corning), then adding $62 \mathrm{ml}$ of $3 \mathrm{mM} \mathrm{Na}_{2} \mathrm{~S}_{2} \mathrm{O}_{3}$ into the polystyrene flask, agitating for 1 minute and letting sit for 45 minutes. The solution was aliquoted into eight $50 \mathrm{ml}$ centrifuge test tubes (VWR) and centrifuged three times at $1,000 \mathrm{~g}$ for $20 \mathrm{~min}$, collecting the pellet each time to purify sample.

\section{E. Diasynth}

This method used the dialyzing role of the dialysis membrane to exchange ions and small gold nanoparticles during synthesis with the surrounding water. The protocol for this process requires a 177-203 mm length of $12 \mathrm{kDa}$ MWCO cellulose dialysis tubing (Flat Width 43mm, Sigma Aldrich). One end of the dialysis tubing was clipped with a weighted dialysis clip and $44 \mathrm{ml}$ of $2 \mathrm{mM} \mathrm{HAuCl}_{4}$ was added into the membrane through the open end of the dialysis tubing. $10 \mathrm{ml}$ of $3 \mathrm{mM} \mathrm{Na}_{2} \mathrm{~S}_{2} \mathrm{O}_{3}$ was added into the solution via mechanical pipette with continued mixing of the solution by bubble mixing through the mechanical pipette for 10 seconds. Subsequently, the other end of the membrane was clipped and air was removed from the tubing. The tubing was placed in $7 \mathrm{~L}$ of $25^{\circ} \mathrm{C}$ DI 
water with a stir bar and allowed to react for $60 \mathrm{~min}$. After synthesis, the GGS nanoparticle solution was stored in 50ml test tubes at room temperature.

\section{F. Reactor}

To ensure reproducibility of the GGS nanoparticles and scale up of the synthesis volume, a reactor was constructed out of glass. Glass was chosen because it does not react readily with gold. The reactor consisted of a $61 \mathrm{~cm}$ tall cylinder with an inner diameter of $10 \mathrm{~cm}$ (Fig. 11a). An inlet and outlet was at the top and bottom, respectively, of the reactor for DI water circulation. A glass membrane frame was made $37 \mathrm{~cm}$ high with a $7 \mathrm{~cm}$ outer diameter to hold open the membrane whereas still maximizing the surface area for diffusion, shown in Fig. 11b. The top of the glass membrane frame had a diameter of $13 \mathrm{~cm}$ so the rest of the frame could be inserted into the reactor while held suspended at the top. A glass stir rod was made for the length of the membrane frame for stirring the solution.

The membrane was placed over top of the membrane frame, tied in a knot at the bottom and zip-tied at the top to secure the membrane overtop the frame. Once the membrane was secured, it is placed within the reactor and then circulation of DI water can begun (Neslab RTE 221 refrigerated bath/circulator). The two reactants were then added into the membrane with the stir rod for mixing (Heidolph RZR 2021). 


\section{a}

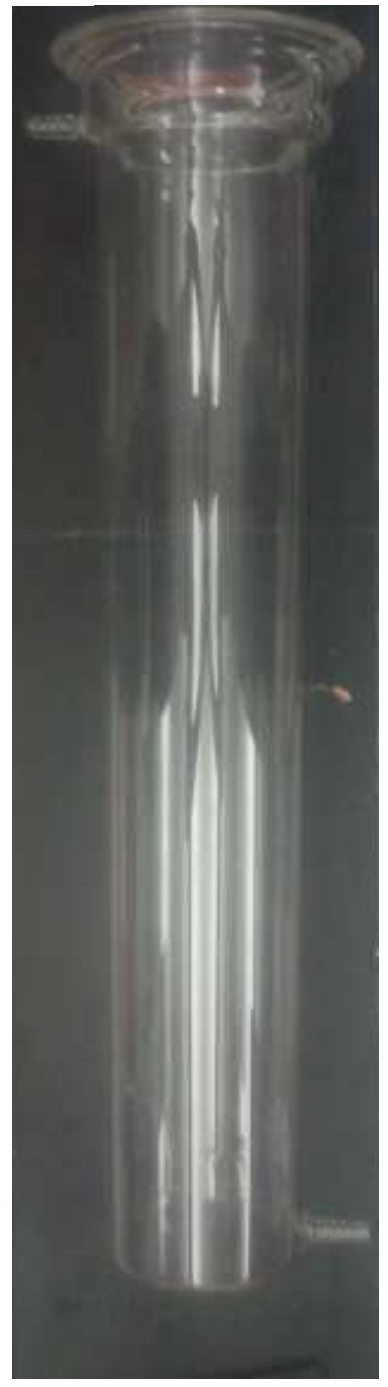

b

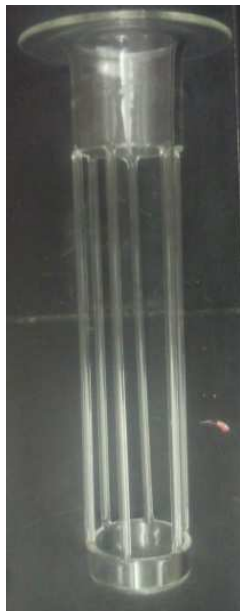

FIGURE 11 - (a) Glass reactor that has inlet and outlet at top and bottom and (b) glass membrane frame that is placed inside of reactor.

\section{G. Experiments}

1. Experiment A

To verify that ions and small particles were being dialyzed out of solution during the Diasynth process, a conductance experiment was performed on the dialysate. A 
sample was made with the Diasynth process: $8 \mathrm{ml}$ of $3 \mathrm{mM} \mathrm{Na} \mathrm{S}_{2} \mathrm{O}_{3}$ was added to $44 \mathrm{ml}$ of $2 \mathrm{mM} \mathrm{HAuCl} 4$ inside a $152 \mathrm{~mm}$ long $12 \mathrm{kDa}$ cellulose membrane (76mm Flat Width) and placed in $7 \mathrm{~L}$ of $25^{\circ} \mathrm{C}$ DI water inside a square plastic $8 \mathrm{~L}$ tub with constant stirring. $1.8 \mathrm{ml}$ of dialysate was collected between half the distance from the cellulose membrane to container wall. The conductance was measured at $0,1,10,20,30,40,50$, and 60 minute time intervals. This same experiment was performed with $52 \mathrm{ml}$ of DI water within the membrane as a control.

\section{Experiment B}

This experiment used the same principles as Patel to perform the Diasynth process on a total volume batch of $216 \mathrm{ml}$. This was the largest volume synthesis, to date: $40 \mathrm{ml}$ of $3 \mathrm{mM} \mathrm{Na}_{2} \mathrm{~S}_{2} \mathrm{O}_{3}$ was added to $176 \mathrm{ml}$ of $2 \mathrm{mM} \mathrm{HAuCl}$ inside a $12 \mathrm{kDa}$ cellulose membrane (43mm Flat Width) and placed in 55L of DI water inside a plastic 113L tub with constant stirring with a magnetic stir bar. The dialysis clips used were weighted on both ends. A magnet was used on the outside of the tub to hold the membrane horizontally across for a uniform distribution of solution across the membrane as seen in Fig. 12. Two different $\mathrm{SA} /$ Vol ratios were used to test their effect on the SPR nIR peak: 150 (375mm; sample M7) and $240 \mathrm{~mm}^{2} / \mathrm{ml}(600 \mathrm{~mm}$; sample M8). 


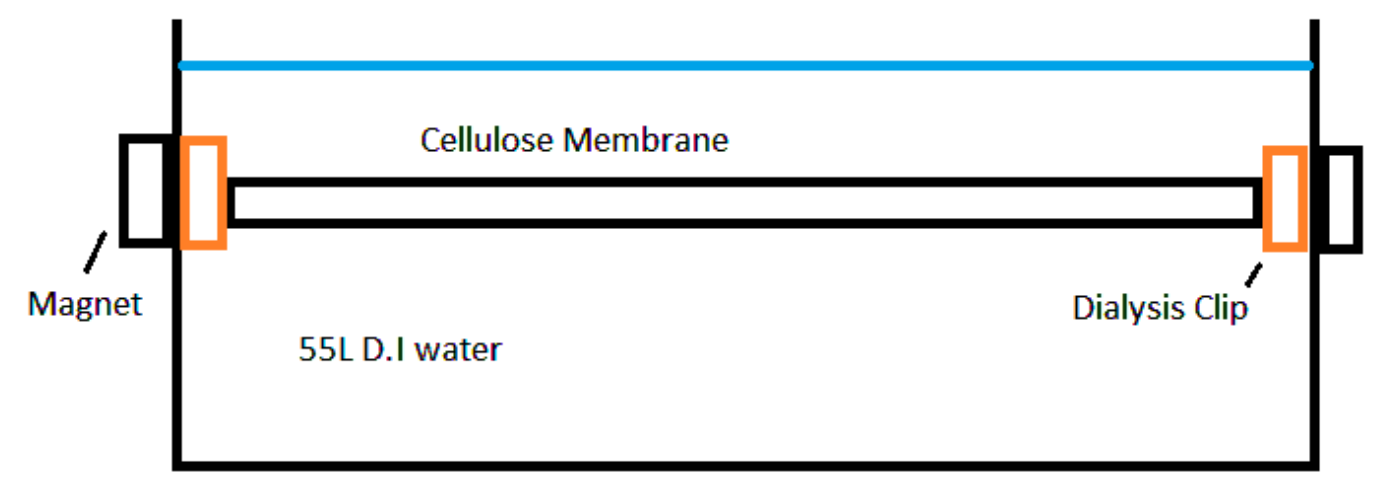

FIGURE 12 - Schematic depicting the Diasynth setup for a $216 \mathrm{ml}$ volume batch.

\section{Experiment $\mathrm{C}$}

This experiment was the first time the new reactor configuration was used and a reaction synthesis volume of $746 \mathrm{ml}$ was produced. A $45 \mathrm{~cm}$ long $12-14 \mathrm{kDa}\left(145 \mathrm{~mm}^{2} / \mathrm{ml}\right.$; $120 \mathrm{~mm}$ Flat Width) membrane was placed overtop the glass membrane frame and tied above and below with zip ties. $608 \mathrm{ml}$ of $2 \mathrm{mM} \mathrm{HAuCl}_{4}$ was mixed with $138 \mathrm{ml}$ of $3 \mathrm{mM}$ $\mathrm{Na}_{2} \mathrm{~S}_{2} \mathrm{O}_{3}$ simultaneously while pouring into the membrane. Stirring occurred at 100rpm. Since the SA/Vol ratio was low, it was expected that a redshift would occur on the SPR absorption. It was theorized that constant stirring would increase the exchange of ions to cause a blue shift, offsetting the redshift caused from low SA/Vol. Constant DI water circulation occurred at a rate of $15 \mathrm{~L} / \mathrm{min}$. The reaction lasted for $60 \mathrm{~min}$ before storing in a $1 \mathrm{~L}$ glass bottle and the UV-spectrum absorption measured. 


\section{Experiment D}

This experiment was performed to determine if either of the reactants reacted with the cellulose membrane during the Diasyth process. $20 \mathrm{ml}$ of $3 \mathrm{mM} \mathrm{Na} \mathrm{S}_{2} \mathrm{O}_{3}$ was placed inside a $5 \mathrm{~cm}$ long 8,12 , and $15 \mathrm{kDa}$ membrane in $7 \mathrm{~L}$ of DI water for 2 hours. The same procedure was followed for $32 \mathrm{ml}$ of $2 \mathrm{mM} \mathrm{HAuCl}_{4}$ poured inside the membranes under the same conditions.

\section{Experiment E}

This experiment was performed to determine the effects of the cellulose membrane on the SPR nIR peak. $32.6 \mathrm{ml}$ of $2 \mathrm{mM} \mathrm{HAuCl} 4$ was placed into $50 \mathrm{ml}$ centrifuge test tube. The cellulose membrane was cut to the desired length that corresponded to surface area to volume $(\mathrm{SA} / \mathrm{Vol})$ ratio and rinsed thoroughly with $\mathrm{DI}$ water. It is then placed inside the test tube along with the $\mathrm{HAuCl}_{4}$ solution. $7.4 \mathrm{ml}$ of $3 \mathrm{mM}$ $\mathrm{Na}_{2} \mathrm{~S}_{2} \mathrm{O}_{3}$ was added to the solution via mechanical pipette and bubble mixed for 10 seconds at room temperature. The cap of the test tube was screwed on and the test tube was rocked back and forth by hand for $1 \mathrm{~min}$. The sample was allowed to react at room temperature for $60 \mathrm{~min}$ before measuring the sample's UV-spectrum absorption. An $n=3$

was performed for each SA/Vol ratio: 0, 320, 650, and $1075 \mathrm{~mm}^{2} / \mathrm{ml}$. An analysis of variance (ANOVA) was performed to confirm the significance.

\section{Experiment $\mathrm{F}$}

An experiment was performed to determine the effects of a dry Diasynth (no DI water) method on the equilibrium shift of SPR nIR peak. The cellulose membrane was used as the reaction vessel with no DI water present for dialysis. $40 \mathrm{ml}$ of $3 \mathrm{mM} \mathrm{Na} 2 \mathrm{~S}_{2} \mathrm{O}_{3}$ 
was added to $176 \mathrm{ml}$ of $2 \mathrm{mM} \mathrm{HAuCl}_{4}$ inside a $508 \mathrm{~mm}\left(360 \mathrm{~mm}^{2} / \mathrm{ml}\right.$; sample M17) and 250mm long (175 $\mathrm{mm}^{2} / \mathrm{ml}$; sample M18) $12 \mathrm{kDa}$ cellulose membrane (76mm Flat Width) and placed flat inside a plastic $113 \mathrm{~L}$ tub. The reaction lasted for $60 \mathrm{~min}$ at room temperature.

\section{Experiment G}

This experiment was performed to determine the effects of temperature and SA/Vol of the cellulose membrane to GGS solution has on the SPR nIR peak during Diasynth. $7.4 \mathrm{ml}$ of $3 \mathrm{mM} \mathrm{Na} 2 \mathrm{~S}_{2} \mathrm{O}_{3}$ was added to $32.6 \mathrm{ml}$ of $2 \mathrm{mM} \mathrm{HAuCl}_{4}$ inside a 100 $\left(220 \mathrm{~mm}^{2} / \mathrm{ml}\right), 150\left(340 \mathrm{~mm}^{2} / \mathrm{ml}\right)$, or $200 \mathrm{~mm}$ long $\left(470 \mathrm{~mm}^{2} / \mathrm{ml}\right) 12 \mathrm{kDa}$ cellulose membrane $\left(43 \mathrm{~mm}\right.$ Flat Width) and placed in $2 \mathrm{~L}$ of DI water at 25,37 , or $50^{\circ} \mathrm{C}$. An $n=3$ was performed for an ANOVA. Measurements were taken at 10min intervals to determine the reaction equilibrium kinetics. The GGS nanoparticle solution for each sample was stored in 50ml centrifuge test tubes at room temperature and size and UVspectrum absorption was measured 14 days after the reaction to test the stability of the particles.

\section{Experiment $\mathrm{H}$}

Experiment $\mathrm{H}$ was similar to Experiment E, except the Diasnyth process was performed in the absence of DI water and different temperatures were investigated. This experiment was performed to determine the effects that the cellulose membrane has on the GGS SPR nIR peak during Diasynth when temperature and SA/Vol ratio were varied. $7.4 \mathrm{ml}$ of $3 \mathrm{mM} \mathrm{Na} \mathrm{S}_{2} \mathrm{O}_{3}$ was added to $32.6 \mathrm{ml}$ of $2 \mathrm{mM} \mathrm{HAuCl}_{4}$ inside a 100 $\left(220 \mathrm{~mm}^{2} / \mathrm{ml}\right), 150\left(340 \mathrm{~mm}^{2} / \mathrm{ml}\right)$, and $200 \mathrm{~mm} \mathrm{long}\left(470 \mathrm{~mm}^{2} / \mathrm{ml}\right) 12 \mathrm{kDa}$ cellulose 
membrane $\left(43 \mathrm{~mm}\right.$ Flat Width) and placed in $2 \mathrm{~L}$ of DI water at 25,50 , and $100^{\circ} \mathrm{C}$. An $n=3$ was performed for an ANOVA. UV-spectrum absorption measurements were taken at 10min intervals to determine the reaction equilibrium kinetics. The GGS nanoparticle solution for each sample was stored in $50 \mathrm{ml}$ centrifuge test tubes at room temperature and the size and UV-spectrum absorption was measured 14 days after the reaction to test the stability of the particles.

\section{Experiment I}

For Experiment I, scanning tunneling electron microcopy (STEM) will be performed on two different samples that have a SPR nIR peak near 800 and $900 \mathrm{~nm}$. The size of the samples will be measured and counted with Imagej software manually. This experiment will determine the size distribution between the two samples. 


\section{RESULTS AND DISCUSSION}

A. Experiment A

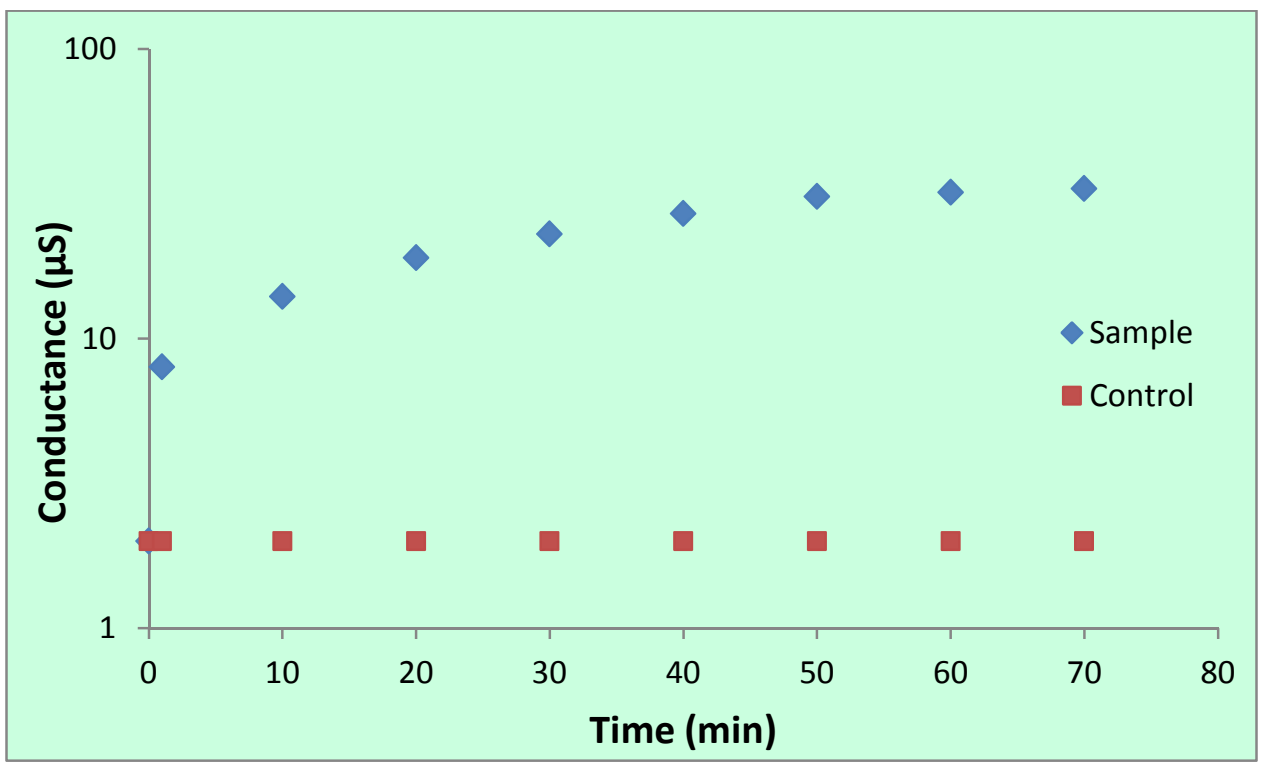

FIGURE 13 - Conductance vs. time for GGS sample dialysate (blue) and DI water control (red).

TABLE I

CONDUCTANCE OVER TIME

\begin{tabular}{|c|c|c|c|}
\hline \multicolumn{2}{|c|}{ Sample } & \multicolumn{2}{c|}{ Control } \\
\hline $\min$ & $\mu \mathrm{S}$ & $\min$ & $\mu \mathrm{S}$ \\
\hline 0 & 2 & 0 & 2 \\
\hline 1 & 8 & 1 & 2 \\
\hline 10 & 14 & 10 & 2 \\
\hline 20 & 19 & 20 & 2 \\
\hline 30 & 23 & 30 & 2 \\
\hline 40 & 27 & 40 & 2 \\
\hline 50 & 31 & 50 & 2 \\
\hline 60 & 32 & 60 & 2 \\
\hline 70 & 33 & 70 & 2 \\
\hline
\end{tabular}

The conductance over time for the GGS sample shows in Fig. 13 and Table I, that there are ions and/or gold nanoparticles within the dialysate. The increase in conductance 
over time in the dialysate is evidence that there is diffusion through the membrane. The control (DI water) shows that no change in conductance occurs over time, proving that the cellulose membrane or the dialysis clips are not attributing to the conductance measurements. The conductance measurements increase steadily until 50 min when it began to plateau at $31 \mu \mathrm{S}$ which marks the reaction reaching the equilibrium point.

\section{B. Experiment B}

The GGS solution was collected after the reaction (60min) and a UV-spectra profile was measured at 10x dilution in water. The results are shown below in Table II and Fig. 14. This experiment shows promising results for the capability of scaling up the reaction volume during synthesis while keeping the tunability of the SPR nIR peak constant by altering the $\mathrm{SA} / \mathrm{Vol}$ ratio. This represents the largest synthesis, to date since Patel performed his Diasynth process under the same conditions, but with a maximum volume of 50ml. The blue shift of the SPR nIR due to increasing the SA/Vol ratio proves the hypothesis. This blueshift could be due to an increased diffusion rate or an interaction between the GGS and the cellulose membrane at the higher SA/Vol ratios.

\section{TABLE II}

\section{EXPERIMENT B GGS SAMPLE PROPERTIES}

\begin{tabular}{|c|c|c|c|c|}
\hline $\begin{array}{c}\text { SA/Vol } \\
\left(\mathrm{mm}^{2} / \mathrm{ml}\right)\end{array}$ & $\begin{array}{c}\text { nIR Peak } \\
(\mathrm{nm})\end{array}$ & $\begin{array}{c}\text { Optical } \\
\text { Density }\end{array}$ & Size $(\mathrm{nm})$ & $\begin{array}{c}\text { Zeta Potential } \\
(\mathrm{mV})\end{array}$ \\
\hline 150 & 920 & 8.6 & 84.27 & -28.25 \\
\hline 240 & 810 & 7.1 & 63.21 & -29.9 \\
\hline
\end{tabular}




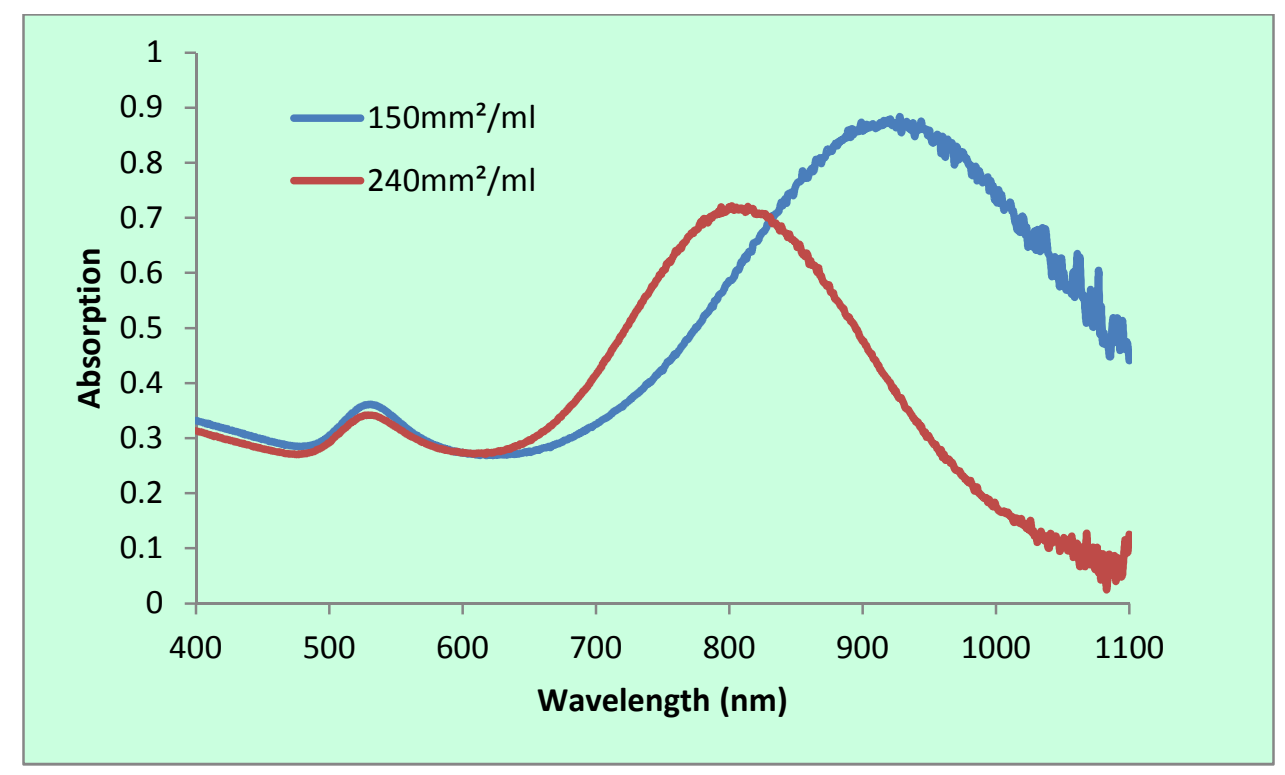

FIGURE 14 - The UV-spectra of gold/gold sulfide nanoparticles synthesized with Diasynth with a total volume of $216 \mathrm{ml}$. Measured with two different SA/Vol ratios: $150 \mathrm{~mm}^{2} / \mathrm{ml}$ (blue curve) and $240 \mathrm{~mm}^{2} / \mathrm{ml}$ (red curve).

\section{Experiment $\mathrm{C}$}

The GGS solution was collected after the reaction (60min) and a UV-spectra profile was measured at 10x dilution in water. The results are shown below in Table III and Fig. 15. The stirring does not shift the SPR nIR peak as originally thought. We theorized that the stirring would increase exchange of ions and/or small gold nanoparticles out of solution and into the DI water space, which would then cause a blue shift in SPR nIR peak equilibrium to accommodate for the decrease in the SA/Vol ratio. The Day 0 SPR nIR peak is above $1100 \mathrm{~nm}$ and shifts towards the blue spectrum (940 $\mathrm{nm}$ ) by Day 3, which the shift in equilibrium is not reached on Day 0, but has reached it by Day 3. Another measurement was performed at Day 5 with no significant difference from Day 3. The SPR nIR peak on Day 3 is broad indicating a varied size distribution from poor particle formation which could be the result of active mixing instead of passive diffusion for ion exchange. Another possibility would be that the low SA/Vol ratio 
$\left(145 \mathrm{~mm}^{2} / \mathrm{ml}\right)$ had a resdshift on the SPR absorption peak not because of poor ion exchange, but from the decrease in cellulose present during the reaction.

TABLE III

EXPERIMENT C GGS SAMPLE PROPERTIES

\begin{tabular}{|c|c|c|c|c|}
\hline Day & $\begin{array}{c}\text { nIR Peak } \\
(\mathrm{nm})\end{array}$ & $\begin{array}{c}\text { Optical } \\
\text { Density }\end{array}$ & $\begin{array}{c}\text { DLS } \\
\text { Size }(\mathrm{nm})\end{array}$ & $\begin{array}{c}\text { Zeta Potential } \\
(\mathrm{mV})\end{array}$ \\
\hline 0 & $>1100$ & 7.0 & NA & NA \\
\hline 3 & 940 & 4.5 & 63.52 & NA \\
\hline
\end{tabular}

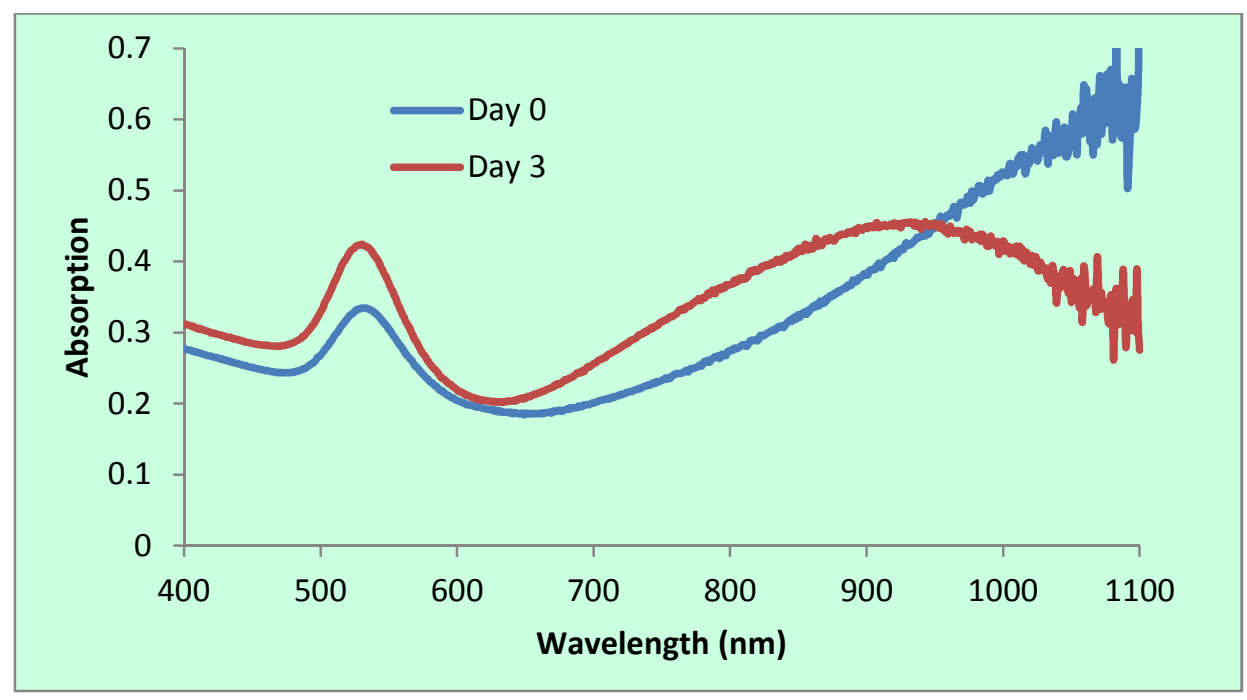

FIGURE 15 - The UV-spectra of gold/gold sulfide nanoparticles synthesized within the reactor with a total volume of $746 \mathrm{ml}$. Measured at Day 0 (blue curve) and Day 3 (red curve).

\section{Experiment D}

The $\mathrm{Na}_{2} \mathrm{~S}_{2} \mathrm{O}_{3}$ shows to have no effect on the change in color on the cellulose membrane for 8,12 , and $15 \mathrm{kDa} \mathrm{MWCO}$. The $\mathrm{HAuCl}_{4}$ did show signs of reacting with the cellulose membrane as shown in Fig. 16. The $12 \mathrm{kDa}$ membrane seems to have had a 
stronger reaction with $\mathrm{HAuCl}_{4}$ than the 8 or $15 \mathrm{kDa}$ membranes from the deeper pink/purple color. This is mostly likely due to trace amounts of sulfur compounds present on the $12 \mathrm{kDa}$ membrane acting as a reducing agent. The other two membranes are purchased from another vendor and do not contain the sulfur compounds. This experiment does show visually some interaction between $\mathrm{HAuCl}_{4}$ and the cellulose membrane. The $8 \mathrm{kDa}$ membrane displays a light pink, $12 \mathrm{kDa}$ membrane displays a deep pink/purple, and the $15 \mathrm{kDa}$ membrane displays a pink/blue color. These results are similar to the findings of $\mathrm{He}$ et al. (He, Kunitake, and Nakao, 2003). The cellulose membrane uptakes the gold ions and entraps them within the cellulose fibers. In He's study, the gold ions are being reduced and retained. Scanning electron microscopy (SEM) is needed to confirm that gold nanoparticles are being reduced on the cellulose fibers.

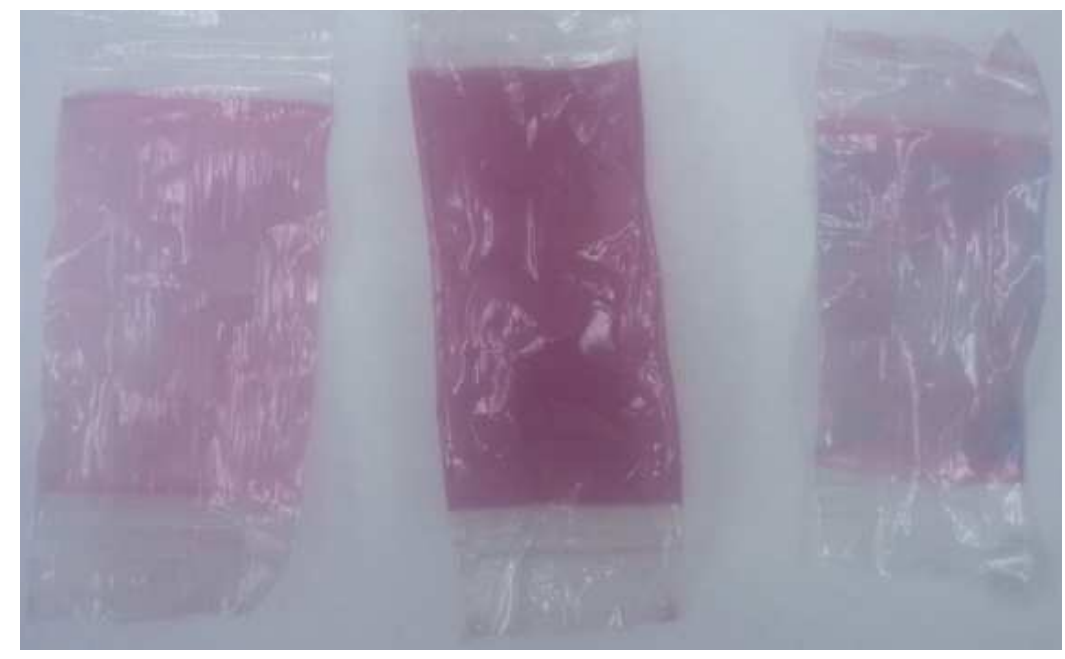

FIGURE 16 - Image of 8 (left), 12 (middle), and 15kDa (right) cellulose membranes in the presence of $\mathrm{HAuCl}_{4}$

\section{E. Experiment: E}

This experiment shows the effect of the SA/Vol ratio of the cellulose membrane to GGS nanoparticle solution has on SPR nIR peak. As shown in Fig. 17 and 18, the 
higher the SA/Vol ratio, the more the nIR peak has a blue shift. The trend shows an asymptotic decay that approaching the wavelength of $800 \mathrm{~nm}$. The error bars are the standard deviation for an $n=3$ for each data point. Since there is no dialysis occurring in this experiment, the equilibrium shift seen must be from the reaction with the cellulose membrane. The decrease in the $530 \mathrm{~nm}$ absorption peak from the traditional synthesis process may be from the cellulose membrane retaining the gold colloid. Table IV summarizes the results of the experiment.

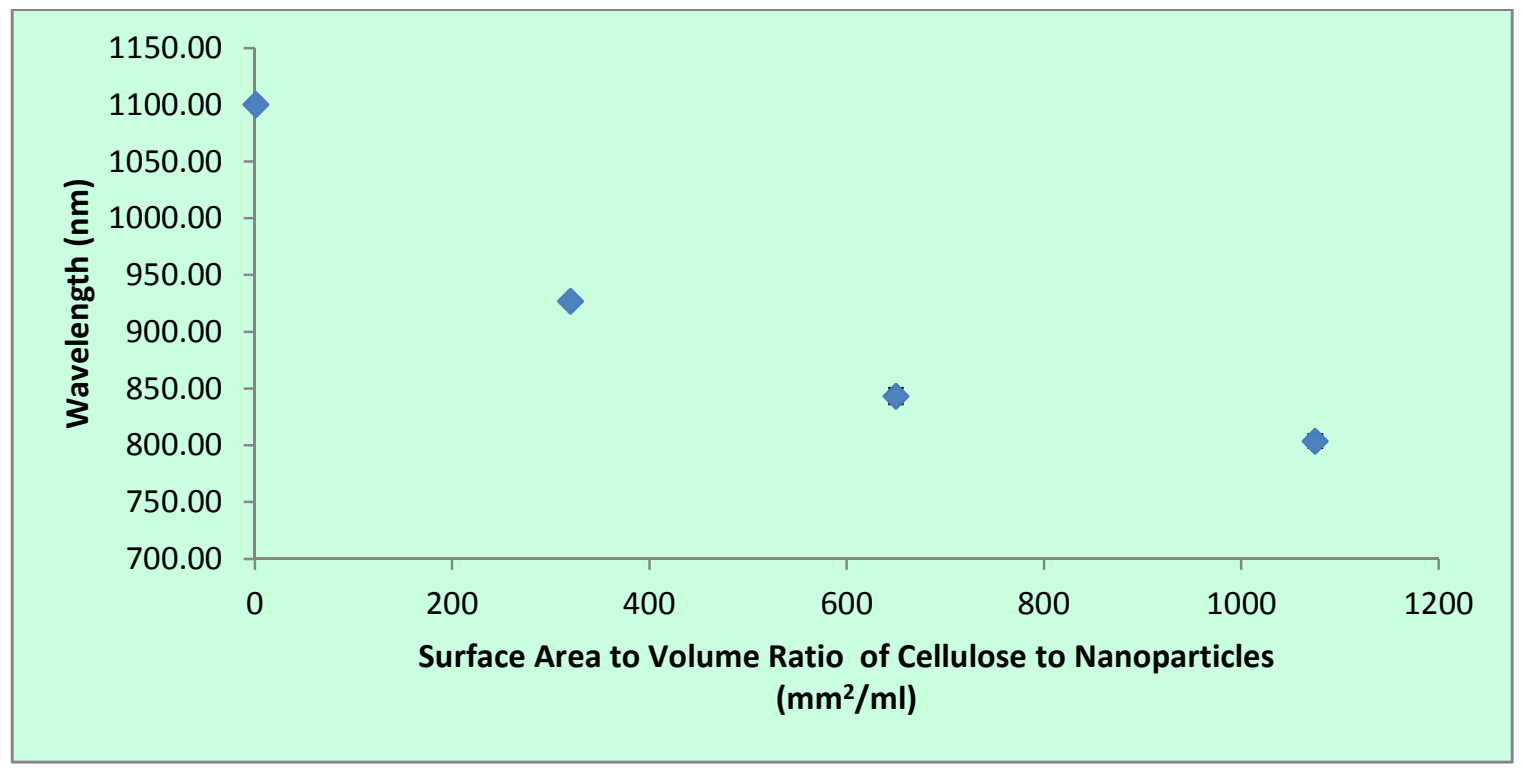

FIGURE 17 - SA/Vol ratio of cellulose membrane to nanoparticle solution vs. SPR nIR peak position for traditional synthesis in $50 \mathrm{ml}$ test tube reacted in presence of cellulose membrane. 


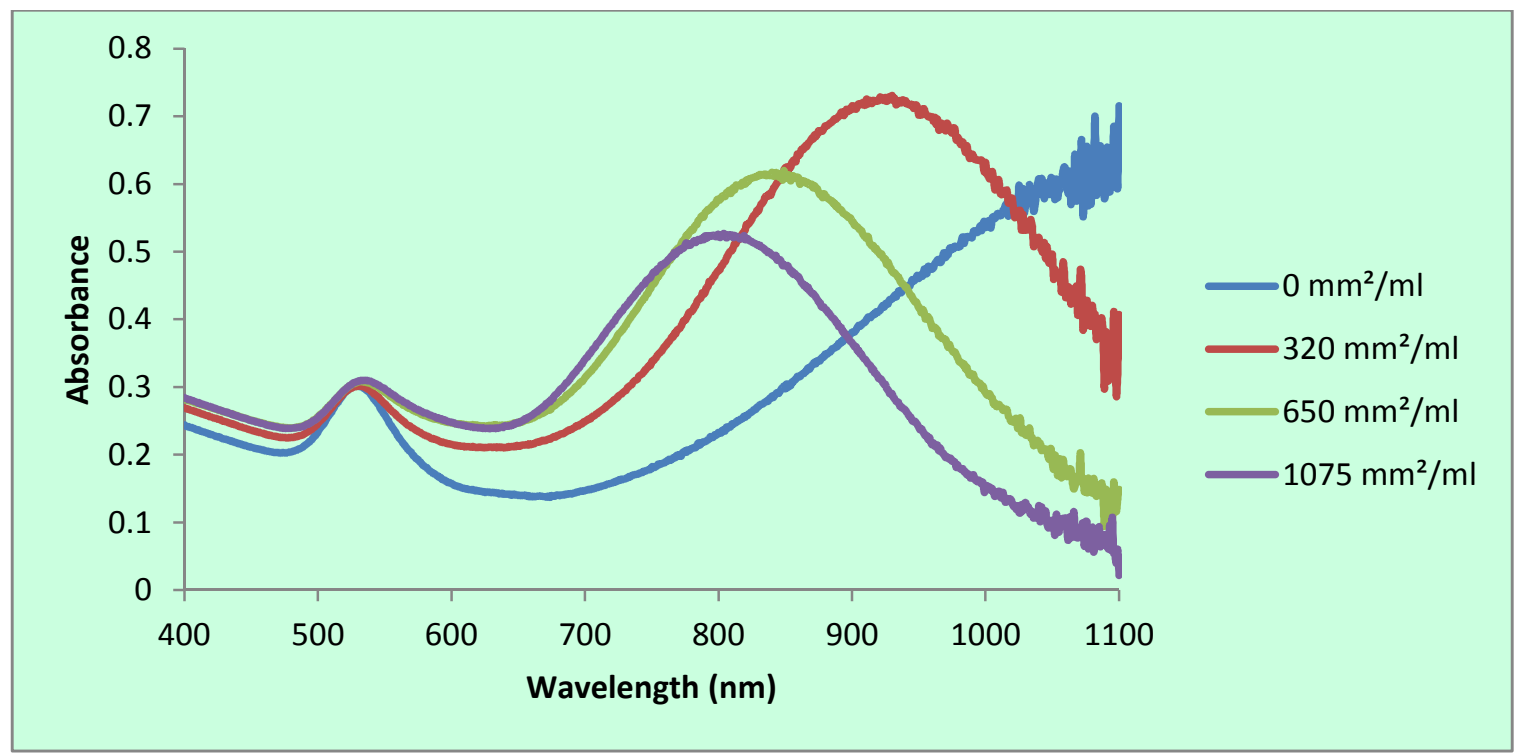

FIGURE 18 - The UV-spectra of gold/gold sulfide nanoparticles synthesized with traditional method in $50 \mathrm{ml}$ test tube in the presence of cellulose membrane. Varying $\mathrm{SA} / \mathrm{Vol}$ ratios of cellulose to nanoparticles solution were used: 0 (blue), 320 (red), 650 (green), and $1075 \mathrm{~mm}^{2} / \mathrm{ml}$ (purple).

TABLE IV

EXPERIMENT E GGS SAMPLE PROPERTIES

\begin{tabular}{|c|c|c|c|c|c|c|c|}
\cline { 2 - 8 } \multicolumn{1}{c|}{} & Sample & \multicolumn{3}{c|}{ NIR Peak } & DLS & $\begin{array}{c}\text { Zeta } \\
(\mathrm{mV})\end{array}$ & $\begin{array}{c}\text { Temp } \\
(\mathrm{C})\end{array}$ \\
\hline & $\begin{array}{c}\text { SA/Vol } \\
(\mathrm{mm} 2 / \mathrm{ml})\end{array}$ & Wavelength & Abs & OD & $\begin{array}{c}\text { Size } \\
(\mathrm{nm})\end{array}$ & & \\
\hline Avg & 0 & 1100.00 & 0.73 & 7.30 & 63.42 & -32.47 & 25.00 \\
\hline Std & & 0.00 & 0.03 & 0.26 & 5.20 & 3.36 & \\
\hline Avg & 340 & 927.00 & 0.77 & 7.73 & 69.53 & -43.37 & 25.00 \\
\hline Std & & 1.73 & 0.02 & 0.21 & 1.40 & 16.11 & \\
\hline Avg & 650 & 843.33 & 0.62 & 6.18 & 66.40 & -34.73 & 25.00 \\
\hline Std & & 7.09 & 0.07 & 0.68 & 3.27 & 2.80 & \\
\hline Avg & 1075 & 803.67 & 0.52 & 5.20 & 65.82 & -32.33 & 25.00 \\
\hline Std & & 5.86 & 0.03 & 0.30 & 1.41 & 5.80 & \\
\hline
\end{tabular}


An ANOVA was performed in mintab along with a Tukey test. The SA/Vol ratio had a $\mathrm{P}<0.000$ and a $\mathrm{R}^{2}$ value of $99.89 \%$. The Tukey test shows that each of the SA/Vol picked were significantly different from one another. The residual plots are acceptable as the histogram and normal probability plot are centered around zero. The $0 \mathrm{~mm}^{2} \mathrm{ml}$ SPR nIR peak cannot be accurately measured, each run was assigned an estimated $1100 \mathrm{~nm}$ giving no calculated variance. This data proves that the hypothesis of increasing $\mathrm{SA} / \mathrm{Vol}$ ratio of cellulose membrane to nanoparticles causes a blueshift of the SPR peak is correct.

\section{F. Experiment $\mathrm{F}$}

This experiment proves that dialysis of ions and/or gold nanoparticles does not affect the SPR nIR peak as much as previously thought. The interaction between reactants and cellulose membrane is what drives the equilibrium shift of the SPR nIR peak. The SA/Vol still has significant effect on the equilibrium shift of the SPR absorption peak as seen in Fig. 19. The reduction of colloidal gold concentration is shown from the decrease at the $530 \mathrm{~nm}$ absorption peak as compared to the tradition synthesis from the cellulose membrane retaining the gold nanoparticles. This alters the concentration of gold ions present during the reaction which causes a shift in SPR nIR peak. This experiment backup the hypothesis that increases in the SA/Vol ratio of cellulose to nanoparticle causes a blueshift on the SPR nIR peak. This dry Diasynth $\left(360 \mathrm{~mm}^{2} / \mathrm{ml}\right)$ method is comparable to Experiment B's Diasynth $\left(240 \mathrm{~mm}^{2} / \mathrm{ml}\right)$, as they have close SPR nIR peaks, but different SA/Vol ratios meaning that the exchange of ions does effect the peak as well (Fig. 20). Table V summarizes the results. 


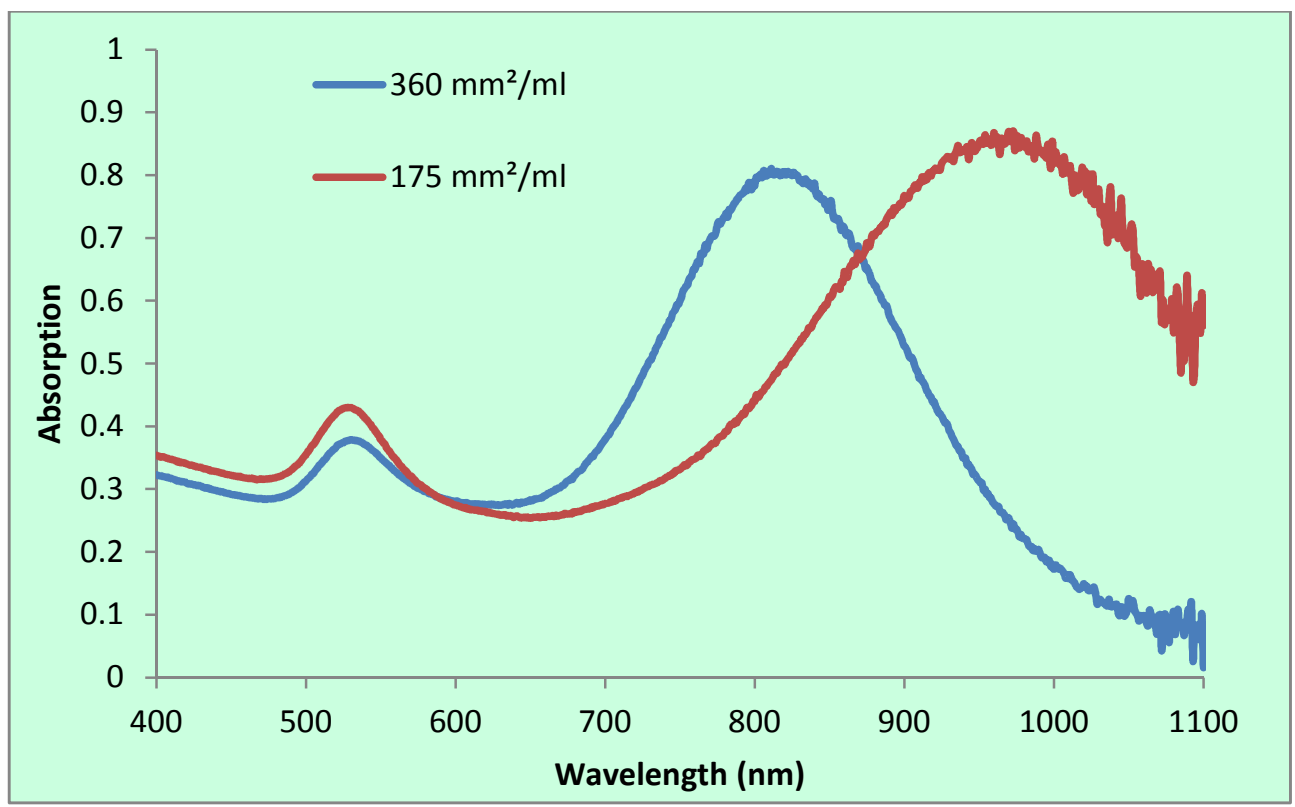

FIGURE 19 - The UV-spectra of gold/gold sulfide nanoparticles synthesized with dry Diasynth at $360 \mathrm{~mm}^{2} / \mathrm{ml}$ (blue) and $175 \mathrm{~mm}^{2} / \mathrm{ml}$ (red) SA/Vol ratios of cellulose to GGS solution with a total volume of $216 \mathrm{ml}$.

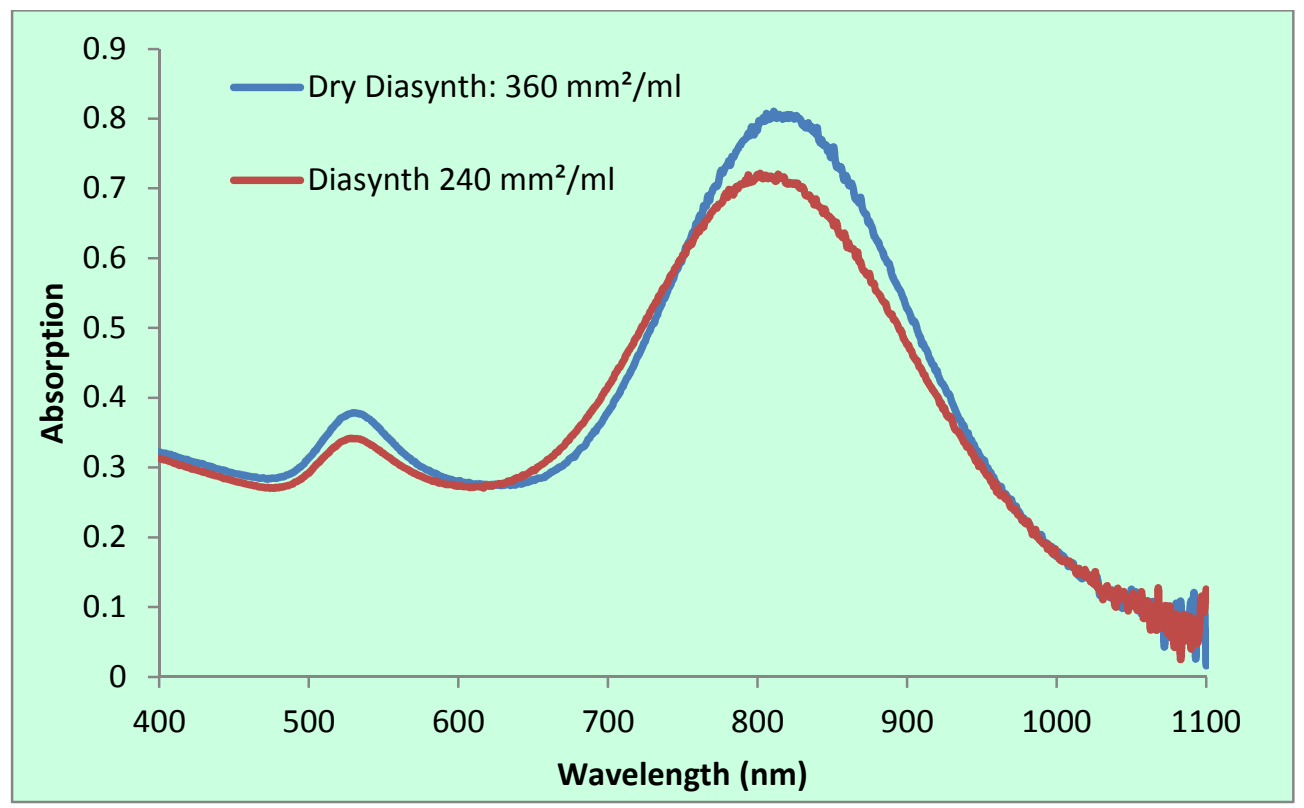

FIGURE 20 - The UV-spectra of gold/gold sulfide nanoparticles synthesized with dry Diasynth (blue) vs. Diasynth (red) method from Experiment B with a total volume of $216 \mathrm{ml}$. Measured with a SA/Vol ratio of $360 \mathrm{~mm}^{2} / \mathrm{ml}$ (blue curve) and $240 \mathrm{~mm}^{2} / \mathrm{ml}$ (red curve). 


\section{TABLE V}

\section{EXPERIMENT F GGS SAMPLE PROPERTIES}

\begin{tabular}{|c|c|c|c|c|c|}
\hline Method & $\begin{array}{c}\text { SA/Vol } \\
\left(\mathrm{mm}^{2} / \mathrm{ml}\right)\end{array}$ & $\begin{array}{c}\mathrm{nIR} \text { Peak } \\
(\mathrm{nm})\end{array}$ & $\begin{array}{c}\text { Optical } \\
\text { Density }\end{array}$ & Size $(\mathrm{nm})$ & $\begin{array}{c}\text { Zeta Potential } \\
(\mathrm{mV})\end{array}$ \\
\hline Dry Diasynth & 175 & 970 & 8.4 & 54.97 & -38.7 \\
\hline Dry Diasynth & 360 & 817 & 8.0 & 62.47 & -38.40 \\
\hline Diasynth & 240 & 810 & 7.1 & 63.21 & -29.9 \\
\hline
\end{tabular}

\section{G. Experiment G}

This experiment gives information about the SA/Vol ratio of cellulose membrane to GGS nanoparticle solution and temperature effects on the SPR peak. There is a relationship with temperature and the SPR peak equilibrium shift shown in Fig. 21. The ANOVA data in Appendix I show that SA/Vol ratio, temperature, and the interaction between the two all have a significant effect on the SPR absorption peak with an $\mathrm{R}^{2}$ value of $98.03 \%$. The Tukey test showed that 340 and $470 \mathrm{~mm}^{2} / \mathrm{ml}$ were not significantly different from each other for temperatures at 25 and $37^{\circ} \mathrm{C}$. This data proves the hypothesis that the increase in SA/Vol of cellulose membrane to nanoparticles creates a blueshift for the SPR nIR peak. The $1^{\text {st }}$ corollary was also proved here, showing that an increase in temperature causes a blueshift for the SPR nIR peak. 


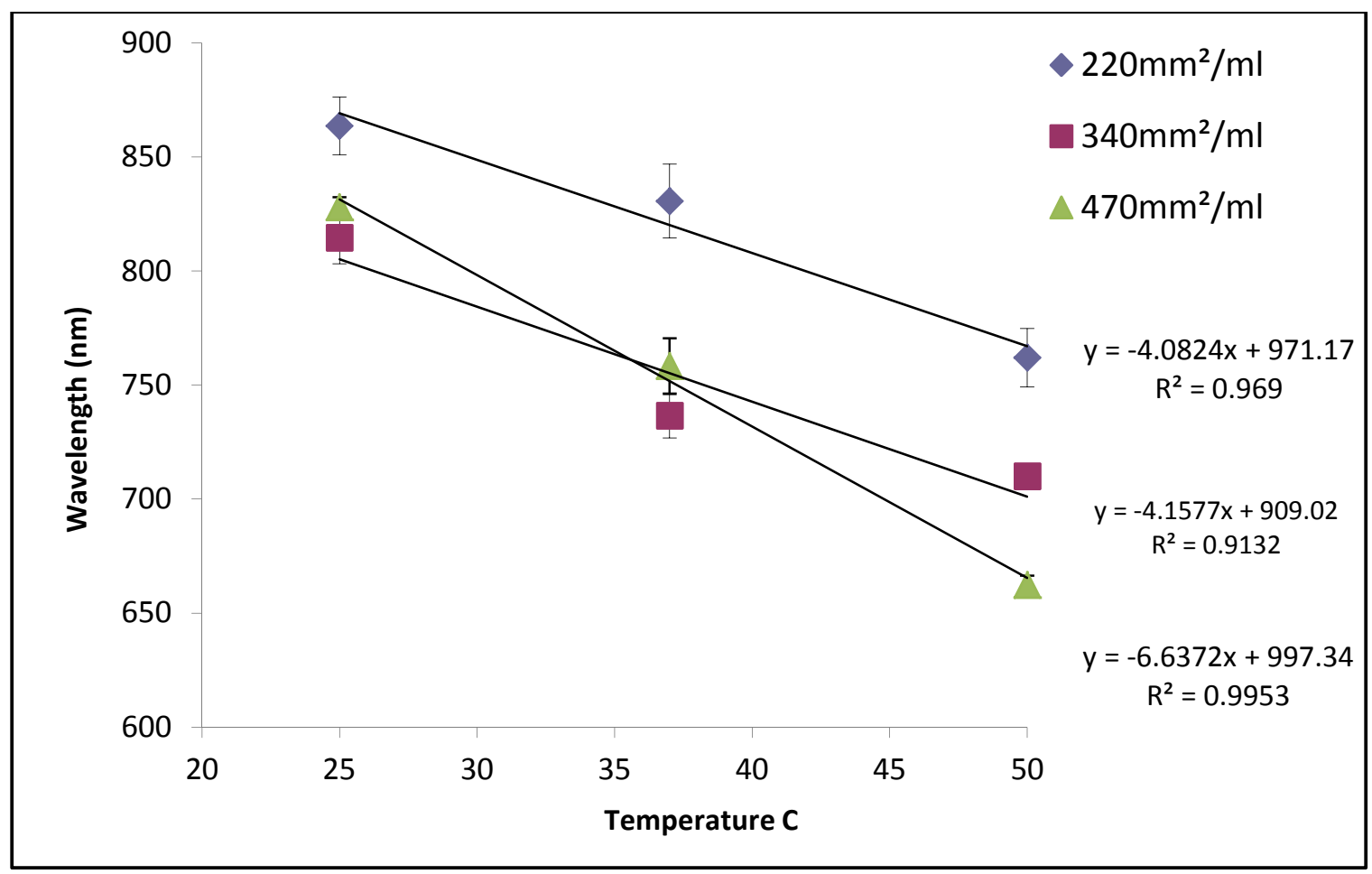

FIGURE 21 - Temperature vs. SPR nIR peak placement for 220,340 , and $470 \mathrm{~mm}^{2} / \mathrm{ml}$. $\mathrm{n}=3$

To determine the time it takes for the reaction to reach equilibrium, every 10 minutes a sample's UV-spectrum absorption was measured to determine its SPR peak placement and the time that it takes to reach equilibrium. Fig. 22 shows an example of the UV spectra of a $220 \mathrm{~mm}^{2} / \mathrm{ml}$ at $37^{\circ} \mathrm{C}$ sample over time. Fig. 23 displays the time at which the equilibrium point is reached $(20 \mathrm{~min})$. Fig 24 proves the $2^{\text {nd }}$ and $3^{\text {rd }}$ collieries that an increase in SA/Vol ratio and/or temperature reduces the equilibrium shift time of the reaction, respectively. 


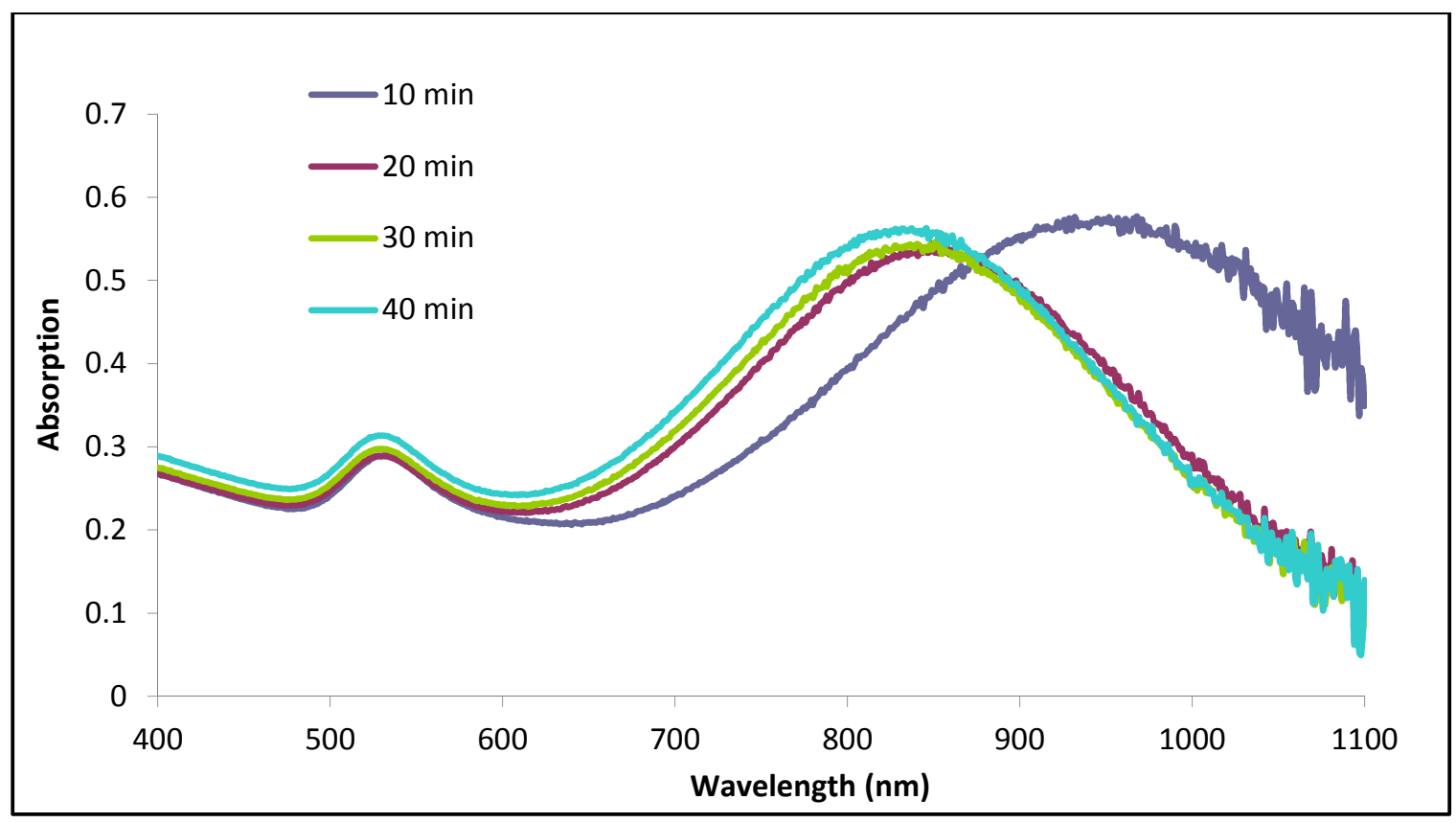

FIGURE 22 - An example showing the equilibrium shift during a Diasynth reaction

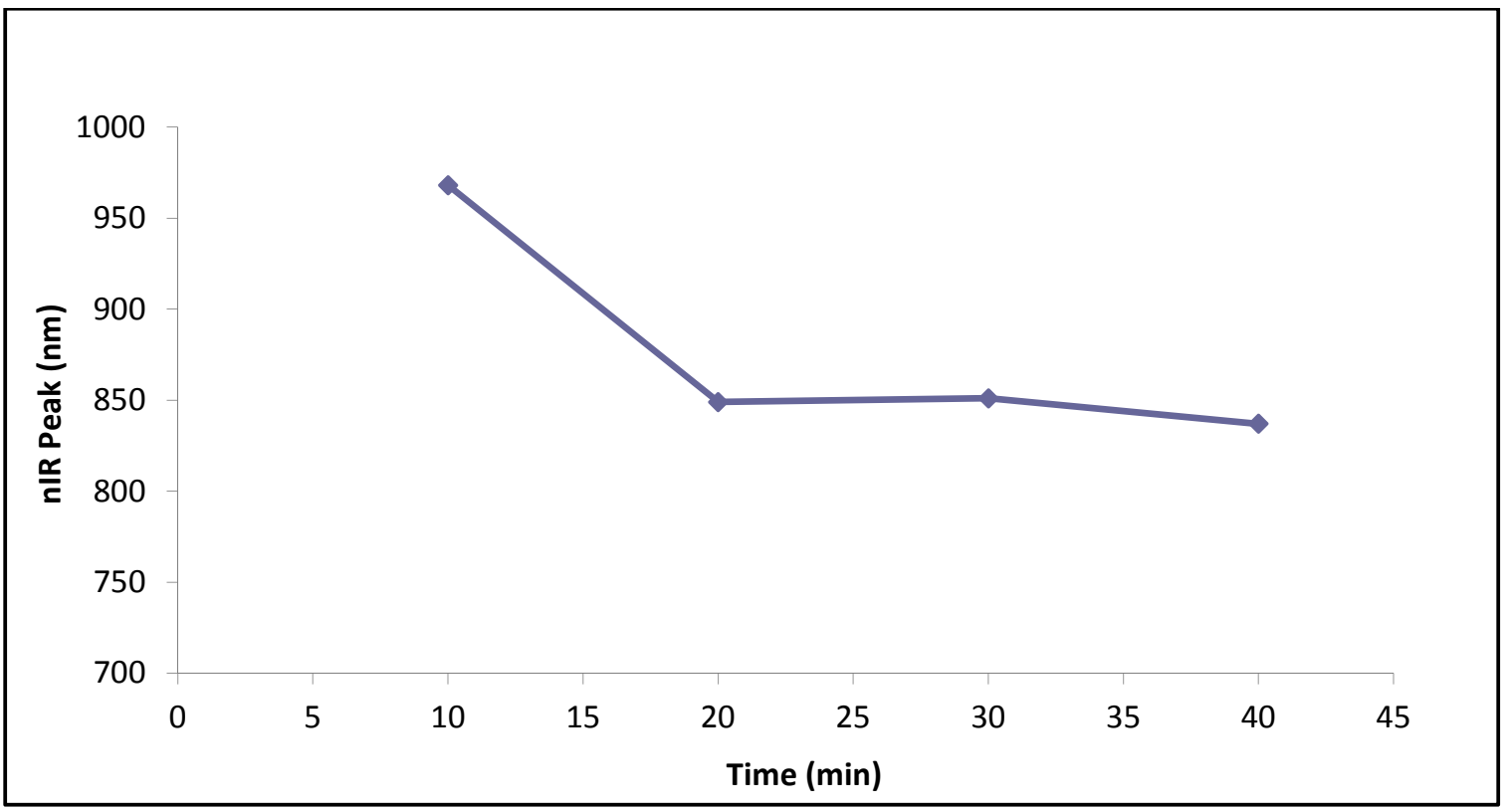

FIGURE 23 - An example showing the equilibrium point for a Diasynth sample 


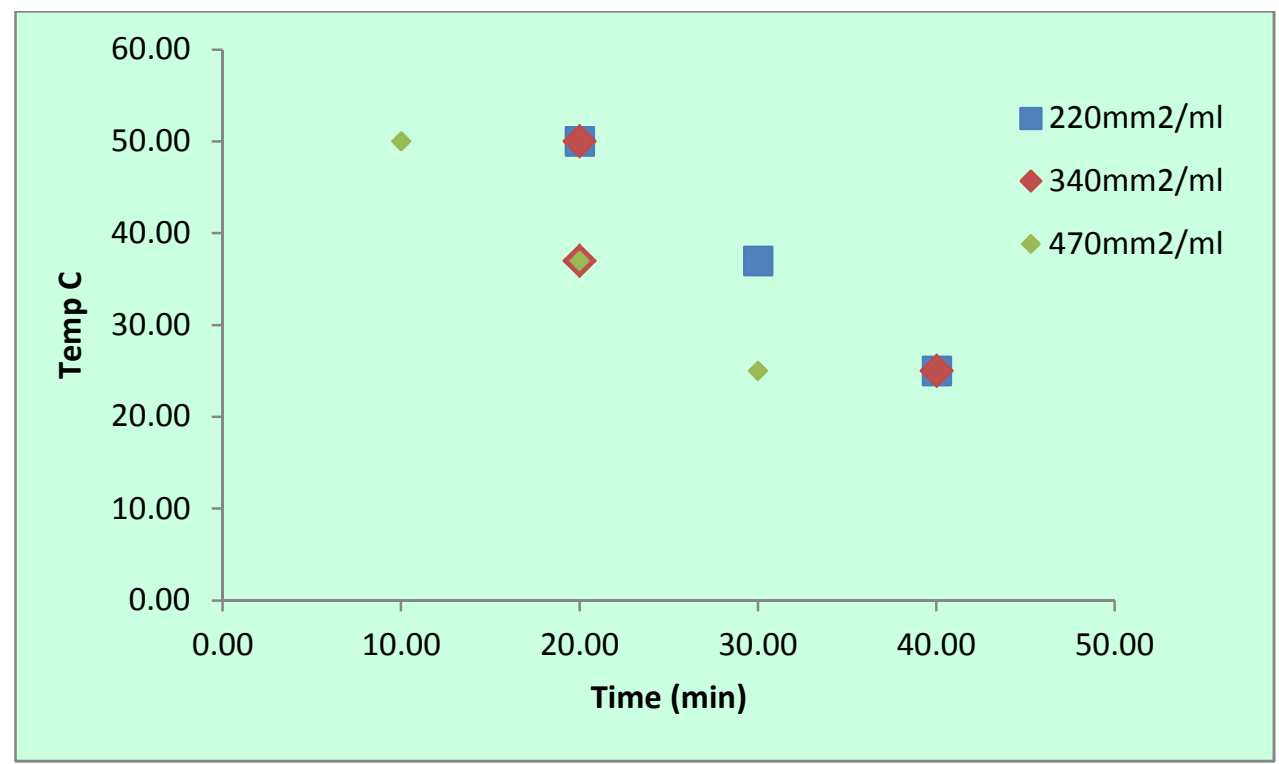

FIGURE 24 - The time ( $\mathrm{min})$ of that it takes to reach equilibrium vs Temperature $\left({ }^{\circ} \mathrm{C}\right)$ for 220,340 , and $470 \mathrm{~mm}^{2} / \mathrm{ml}$.

All of the samples' UV absorption spectra were measured at Day 0 and 14 (Fig. 25). The samples subjected to the Diasynth process seem to remain stable without being capped or protected. This proves the $4^{\text {th }}$ corollary with Experiment H's stability results showing that an exchange of ions in this experiment improves stability over time wheras Experiment $\mathrm{H}$ has no ion exchange reducing the stability over time. The sample at $50^{\circ} \mathrm{C}$ with a $470 \mathrm{~mm}^{2} / \mathrm{ml}$ was the only sample that was unstable over 14 days and is most likely due to the large $\mathrm{SA} / \mathrm{Vol}$ ratio at the highest temperature point causes a fast reaction that was seen under $5 \mathrm{~min}$ This reaction may be too fast for stable particle formation. 


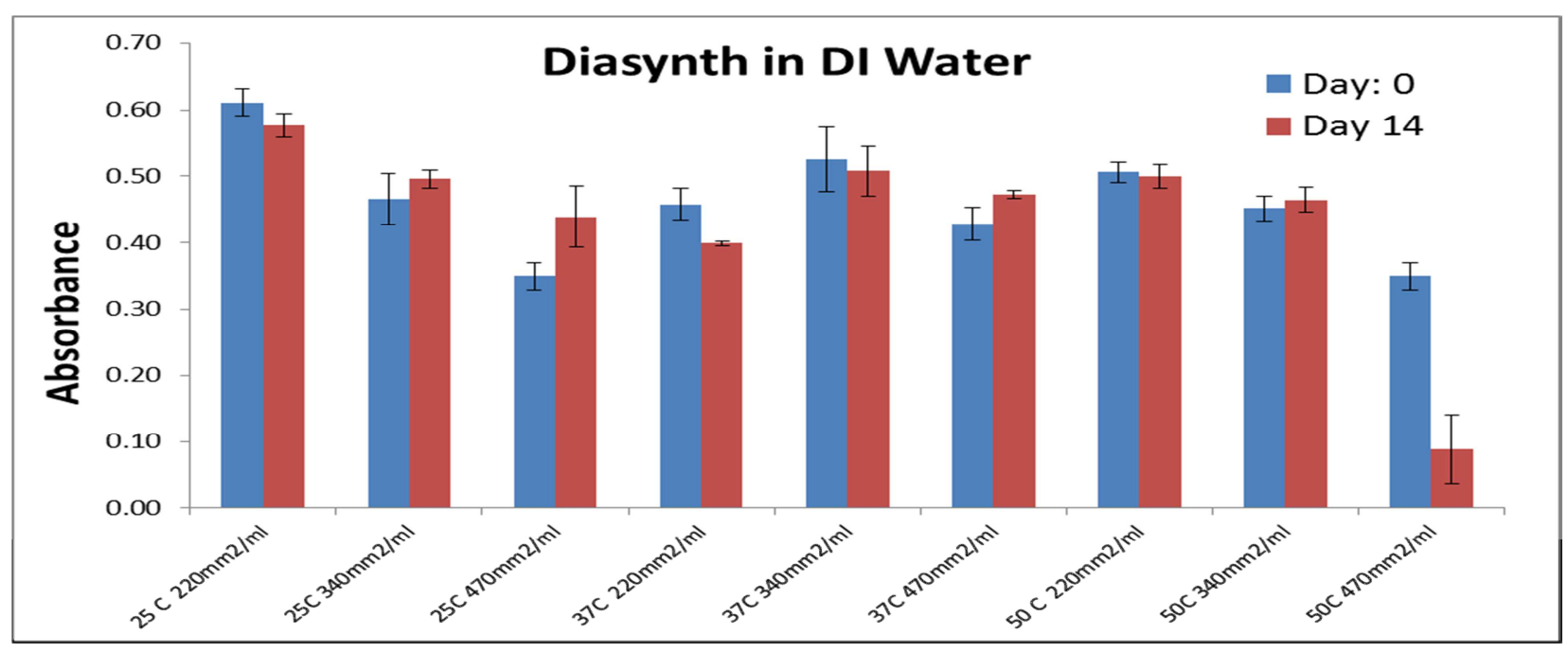

FIGURE 25 - Stability of the GGS nanoparticles after 14 days

\section{H. Experiment $\mathrm{H}$}

This experiment shows the SA/Vol ratio of cellulose membrane to GGS nanoparticle solution and temperature effects on the SPR peak for dry Diasynth (no DI water). There is not a linear relationship with temperature and the SPR peak equilibrium shifts like in Experiment G shown in Fig. 26. This non-linearity is most likely from the evaporation of water from the GGS solution which causes the GGS sample to concentrate while reacting. The ANOVA data in Appendix I shows that SA/Vol ratio, temperature, and the interaction between the two all have a significant effect on the SPR absorption peak with an $\mathrm{R}^{2}$ value of $97.53 \%$. Similar to Experiment $\mathrm{G}$, this experiment backups the hypothesis and $1^{\text {st }}$ corollary that an increase in SA/Vol ratio of cellulose membrane to nanoparticles and increase in temperature has a blueshift on the SPR nIR peak, respectively. 


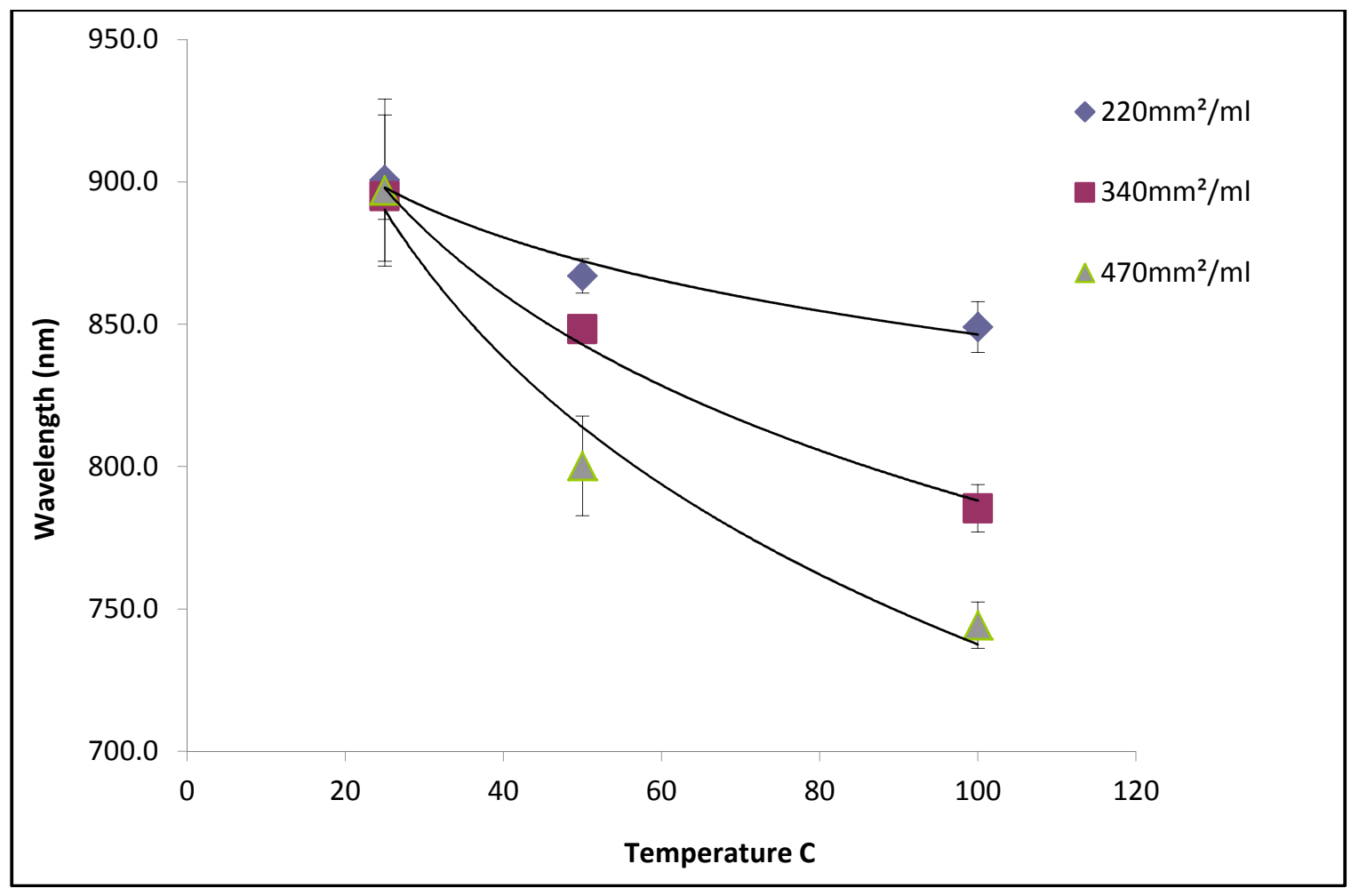

FIGURE 26 - Temperature vs. SPR nIR peak placement for 220,340 , and $470 \mathrm{~mm}^{2} / \mathrm{ml}$ for dry Diasynth. $n=3$

To determine the time it takes for the reaction to reach equilibrium, a sample was taken every 10 minutes to determine its SPR peak placement and the time that it takes to reach equilibrium. Fig. 22 from Experiment G shows an example of the UV spectra of a $220 \mathrm{~mm}^{2} / \mathrm{ml}$ at $37^{\circ} \mathrm{C}$ sample over time. Fig. 23 displays the time at which the equilibrium point is reached $(20 \mathrm{~min})$. Fig 27 shows that an increase in SA/Vol ratio and/or temperature reduces the equilibrium shift time. The temperature most likely increases the number of collisions during the reaction, whereas it is unclear why SA/Vol reduces reaction time. Again, similar to Experiment $G$, the results proved the $2^{\text {nd }}$ and $3^{\text {rd }}$ corollaries where an increase in $\mathrm{SA} / \mathrm{Vol}$ and temperature will decrease the reaction time, 
respectively. 220 and $340 \mathrm{~mm}^{2} / \mathrm{ml}$ seem to have the same the same reaction time to reach equilibrium, however measurements at smaller time intervals would be needed to verify.

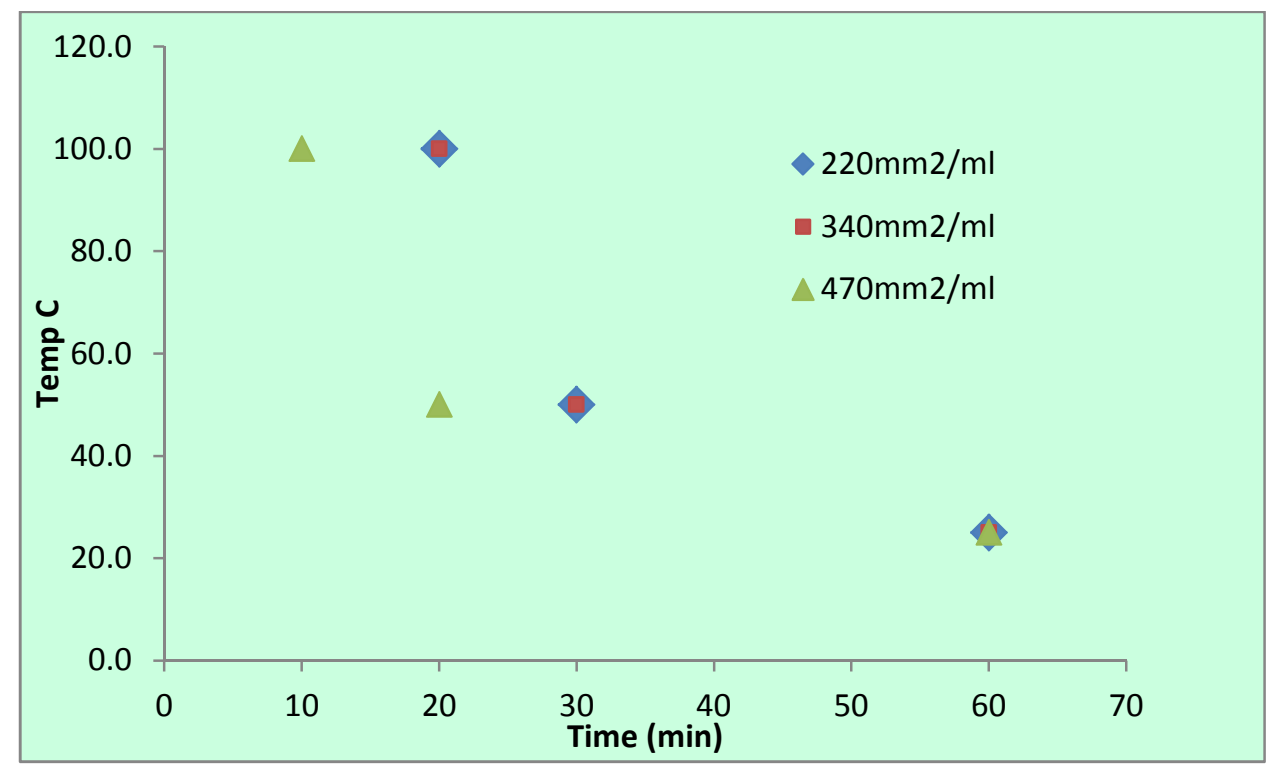

FIGURE 27 - Time (min) of equilibrium vs Temperature $\left({ }^{\circ} \mathrm{C}\right)$ for 220,340 , and $470 \mathrm{~mm}^{2} / \mathrm{ml}$.

All of the samples' UV absorption spectra was measured at Day 0 and 14. The samples that were subjected to the dry Diasynth process become unstable and aggregate over 14 days. Fig. 28 also shows the stability of the particles. This experiment confirms the $4^{\text {th }}$ corollary with the stability results from Experiment G, where this experiment has no exchange of ions out of the GGS solution. The GGS nanoparticles remain stable in solution by not coming into contact with one another from the repulsion forces due to their negative surface charge. Ions can mask the surface charge of the GGS nanoparticles allowing for the repulsion forces become reduced and come into contact with other nanoparticles reacting with one another forming larger aggregates. This continues until the entire solution has aggregated. 


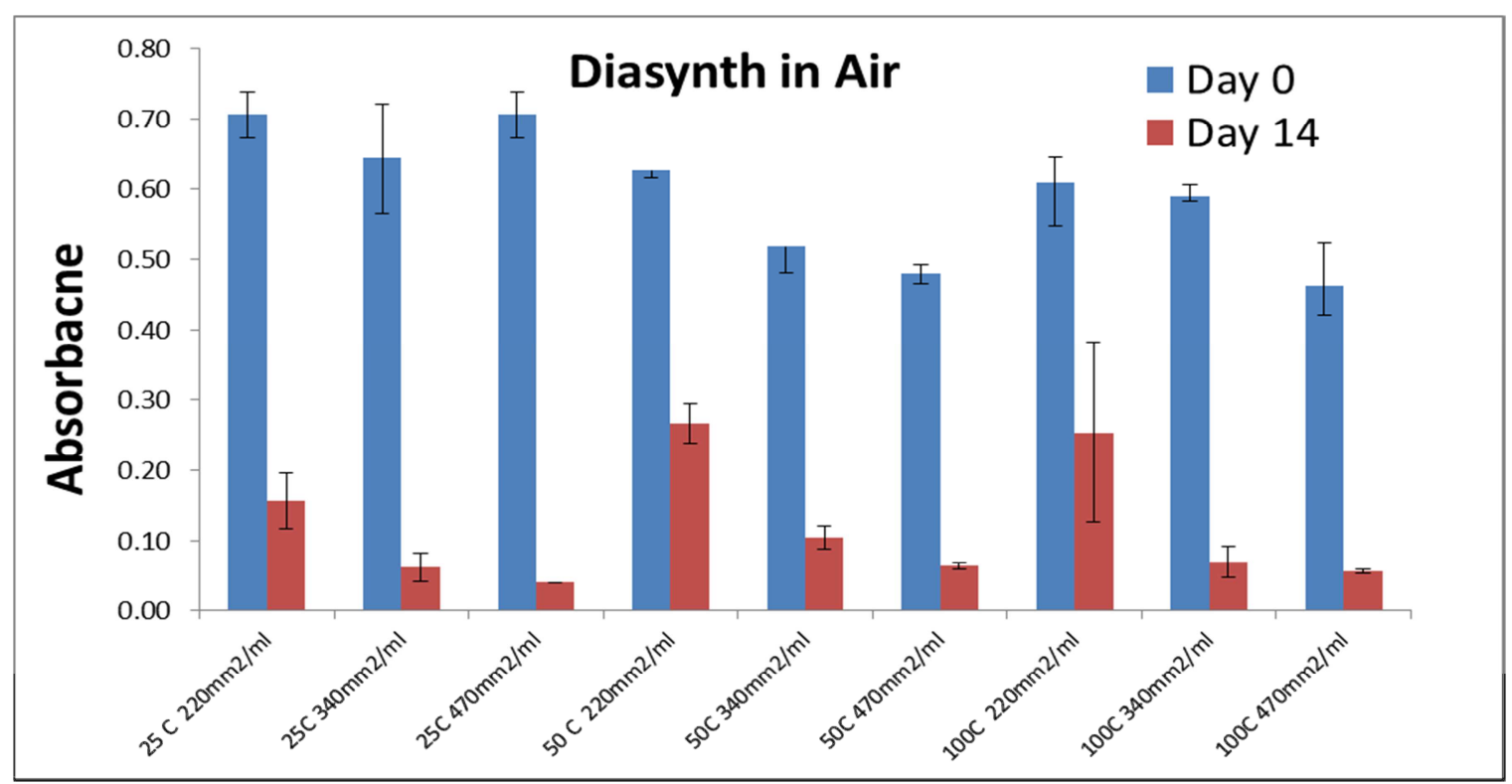

FIGURE 28 - Stability of the GGS nanoparticles after 14 days

\section{Experiment I}

Two different GGS samples were imaged using STEM with the Zeiss SUPRA FE-SEM. The two samples imaged have a nIR absorption peak close to 800 and $900 \mathrm{~nm}$ shown in Fig. 29. Image j software was used manually count and measure the size distribution data as shown in Fig. 30. 


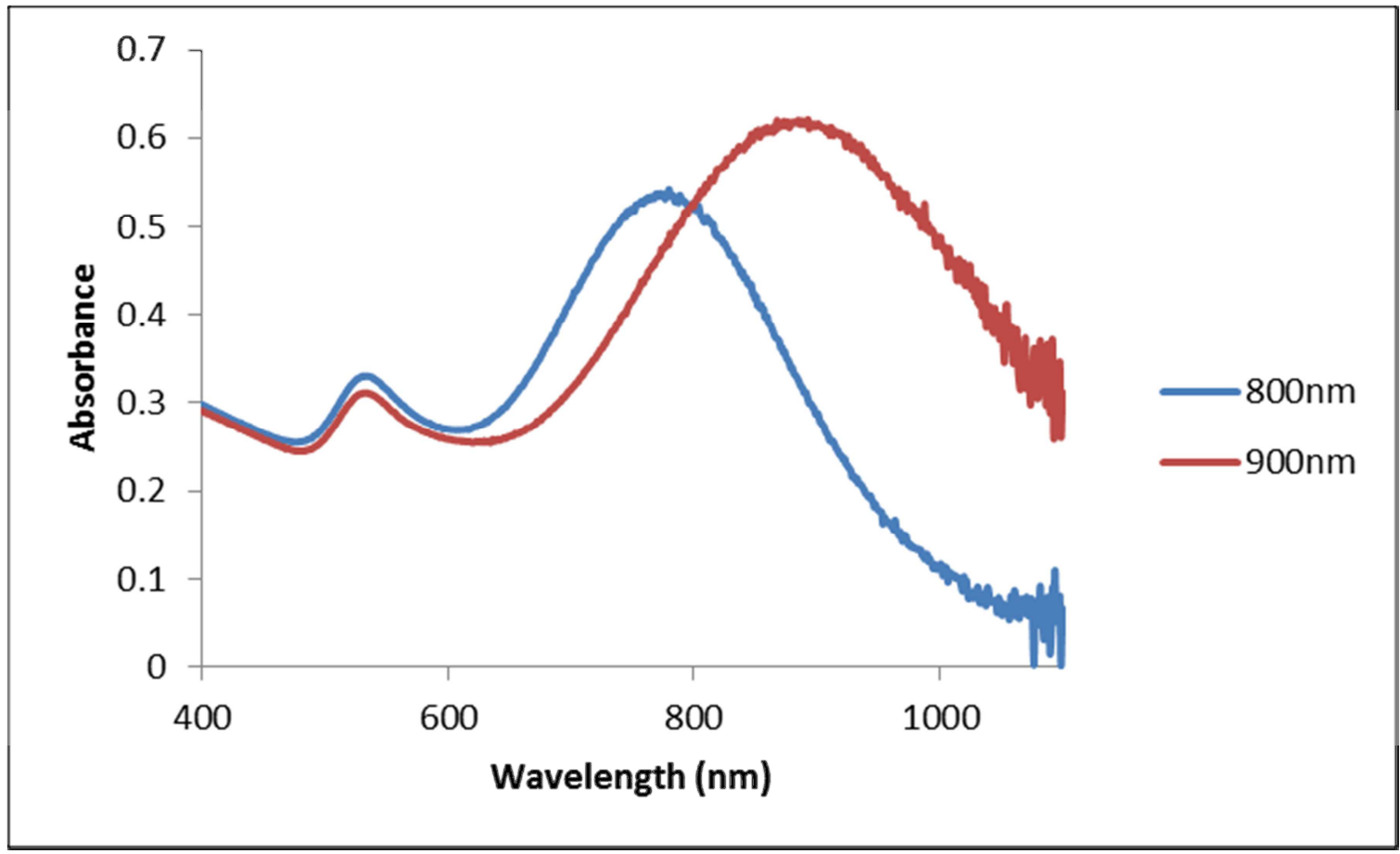

FIGURE 29 - The UV-spectra of gold/gold sulfide nanoparticles synthesized close to 800nm (blue) and 900nm (red).

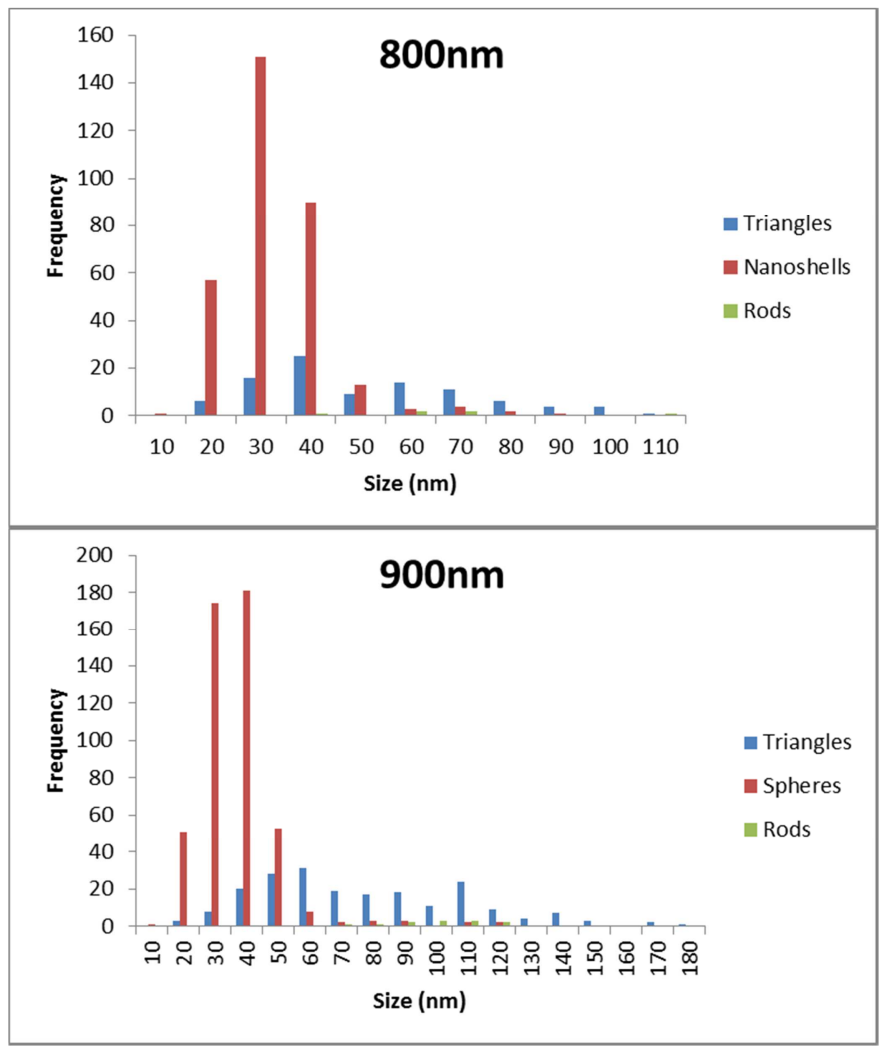

FIGURE 30 - Histogram of size distribution for two samples 
TABLE VI

GGS SIZE DISTRUBUTION DATA

\begin{tabular}{l|c|c|c|c|}
\multicolumn{5}{c}{$800 \mathrm{~nm}$} \\
\hline \multirow{1}{*}{$\mathrm{N}=426$} & & Count & $\%$ & AVG Size $(\mathrm{nm})$ \\
\hline \multirow{1}{*}{} & Shells & 323 & 75.8 & 28.0 \\
\hline Triangles & 96 & 22.5 & 47.0 \\
\hline Rods & 7 & 1.6 & 69.0 \\
\hline
\end{tabular}

$900 \mathrm{~nm}$

\begin{tabular}{|c|c|c|c|c|}
\hline $\mathbf{N}=697$ & & Count & $\%$ & AVG Size \\
\hline & Shells & 480 & 68.9 & 32.0 \\
\hline \multirow{2}{*}{ Triangles } & 205 & 29.4 & 72.8 \\
\hline Rods & 12 & 1.7 & 94.1 \\
\hline
\end{tabular}

The average size in Table VI refers to diameter, edge length, and length for nanoshells, nanotriangles, and nanorods respectively. The images used for the histogram were Figs. 38-40 for 800 and Figs. 41-43 for 900nm in Appendix III. The edge length of the nanotriangles increase in size from the 800 to $900 \mathrm{~nm}$ sample, which follows the same trend with findings by Young et al. (Young et al., 2012). The nanoshells also increase in size from the $800 \mathrm{~nm}$ sample to the $900 \mathrm{~nm}$ sample. Mie theory needs to be performed to determine the core and shell dimensions.

\section{CONCLUSION}

It was demonstrated in this paper that ions are diffusing out of the cellulose membrane during the Diasynth process. These ions do not have a significant effect on the equilibrium shift of the surface plasmon absorption as previously thought. However, 
these ions do affect the stability of non-coated GGS nanoparticles. The GGS particles that dialyzed out of the ions remained stable for up to 2 weeks whereas the particles which had no dialysis aggregated. It was discovered that the cellulose membrane retains the small gold colloid $(<10 \mathrm{~nm})$ that was problematic before with the traditional synthesis that required purification.

The Diasynth method has shown to be able to increase in synthesis volume from $50 \mathrm{ml}$ (Patel, 2012) to $216 \mathrm{ml}$. Not shown in this paper, but the volume has been scaled up even further to $500 \mathrm{ml}$ with control over SPR peak placement. Further volume increase can be performed with more precise control over the reaction by adjusting molar ratio, temperature, and/or surface area to volume ratio of cellulose membrane to gold/goldsulfide nanoparticles. The $\mathrm{SA} / \mathrm{Vol}$ ratio and temperature were found to significantly affect the SPR equilibrium shift. The temperature SA/Vol ratio not only helps to control the surface plasmon resonance peak, but also reduce the time the reaction takes.

\section{RECOMMENDATIONS}

There is still room for potential expansion upon this synthesis process. Using $\mathrm{Na}_{2} \mathrm{~S}$ with the Diasynth method (wet or dry) could give better stable GGS nanoparticles. From Eq. 1, there are fewer ions associated with this reaction which could yield a more stable GGS solution as well as be performed with the dry Diasynth method. Mie theory calculations can be performed to determine the nanoshell thickness from Experiment I's data. Better initial mixing techniques of the two reactants should be investigated, as this now will begin to affect the volumetric scale up process due to initial colloidal gold 
formation. The largest reaction thus far has been $500 \mathrm{ml}$ which had an nIR peak at 820 $\mathrm{nm}$. An important future work would be to increase the volume of the reaction to $1 \mathrm{~L}$. 


\title{
APPENDIX I
}

\author{
Experiment $\mathrm{E}$
}

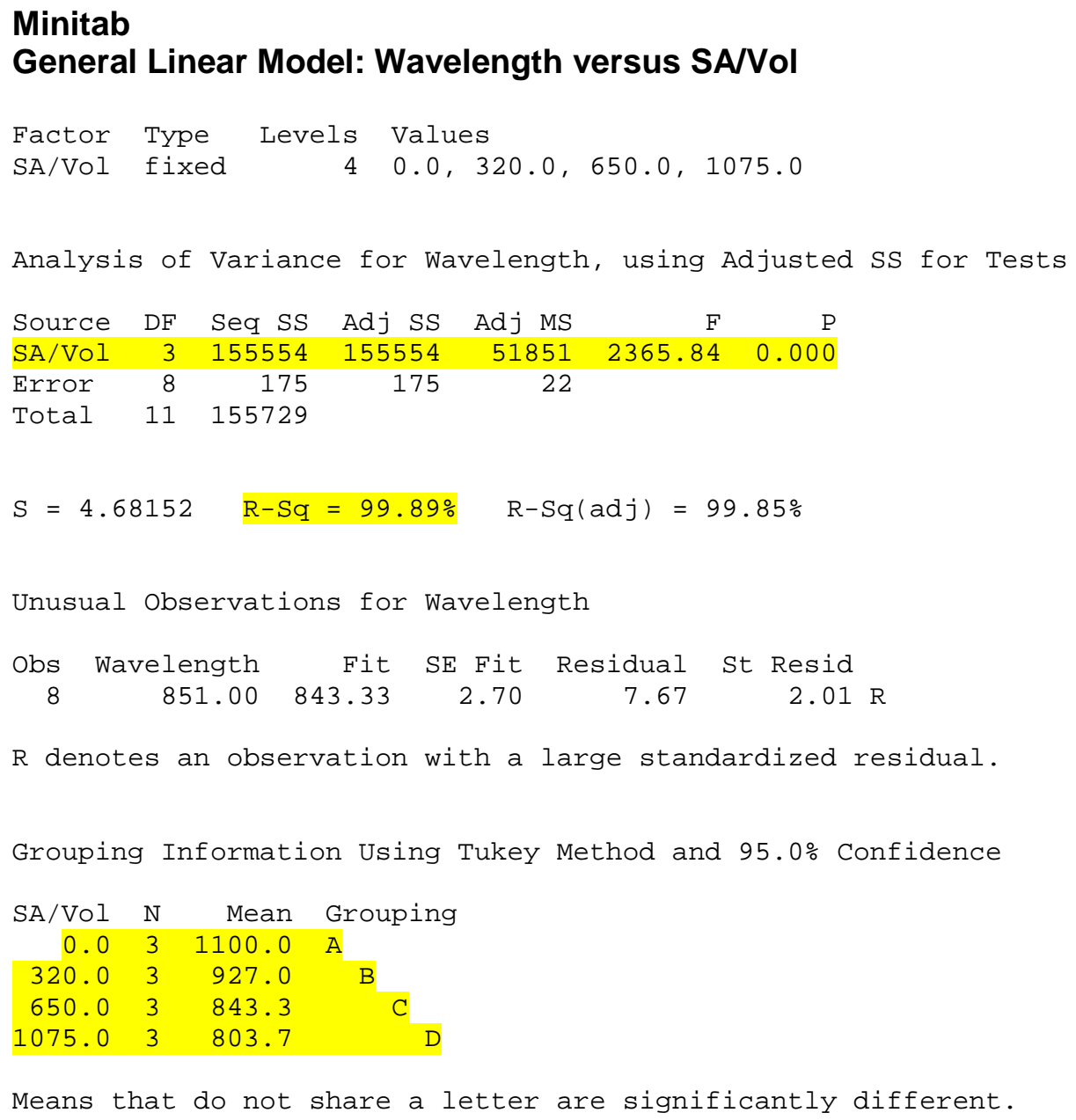

Minitab

General Linear Model: Wavelength versus SA/Vol 


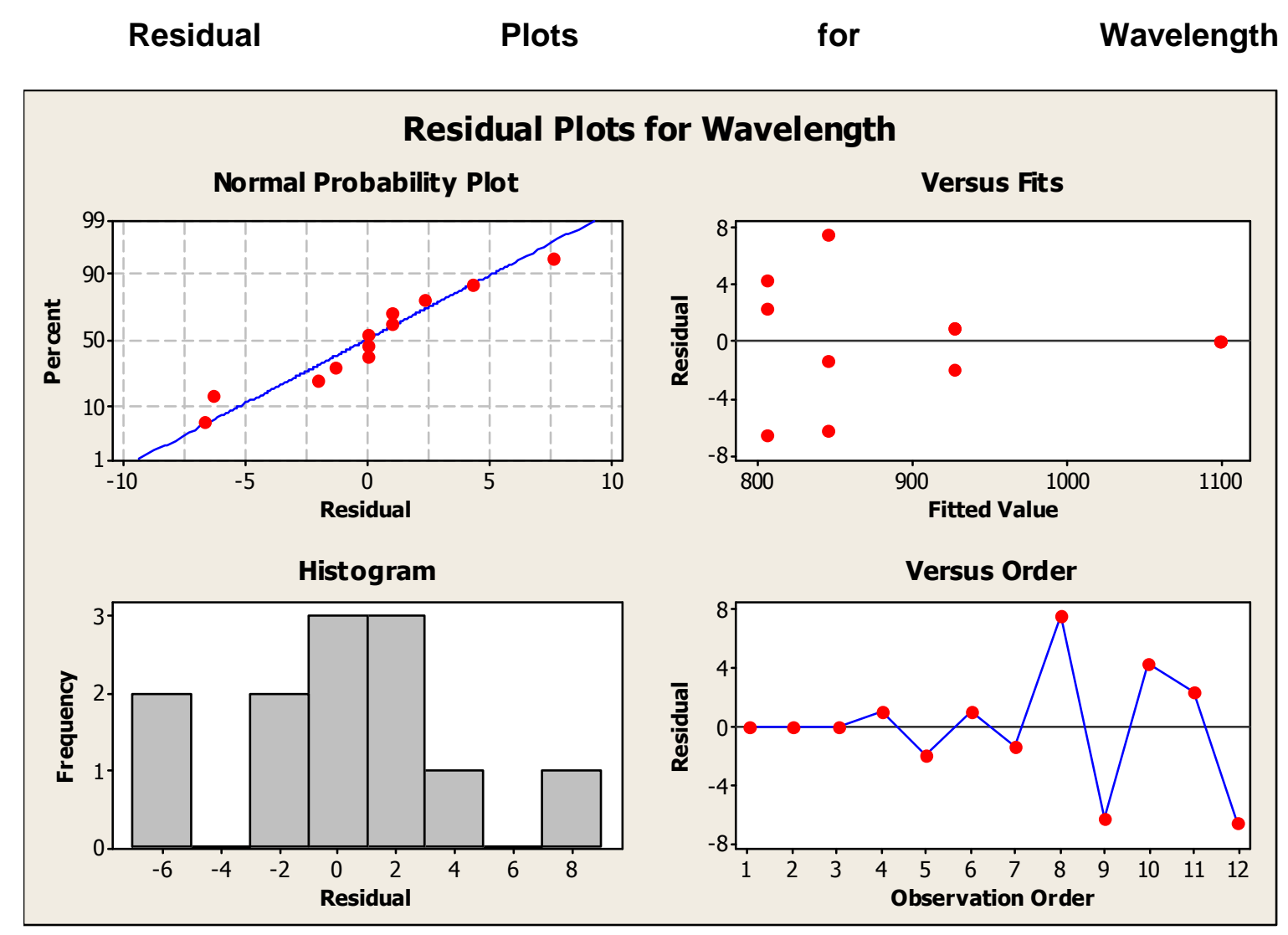

FIGURE 31 - Residual Plots for Experiment E 


\section{Experiment G}

\section{MINITAB}

General Linear Model: wavelength versus Temp (C), SA (mm2/ml)

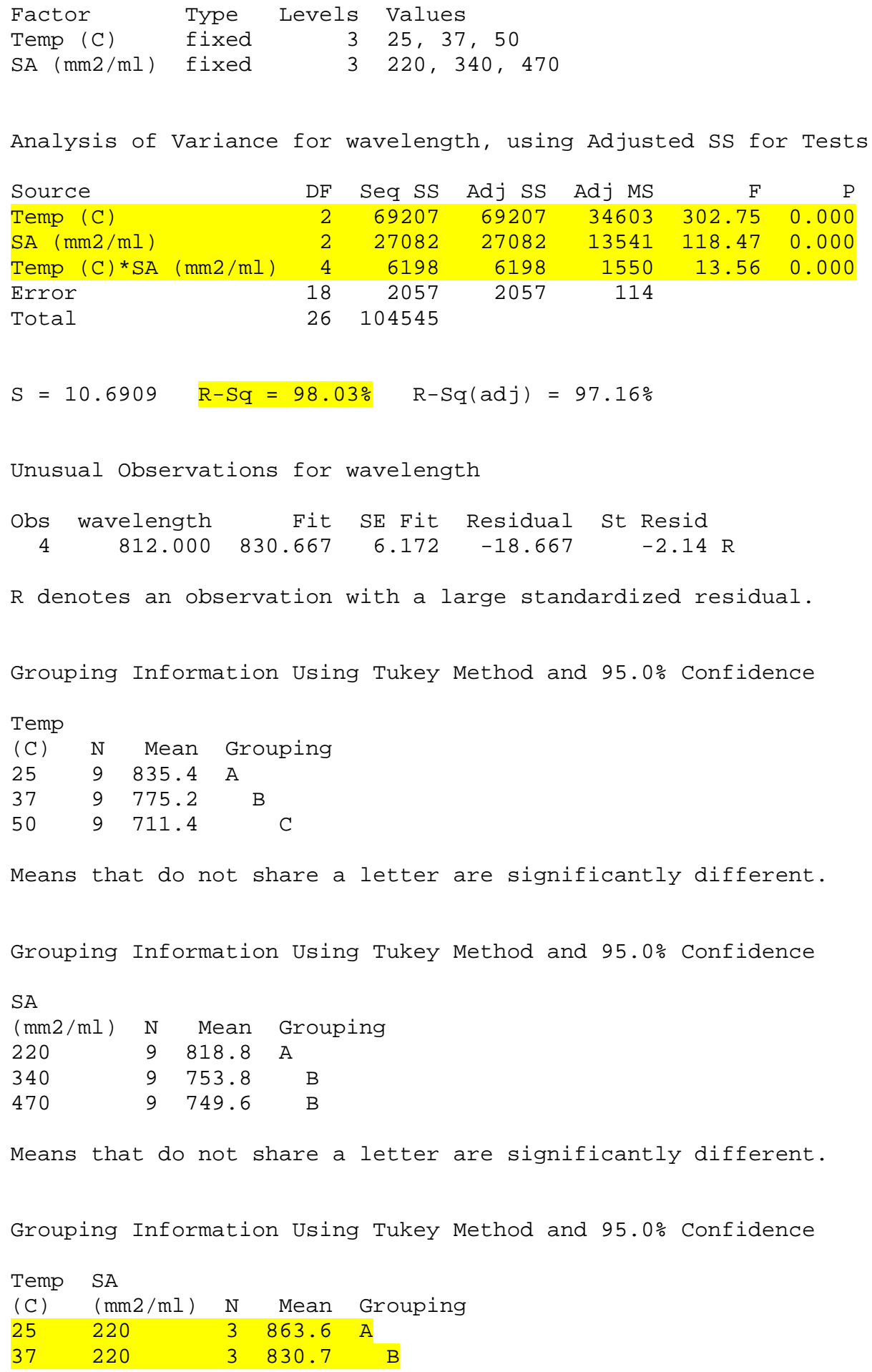




\begin{tabular}{|c|c|c|c|c|c|}
\hline 25 & 470 & 3 & 828.0 & B & \\
\hline 25 & 340 & 3 & 814.7 & B & \\
\hline 50 & 220 & 3 & 762.0 & & C \\
\hline 37 & 470 & 3 & 758.3 & & C \\
\hline 37 & 340 & 3 & 736.7 & & C \\
\hline 50 & 340 & 3 & 710.0 & & \\
\hline 50 & 470 & 3 & 662.3 & & \\
\hline
\end{tabular}

Means that do not share a letter are significantly different.

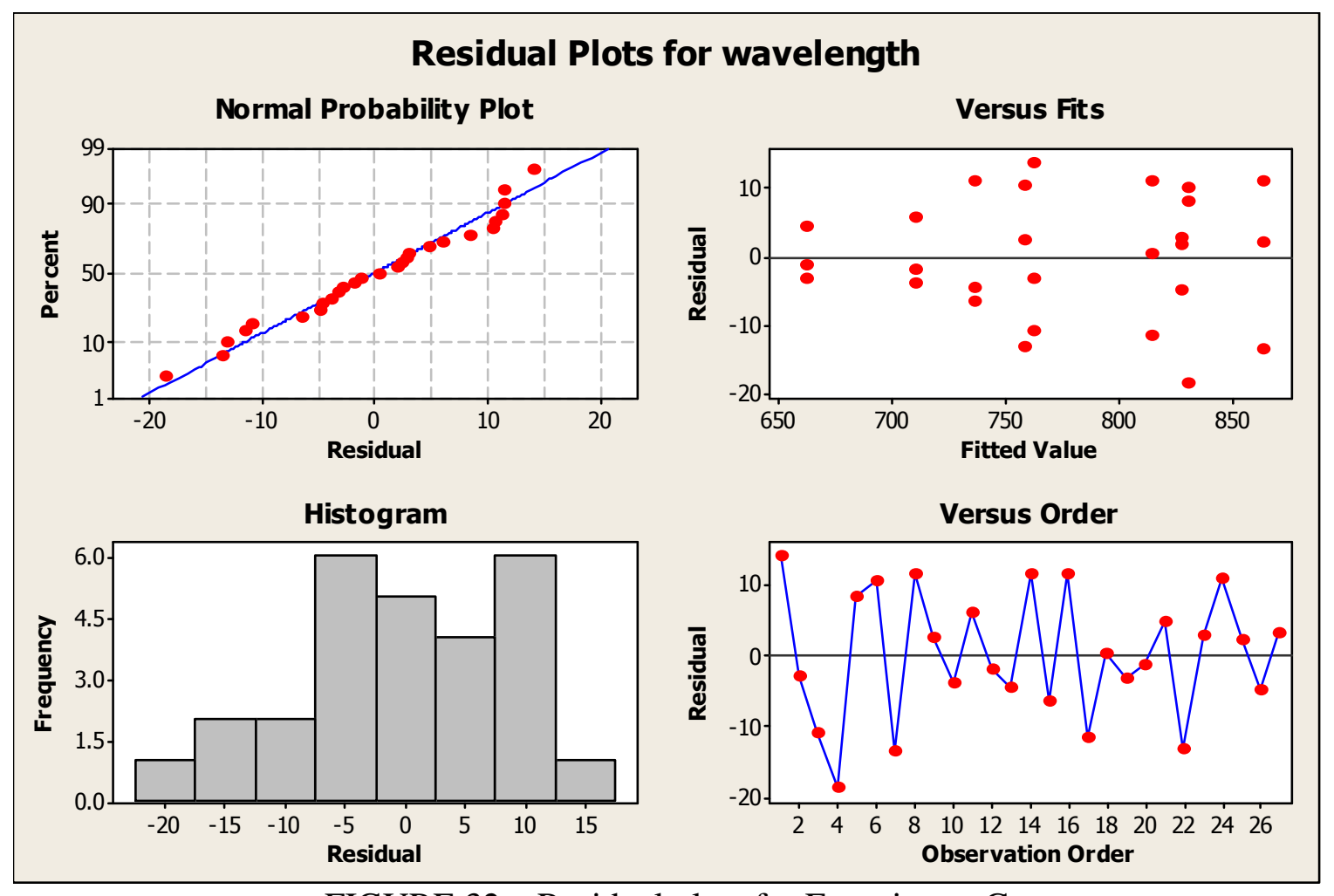

FIGURE 32 - Residual plots for Experiment G 


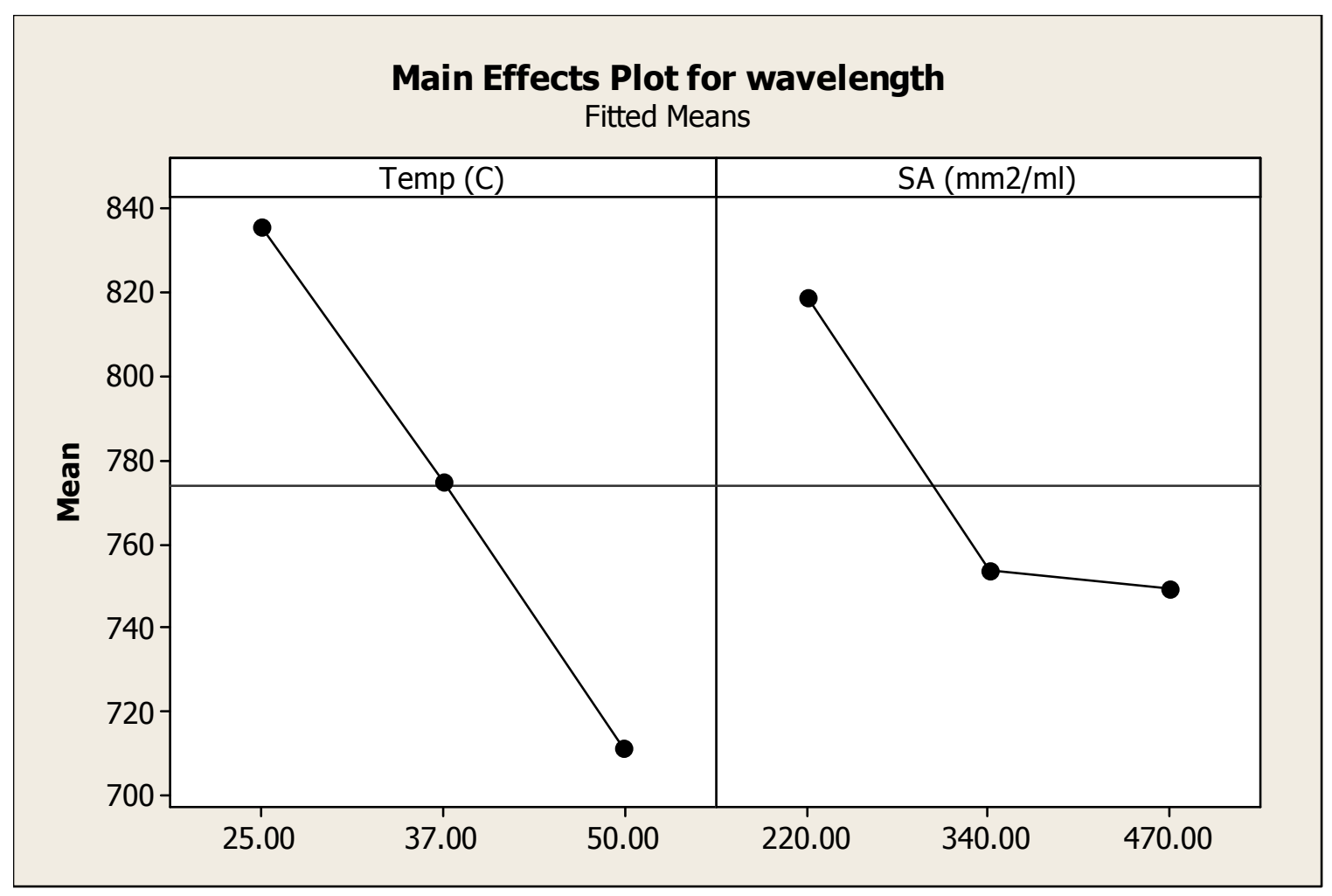

FIGURE 33 -Main Effects plots for Experiment G

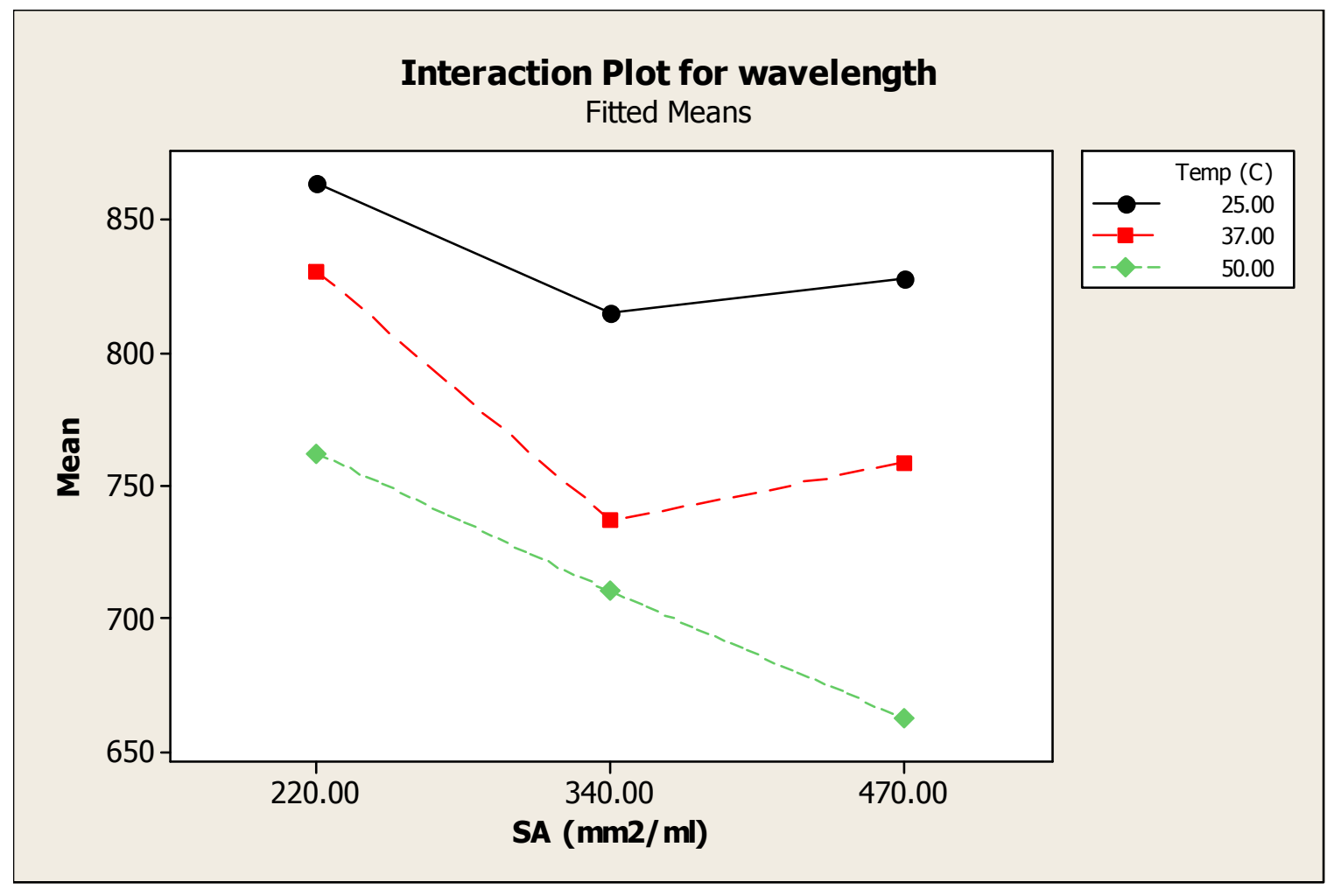

FIGURE 34 - Interaction plot for Experiment G 


\section{Experiment $\mathrm{H}$}

\section{General Linear Model: Wavelength versus Temp, SA/Vol}

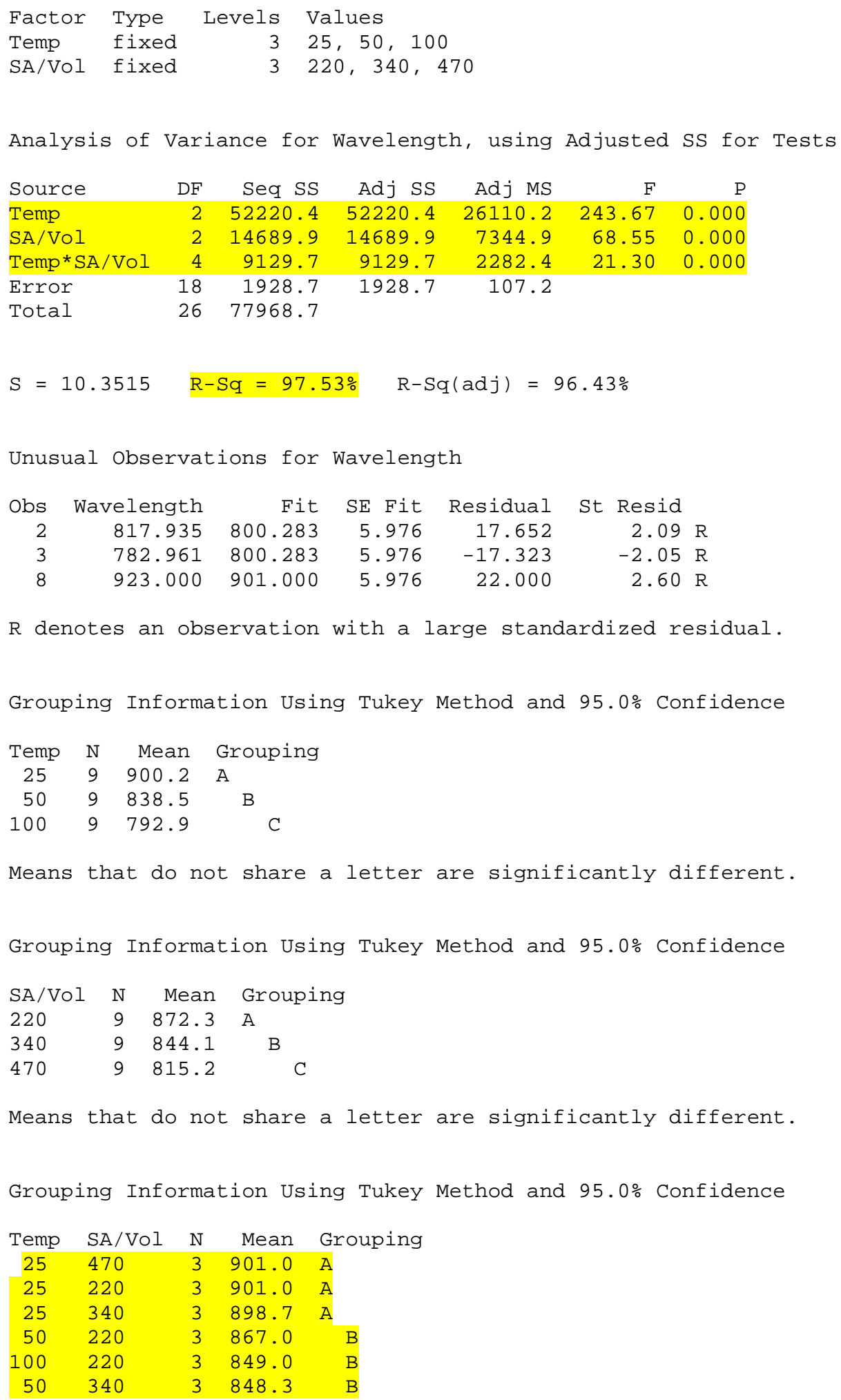




\begin{tabular}{|c|c|c|c|c|}
\hline 50 & 470 & 3 & 800.3 & C \\
\hline 100 & 340 & 3 & 785.3 & $\mathrm{C}$ \\
\hline 100 & 470 & 3 & 744.3 & \\
\hline
\end{tabular}

Means that do not share a letter are significantly different.

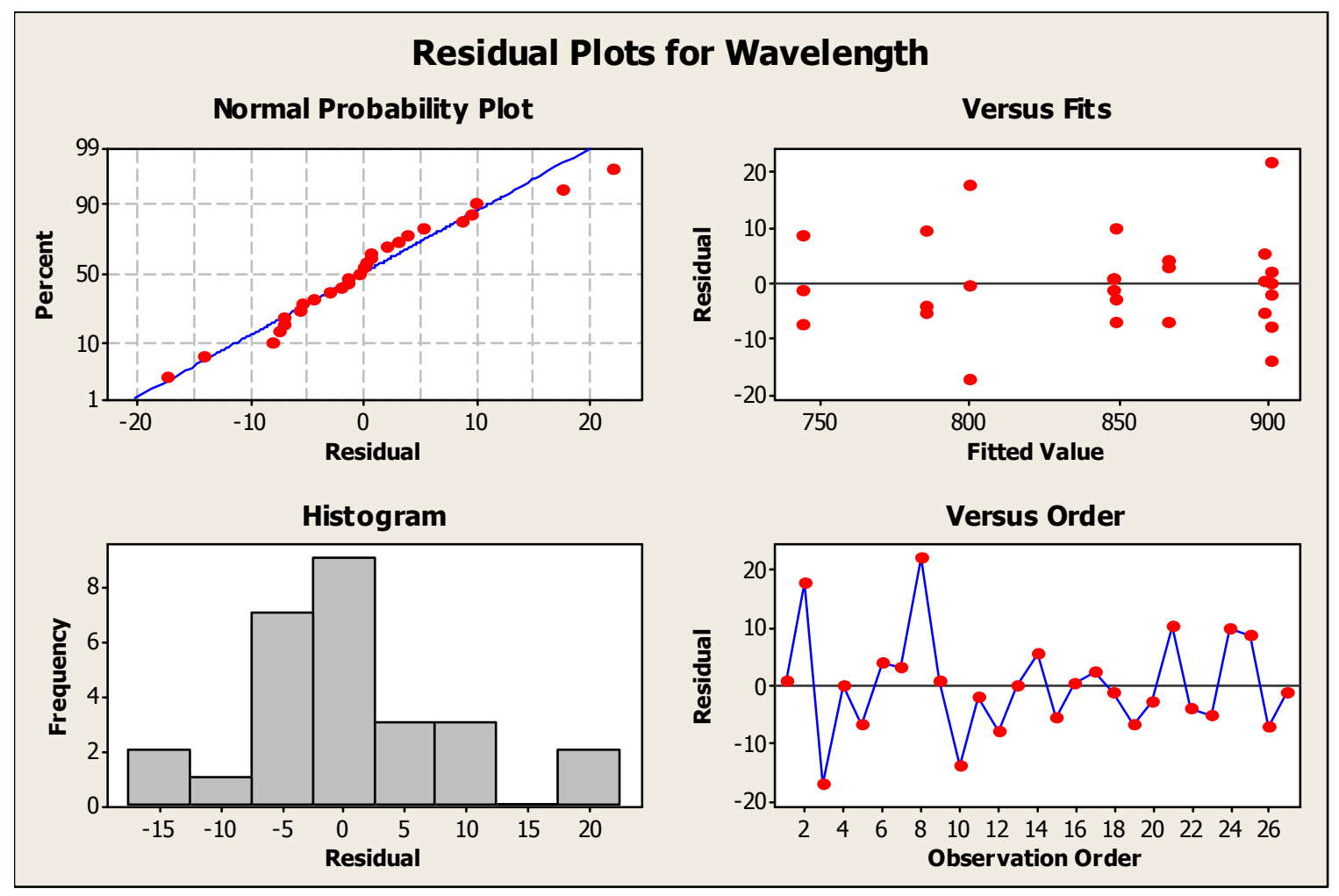

FIGURE 35 - Residual plots for Experiment $\mathrm{H}$ 


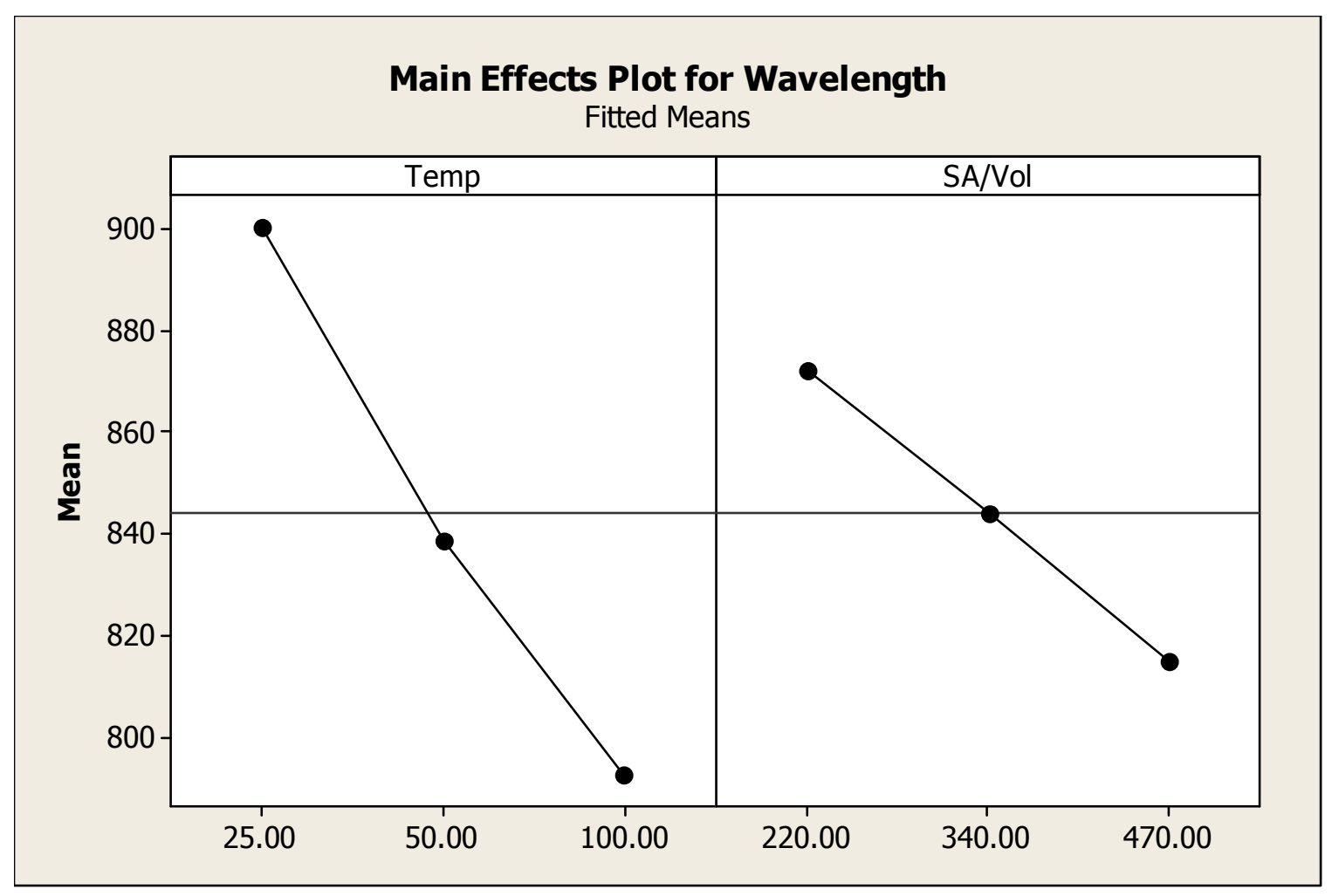

FIGURE 36 - Main effects plots for Experiment $\mathrm{H}$

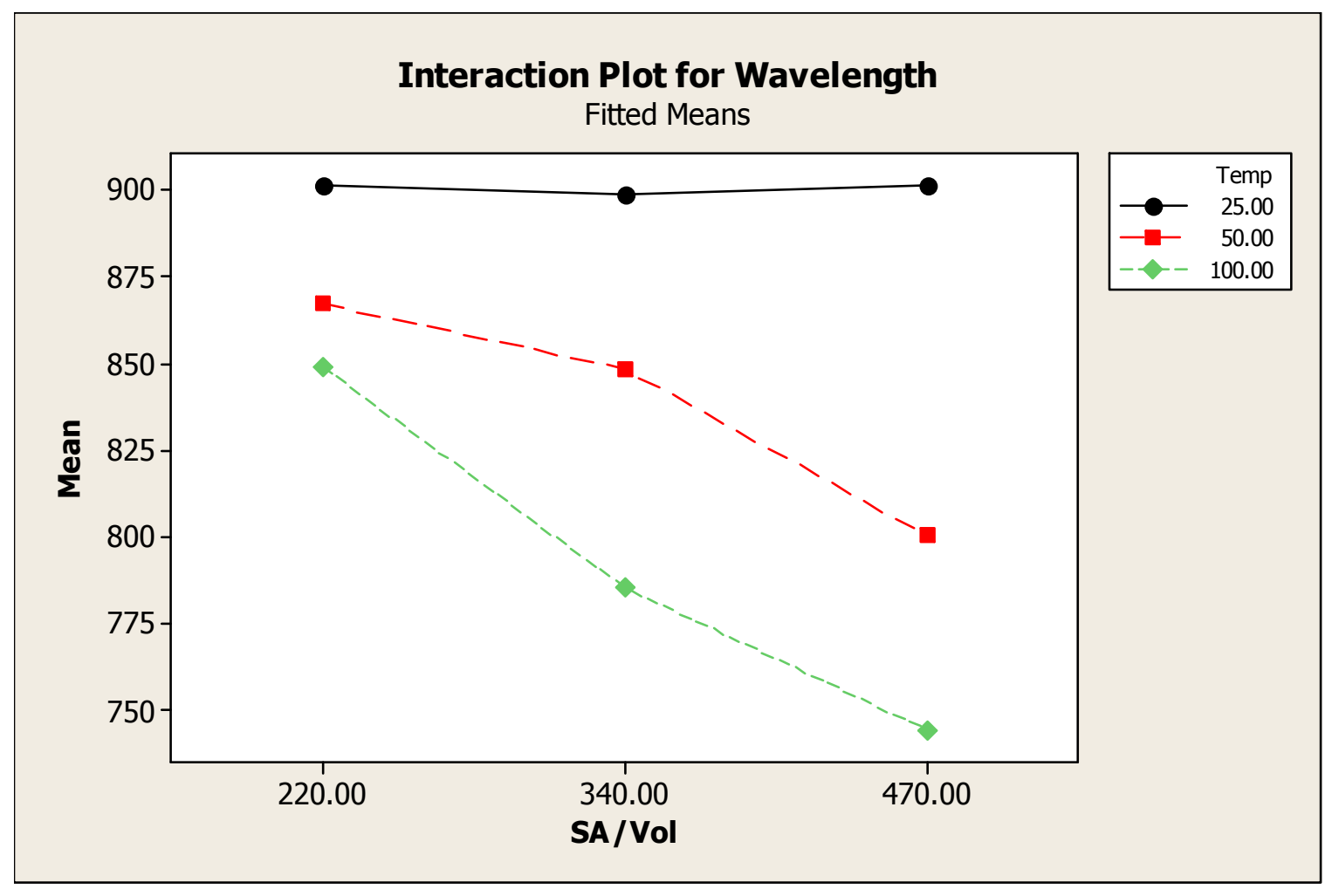

FIGURE 37 - Interaction plot for Experiment $\mathrm{H}$ 


\section{APPENDIX II}

\section{TABLE VII}

\section{EXPERIMENT G SAMPLE PROPERTIES}

\begin{tabular}{|c|c|c|c|c|c|c|c|}
\hline Sample & NIR Peak & & Ratio* & $\begin{array}{l}\text { Size } \\
(\mathrm{nm})\end{array}$ & $\begin{array}{l}\text { Temp } \\
\text { (C) }\end{array}$ & $\begin{array}{c}\mathrm{SA} \\
(\mathrm{mm} 2 / \mathrm{ml})\end{array}$ & $\begin{array}{l}\text { Time } \\
\text { (min) }\end{array}$ \\
\hline & wavelength & OD & NIR/Coll & & & & \\
\hline $\begin{array}{c}\text { Diasynth } \\
14\end{array}$ & 775.96 & 5.29 & 1.60 & 56.92 & 50.00 & 220.00 & 10.00 \\
\hline Diasynth15 & 758.95 & 5.00 & 1.55 & 59.24 & 50.00 & 220.00 & 20.00 \\
\hline Diasynth19 & 751.05 & 4.99 & 1.47 & 55.11 & 50.00 & 220.00 & 20.00 \\
\hline Avg & 761.99 & 5.09 & 1.54 & 57.09 & 50.00 & 220.00 & 20.00 \\
\hline Std & 12.73 & 0.17 & 0.06 & 2.07 & 0.00 & 0.00 & \\
\hline Diasynth29 & 812 & 4.702 & 1.61 & 57.01 & 37 & 220 & 20 \\
\hline Diasynth30 & 839 & 5.465 & 1.84 & 58.04 & 37 & 220 & 30 \\
\hline Diasynth31 & 841 & 5.436 & 1.75 & 59.71 & 37 & 220 & 20 \\
\hline Avg & 830.7 & 5.201 & 1.732 & 58.3 & 37 & 220 & 30 \\
\hline Std & 16.20 & 0.43 & 0.12 & 1.36 & 0.00 & 0.00 & \\
\hline Diasynth23 & 850 & 4.140 & 1.64 & 68.7 & 25 & 220 & 30 \\
\hline Diasynth24 & 875 & 4.965 & 1.85 & 74.63 & 25 & 220 & 30 \\
\hline Diasynth25 & 866 & 5.383 & 1.85 & 81.03 & 25 & 220 & 40 \\
\hline Avg & 863.6 & 4.829 & 1.780 & 74.8 & 25 & 260 & 40 \\
\hline Std & 12.66 & 0.63 & 0.12 & 6.17 & 0.00 & 69.28 & \\
\hline & NIR Peak & & Ratio* & $\begin{array}{l}\text { Size } \\
(\mathrm{nm})\end{array}$ & $\begin{array}{l}\text { Temp } \\
\text { (C) }\end{array}$ & $\begin{array}{c}\mathrm{SA} \\
(\mathrm{mm} 2 / \mathrm{ml})\end{array}$ & $\begin{array}{l}\text { Time } \\
\text { (min) }\end{array}$ \\
\hline Sample & wavelength & OD & NIR/Coll & & & & \\
\hline Diasynth16 & 706.00 & 4.31 & 1.41 & 49.02 & 50.00 & 340.00 & 10.00 \\
\hline Diasynth17 & 716.04 & 4.62 & 1.45 & 54.87 & 50.00 & 340.00 & 20.00 \\
\hline Diasynth18 & 708.01 & 4.63 & 1.39 & 53.69 & 50.00 & 340.00 & 20.00 \\
\hline Avg & 710.02 & 4.52 & 1.42 & 52.53 & 50.00 & 340.00 & 20.00 \\
\hline Std & 5.31 & 0.18 & 0.03 & 3.09 & 0.00 & 0.00 & \\
\hline Diasynth26 & 732 & 4.357 & 1.46 & 58.95 & 37 & 340 & 20 \\
\hline Diasynth27 & 748 & 4.357 & 1.47 & 62.75 & 37 & 340 & 20 \\
\hline Diasynth28 & 730 & 4.126 & 1.48 & 60.29 & 37 & 340 & 20 \\
\hline Avg & 736.7 & 4.280 & 1.470 & 60.7 & 37 & 340 & 20 \\
\hline Std & 9.85 & 0.13 & 0.01 & 1.93 & 0.00 & 0.00 & 0.00 \\
\hline Diasynth20 & 826.05 & 4.23 & 1.60 & 68.42 & 25.00 & 340.00 & 40.00 \\
\hline Diasynth21 & 803.01 & 4.51 & 1.69 & 69.02 & 25.00 & 340.00 & 30.00 \\
\hline Diasynth22 & 815.04 & 4.67 & 1.79 & 69.70 & 25.00 & 340.00 & 30.00 \\
\hline Avg & 814.70 & 4.47 & 1.69 & 69.05 & 25.00 & 340.00 & 40.00 \\
\hline Std & 11.53 & 0.22 & 0.10 & 0.64 & 0.00 & 0.00 & \\
\hline
\end{tabular}




\begin{tabular}{|c|c|c|c|c|c|c|c|}
\hline Diasynth32 & 659 & 3.265 & 1.11 & 51.52 & 50 & 470 & 10 \\
\hline Diasynth33 & 661 & 3.595 & 1.17 & 54.11 & 50 & 470 & 10 \\
\hline Diasynth34 & 667 & 3.623 & 1.21 & 53.26 & 50 & 470 & 10 \\
\hline Avg & 662.3 & 3.494 & 1.162 & 53.0 & 50 & 470 & 10 \\
\hline Std & 4.2 & 0.199 & 0.0 & 1.32 & 0.0 & 0.0 & 0.0 \\
\hline Diasynth35 & 745 & 4.042 & 1.44 & 59.31 & 37 & 470 & 20 \\
\hline Diasynth36 & 761 & 4.535 & 1.47 & 60.83 & 37 & 470 & 20 \\
\hline Diasynth37 & 769 & 4.264 & 1.50 & 62.43 & 37 & 470 & 20 \\
\hline Avg & 758.3 & 4.280 & 1.468 & 60.9 & 37 & 470 & 20 \\
\hline Std & 12.2 & 0.247 & 0.0 & 1.56 & 0.0 & 0.0 & 0.0 \\
\hline Diasynth38 & 830 & 4.412 & 1.70 & 69.25 & 25 & 470 & 30 \\
\hline Diasynth39 & 823 & 4.377 & 1.68 & 74.93 & 25 & 470 & 30 \\
\hline Diasynth40 & 831 & 4.479 & 1.67 & 68.37 & 25 & 470 & 30 \\
\hline Avg & 828.0 & 4.423 & 1.682 & 70.9 & 25 & 470 & 30 \\
\hline Std & 4.4 & 0.052 & 0.0 & 3.56 & 0.0 & 0.0 & 0.0 \\
\cline { 1 - 5 } & & & & & & & \\
\cline { 1 - 5 } & & & & &
\end{tabular}

TABLE VIII

EXPERIMENT H SAMPLE PROPERTIES

\begin{tabular}{|c|c|c|c|c|c|c|c|}
\hline Sample & \multicolumn{2}{|c|}{ NIR Peak } & Ratio* & $\begin{array}{c}\text { Size } \\
(\mathrm{nm})\end{array}$ & $\begin{array}{c}\text { Temp } \\
(\mathrm{C})\end{array}$ & $\begin{array}{c}\text { SA } \\
(\mathrm{mm} 2 / \mathrm{ml})\end{array}$ & $\begin{array}{c}\text { Time } \\
(\mathrm{min})\end{array}$ \\
\hline & wavelength & OD & NIR/Coll & \multicolumn{4}{|l|}{} \\
\hline MR19 & 923 & 7.536 & 2.19 & 72 & 25 & 220 & 60 \\
\hline MR20 & 887 & 7.288 & 2.15 & 86.37 & 25 & 220 & 60 \\
\hline MR21 & 893 & 6.823 & 2.06 & 84.89 & 25 & 220 & 60 \\
\hline Avg & 901.0 & 7.2 & 2.1 & 81.1 & 25.0 & 220.0 & 60.0 \\
\hline Std & 19.29 & 0.36 & 0.06 & 7.90 & 0.00 & 0.00 & 0.00 \\
\hline
\end{tabular}

\begin{tabular}{|c|c|c|c|c|c|c|c|}
\hline Sample & \multicolumn{2}{|c|}{ NIR Peak } & Ratio* & $\begin{array}{c}\text { Size } \\
(\mathrm{nm})\end{array}$ & $\begin{array}{c}\text { Temp } \\
(\mathrm{C})\end{array}$ & $\begin{array}{c}\text { SA } \\
(\mathrm{mm} 2 / \mathrm{ml})\end{array}$ & $\begin{array}{c}\text { Time } \\
(\mathrm{min})\end{array}$ \\
\hline & wavelength & OD & NIR/Coll & \multicolumn{4}{|l|}{} \\
\hline MR22 & 904 & 5.884 & 1.94 & 76.3 & 25 & 340 & 60 \\
\hline MR23 & 893 & 6.207 & 2.00 & 78.43 & 25 & 340 & 60 \\
\hline MR24 & 899 & 6.988 & 2.00 & 76.33 & 25 & 340 & 60 \\
\hline Avg & 898.7 & 6.359 & 1.982 & 77.0 & 25 & 340 & 60 \\
\hline Std & 5.49 & 0.57 & 0.03 & 1.22 & 0.00 & 0.00 & 34.64
\end{tabular}

\begin{tabular}{|l|l|l|l|c|c|c|}
\hline Sample & NIR Peak & Ratio* $^{*}$ & $\begin{array}{c}\text { Size } \\
(\mathrm{nm})\end{array}$ & $\begin{array}{c}\text { Temp } \\
(\mathrm{C})\end{array}$ & $\begin{array}{c}\text { SA } \\
(\mathrm{mm} 2 / \mathrm{ml})\end{array}$ & $\begin{array}{c}\text { Time } \\
(\mathrm{min})\end{array}$ \\
\hline
\end{tabular}




\begin{tabular}{|c|c|c|c|c|c|c|c|} 
& wavelength & OD & NIR/Coll & \multicolumn{4}{|l|}{} \\
\cline { 1 - 7 } MR25 & 903 & 5.282 & 2.00 & 82.27 & 25 & 470 & 60 \\
\hline MR20 & 899 & 7.288 & 2.15 & 86.37 & 25 & 470 & 60 \\
\hline MR21 & 901 & 6.823 & 2.06 & 84.89 & 25 & 470 & 60 \\
\hline Avg & 901.0 & 6.5 & 2.1 & 84.5 & 25.0 & 470.0 & 60.0 \\
\hline Std & 2.00 & 1.05 & 0.08 & 2.08 & 0.00 & 0.00 & 0.00
\end{tabular}

\begin{tabular}{|c|c|c|c|c|c|c|c|}
\hline Sample & NIR Peak & & Ratio* & $\begin{array}{c}\text { Size } \\
(\mathrm{nm})\end{array}$ & $\begin{array}{c}\text { Temp } \\
(\mathrm{C})\end{array}$ & $\begin{array}{c}\text { SA } \\
(\mathrm{mm} 2 / \mathrm{ml})\end{array}$ & $\begin{array}{c}\text { Time } \\
(\mathrm{min})\end{array}$ \\
\hline & wavelength & OD & NIR/Coll & & \multicolumn{3}{|l}{} \\
\hline MR16 & 860.00 & 6.19 & 2.07 & 87.70 & 50 & 220 & 30 \\
\hline MR17 & 870.93 & 6.18 & 2.12 & 73.20 & 50 & 220 & 30 \\
\hline MR18 & 869.99 & 6.35 & 1.97 & 94.20 & 50 & 220 & 30 \\
\hline Avg & 866.97 & 6.24 & 2.05 & 85.03 & 50 & 220 & 30 \\
\hline Std & 6.06 & 0.09 & 0.08 & 10.75 & & &
\end{tabular}

\begin{tabular}{|c|c|c|c|c|c|c|c|}
\hline Sample & NIR Peak & & Ratio* & $\begin{array}{c}\text { Size } \\
(\mathrm{nm})\end{array}$ & $\begin{array}{c}\text { Temp } \\
(\mathrm{C})\end{array}$ & $\begin{array}{c}\text { SA } \\
(\mathrm{mm} 2 / \mathrm{ml})\end{array}$ & $\begin{array}{c}\text { Time } \\
(\mathrm{min})\end{array}$ \\
\hline & wavelength & OD & NIR/Coll & & & & \\
\hline MR1 & 849.01 & 4.92 & 1.73 & 104.60 & 50.00 & 340.00 & 30.00 \\
\hline MR2 & 849.01 & 4.55 & 1.76 & 74.65 & 50.00 & 340.00 & 30.00 \\
\hline MR3 & 846.97 & 5.43 & 1.74 & 76.76 & 50.00 & 340.00 & 30.00 \\
\hline Avg & 848.33 & 4.97 & 1.74 & 85.34 & 50.00 & 340.00 & 30.00 \\
\hline Std & 1.18 & 0.45 & 0.01 & 16.72 & 0.00 & 0.00 & 0.00 \\
\hline
\end{tabular}

\begin{tabular}{|c|c|c|c|c|c|c|c|}
\hline Sample & NIR Peak & & Ratio* & $\begin{array}{c}\text { Size } \\
(\mathrm{nm})\end{array}$ & $\begin{array}{c}\text { Temp } \\
(\mathrm{C})\end{array}$ & $\begin{array}{c}\text { SA } \\
(\mathrm{mm} 2 / \mathrm{ml})\end{array}$ & $\begin{array}{c}\text { Time } \\
(\mathrm{min})\end{array}$ \\
\hline & wavelength & OD & NIR/Coll & & & & \\
\hline MR13 & 817.94 & 4.91 & 1.56 & 76.63 & 50.00 & 470.00 & 20.00 \\
\hline MR14 & 782.96 & 4.49 & 1.48 & 76.85 & 50.00 & 470.00 & 20.00 \\
\hline MR15 & 799.95 & 4.70 & 1.54 & 64.72 & 50.00 & 470.00 & 20.00 \\
\hline Avg & 800.28 & 4.70 & 1.53 & 72.73 & 50.00 & 470.00 & 20.00 \\
\hline Std & 17.49 & 0.21 & 0.04 & 6.94 & 0.00 & 0.00 & 0.00 \\
\hline
\end{tabular}

\begin{tabular}{|c|c|c|c|c|c|c|c|}
\hline Sample & NIR Peak & & Ratio* & $\begin{array}{c}\text { Size } \\
(\mathrm{nm})\end{array}$ & $\begin{array}{c}\text { Temp } \\
(\mathrm{C})\end{array}$ & $\begin{array}{c}\text { SA } \\
(\mathrm{mm} 2 / \mathrm{ml})\end{array}$ & $\begin{array}{c}\text { Time } \\
(\mathrm{min})\end{array}$ \\
\hline & wavelength & OD & NIR/Coll & & & & \\
\hline MR4 & 842.07 & 5.67 & 1.82 & 68.03 & 100.00 & 220.00 & 20.00 \\
\hline MR5 & 846.02 & 5.17 & 1.78 & 67.54 & 100.00 & 220.00 & 20.00 \\
\hline MR6 & 859.05 & 6.52 & 1.86 & 68.33 & 100.00 & 220.00 & 20.00 \\
\hline Avg & 849.05 & 5.78 & 1.82 & 67.97 & 100.00 & 220.00 & 20.00 \\
\hline Std & 8.89 & 0.68 & 0.04 & 0.40 & 0.00 & 0.00 & 0.00 \\
\hline
\end{tabular}




\begin{tabular}{|c|c|c|c|c|c|c|c|}
\hline Sample & NIR Peak & & Ratio* & $\begin{array}{c}\text { Size } \\
(\mathrm{nm})\end{array}$ & $\begin{array}{c}\text { Temp } \\
(\mathrm{C})\end{array}$ & $\begin{array}{c}\text { SA } \\
(\mathrm{mm} 2 / \mathrm{ml})\end{array}$ & $\begin{array}{c}\text { Time } \\
(\mathrm{min})\end{array}$ \\
\hline & wavelength & OD & NIR/Coll & & & & \\
\hline MR10 & 781.00 & 5.96 & 1.63 & 67.03 & 100.00 & 340.00 & 20.00 \\
\hline MR11 & 780.02 & 5.43 & 1.64 & 69.20 & 100.00 & 340.00 & 20.00 \\
\hline MR12 & 794.95 & 5.85 & 1.62 & 61.94 & 100.00 & 340.00 & 20.00 \\
\hline Avg & 785.33 & 5.75 & 1.63 & 66.06 & 100.00 & 340.00 & 20.00 \\
\hline Std & 8.35 & 0.28 & 0.01 & 3.73 & 0.00 & 0.00 & 0.00 \\
\hline
\end{tabular}

\begin{tabular}{|c|c|c|c|c|c|c|c|}
\hline Sample & NIR Peak & & Ratio* & $\begin{array}{c}\text { Size } \\
(\mathrm{nm})\end{array}$ & $\begin{array}{c}\text { Temp } \\
(\mathrm{C})\end{array}$ & $\begin{array}{c}\text { SA } \\
(\mathrm{mm} 2 / \mathrm{ml})\end{array}$ & $\begin{array}{c}\text { Time } \\
(\mathrm{min})\end{array}$ \\
\hline wavelength & OD & NIR/Coll & & & & \\
\hline MR7 & 753.02 & 4.93 & 1.53 & 63.93 & 100.00 & 470.00 & 10.00 \\
\hline MR8 & 737.01 & 4.47 & 1.45 & 64.07 & 100.00 & 470.00 & 10.00 \\
\hline MR9 & 742.97 & 4.33 & 1.43 & 61.35 & 100.00 & 470.00 & 10.00 \\
\hline Avg & 744.34 & 4.57 & 1.47 & 63.12 & 100.00 & 470.00 & 10.00 \\
\hline Std & 8.09 & 0.31 & 0.05 & 1.53 & 0.00 & 0.00 & 0.00 \\
\hline
\end{tabular}




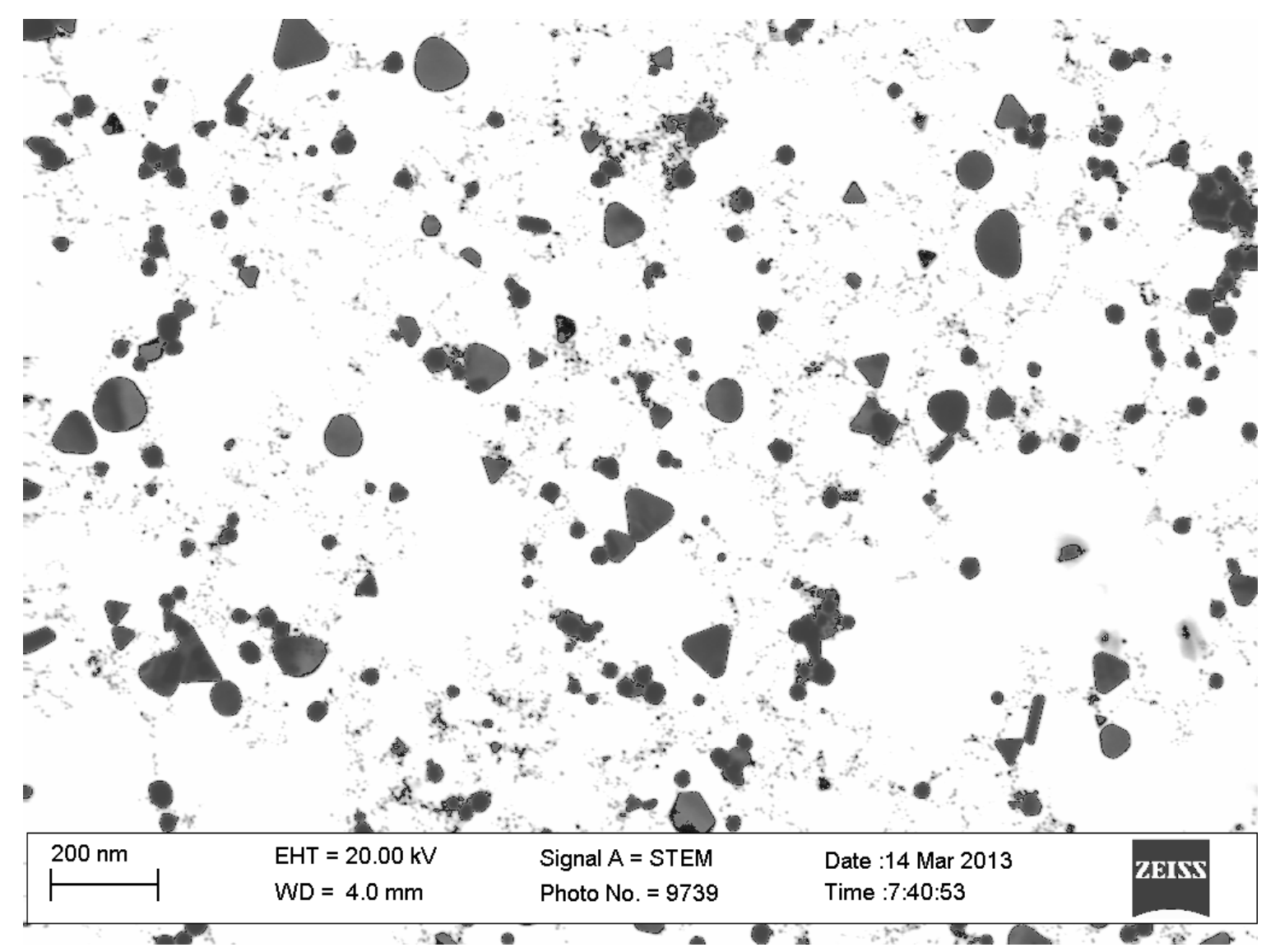

FIGURE 38 - STEM Image 01 


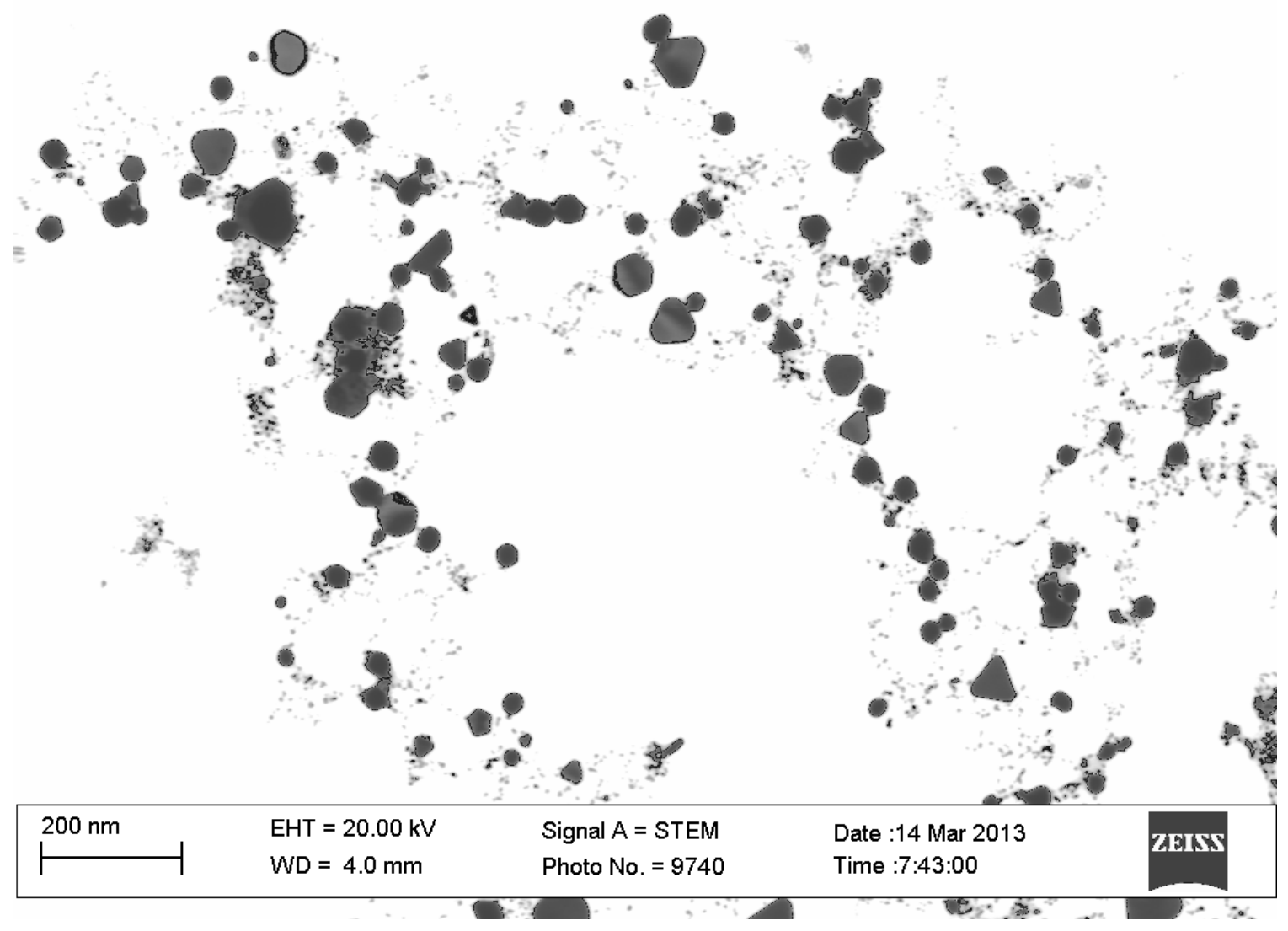

FIGURE 39 - STEM Image 02 


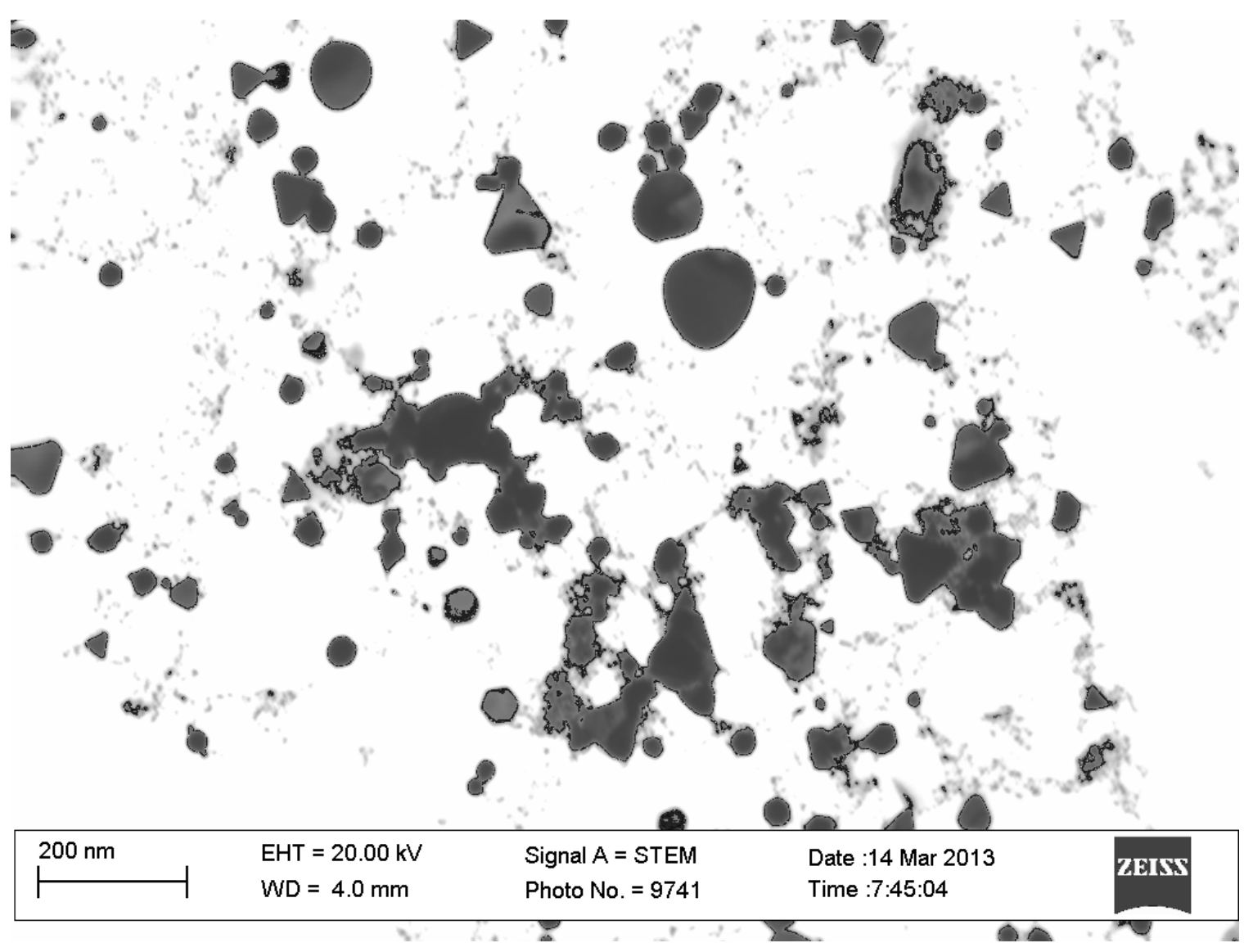

FIGURE 40 - STEM Image 03 


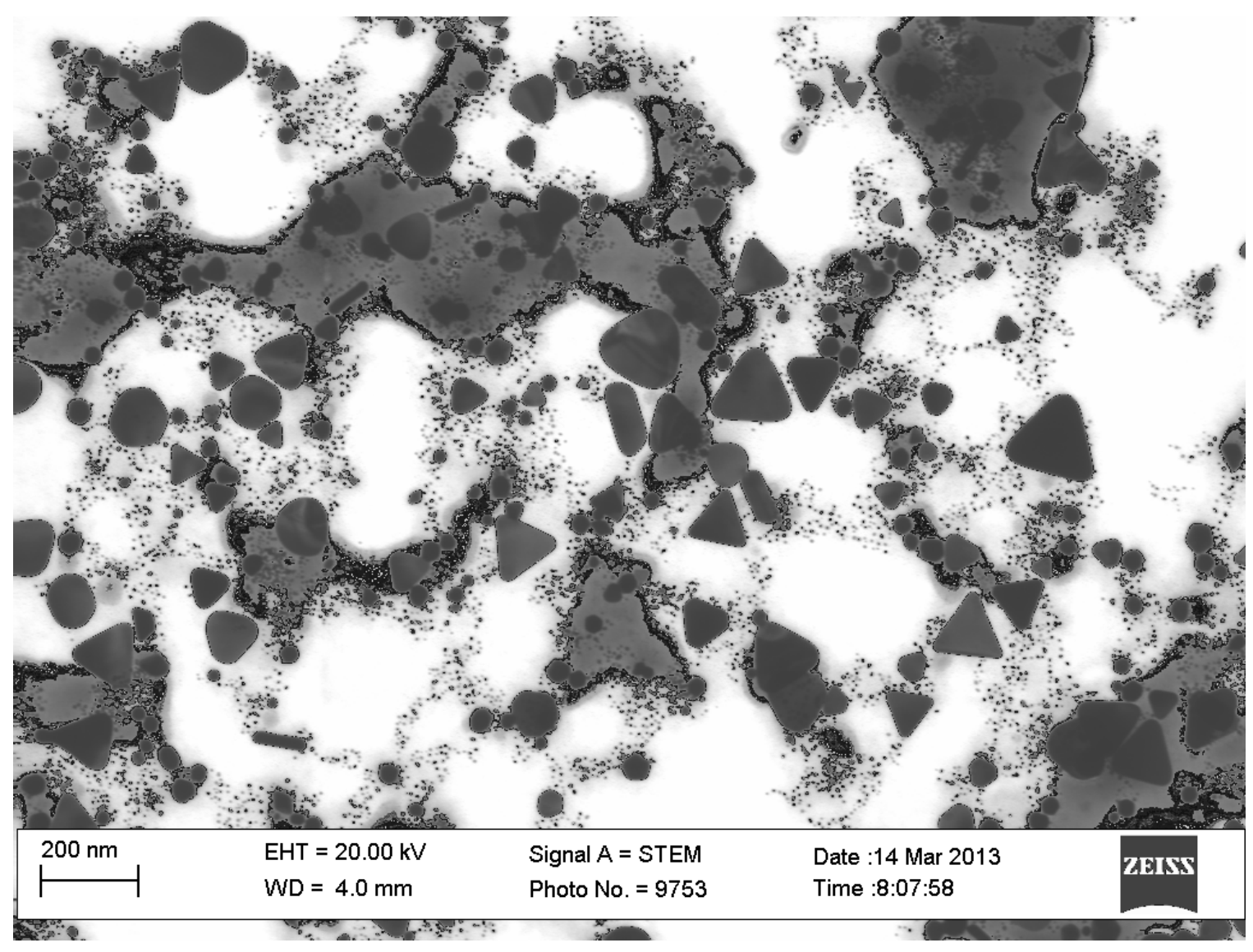

FIGURE 41 - STEM Image 04 


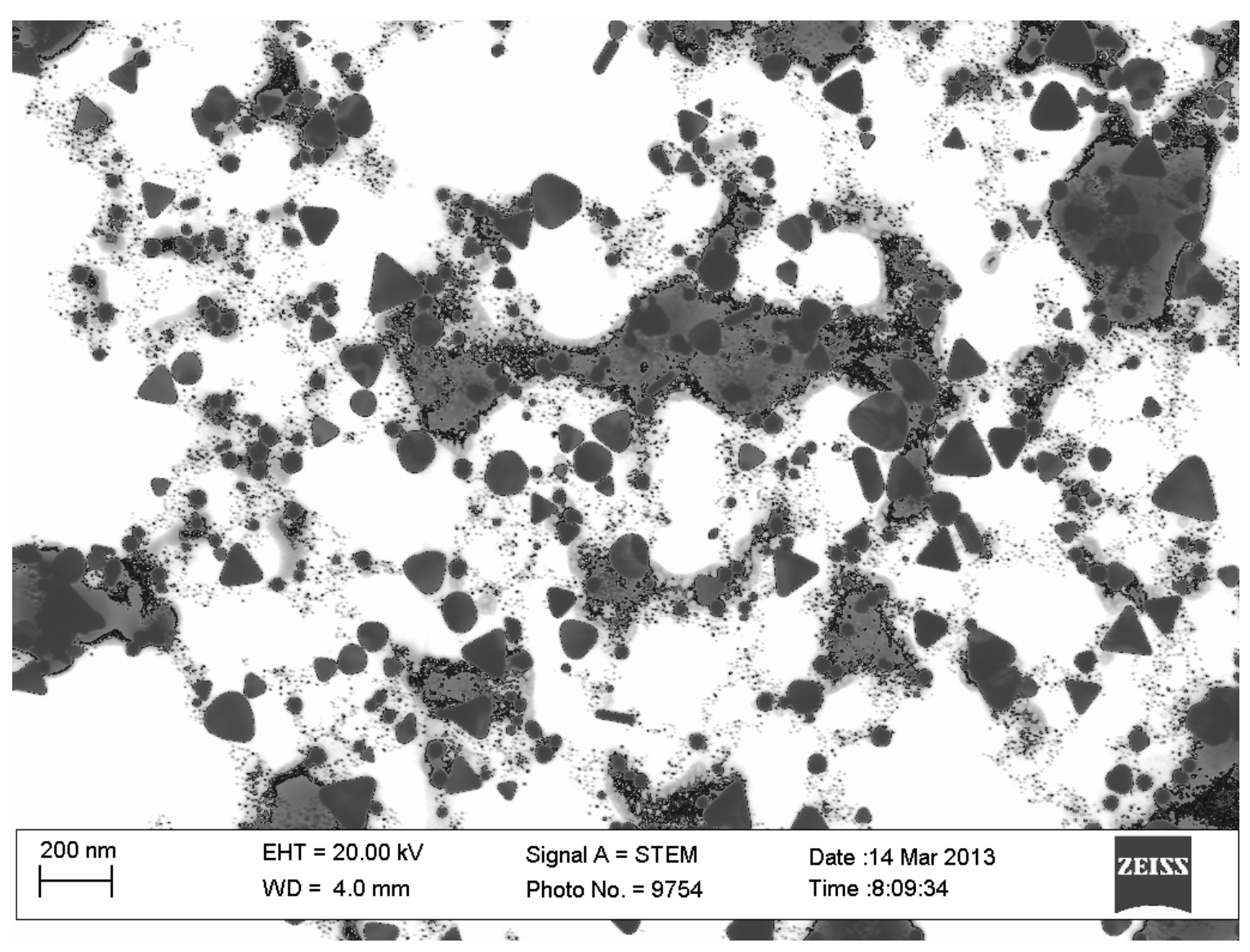

FIGURE 42 - STEM Image 05 


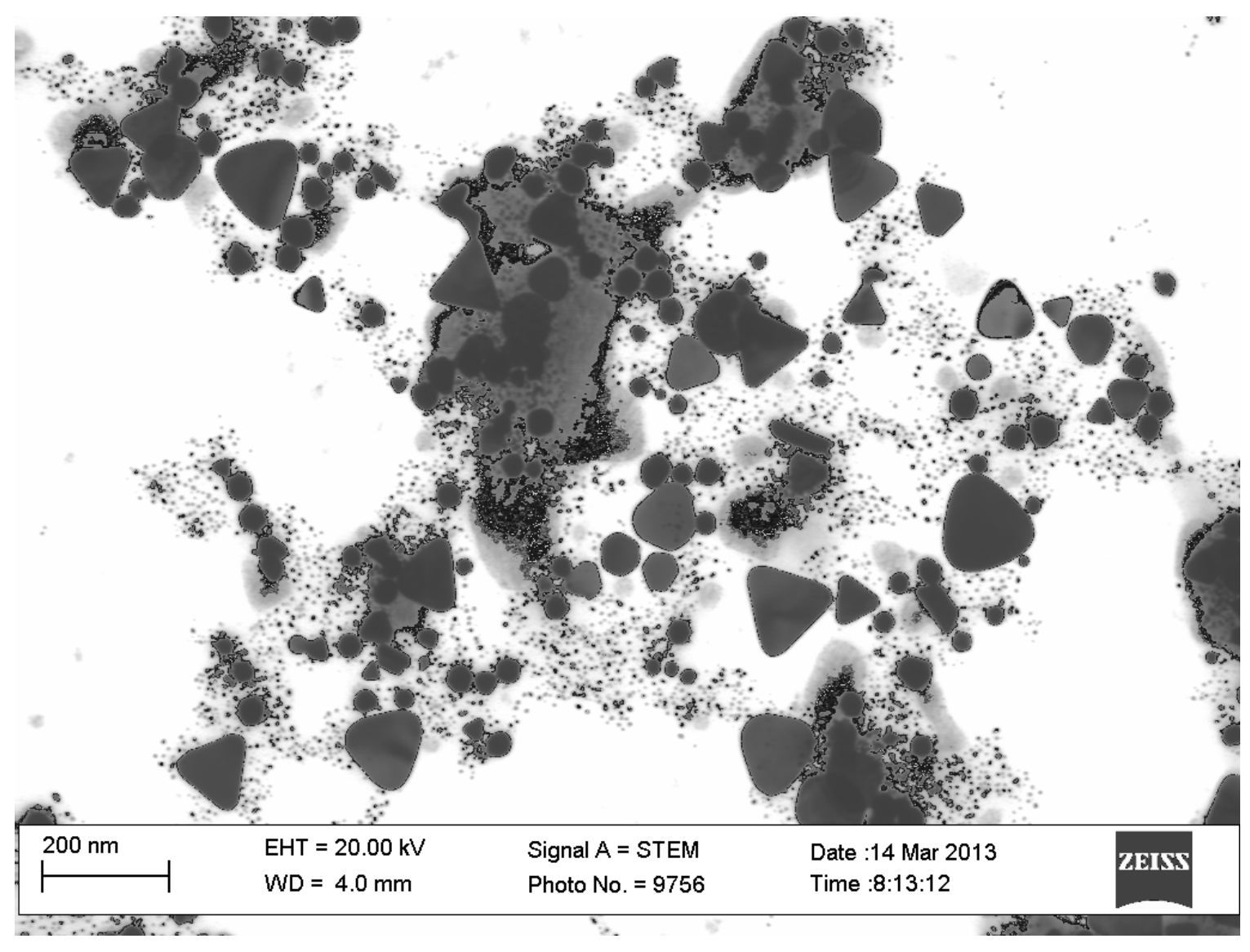

FIGURE 43 - STEM Image 06 


\section{REFERENCES}

Atwater, H.A. and Polman, A. (2010). "Plasmonics for improved photovoltaic devices." Nature Materials 9: 205-213.

Averitt, R., Sarkar, D., and Halas, N. (1997). "Plasmon Resonance Shifts of AuCoated Au2S Nanoshells: Insight into Multicomponent Nanoparticle Growth" Physical Review Letters 78: 4217-4220.

Averitt, R.D., Westcott, S.L., and Halas, N.J. (1999). "Linear optical properties of gold nanoshells.” Journal of the Optical Society of America 16: 1824-1832.

Azzazy, H., and Mansour, M. (2009). "In vitro diagnostic prospects of nanoparticles." Clinica Chimica Acta 403: 1-8.

Bode, A. and Dong, Z. (2009). "Cancer prevention research-then and now." Nature Review Cancer 9:508-516.

Cai, W., Gao, T., Hong, H., and Sun, J. (2008) “Applications of gold nanoparticles in cancer nanotechnology." Nanotechnology, Science and Applications 1: 17-32

Cao, Y.C., Jin, R., and Mirkin, C.A. (2002). "Nanoparticles with Raman Spectroscopic Fingerprints for DNA and RNA Detection” Science 297: 1536-1540.

Chandran, S.P., Chaudhary M., Pasricha R., Ahmad, A. and Sastry, M. (2006) "Synthesis of Gold Nanotriangles and Silver Nanoparticles Using Aloe vera Plant Extract” Biotechnology Progress 22: 577-583.

Diao, J. and Chen, H. (2006). "Near infrared surface plasmon resonance of gold tabular nanostructures in the HAuCl4-Na2S reaction." The Journal of Chemical Physics 124: 116103.

El-Sayed, I., Huang, X., and El-Sayed, M. (2005). "Surface Plasmon Resonance Scattering and Absorption of anti-EGFR Antibody Conjugated Gold Nanoparticles in Cancer Diagnostics: Applications in Oral Cancer." Nano Letters 5: 829-834.

Faraday, M. (1857). "The Bakerian Lecture: Experimental Relations of Gold (and Other Metals) to Light." Philosophical Transactions of the Royal Society 147: 145181.

Gobin, A.M., Watkins, E., Quevedo, E., Colvin, V., and West, J. (2010). "NearInfrared-Resonant Gold/Gold Sulfide Nanoparticles as a Photothermal Cancer Therapeutic Agent" Small 6: 745-752. 
Gosh, S.K. and Pal, T. (2007). "Interparticle Coupling Effect on the Surface Plasmon Resonance of Gold Nanoparticles: From Theory to Applications." Chemical Reviews 107: 4797-4862.

He, J., Kunitake, T., and Nakao, A. (2003). “Facile In Situ Synthesis of Noble Metal Nanoparticles in Porous Cellulose Fibers.” Chem. Mater. 15: 4401-4406.

Hirsch, L., Stafford, R., Bankson, J., Sershen, S., Rivera, B., Price, R., Hazle, J., Halas, N., and West, J. (2003). "Nanoshell-mediated near-infrared thermal therapy of tumors under magnetic resonance guidance." PNAS 100: 13549-13554.

Huang, D., Liao, F., Molesa, S., Redinger, D., and Subramanian, V. (2003). "PlasticCompatible Low Resistance Printable Gold Nanoparticle Conductors for Flexible Electronics." Journal of Electrochemical Society 150: G412-G417.

Huang, X., Jain, P., El-Sayed, I., and El-Sayed, M. (2008). "Plasmonic photothermal therapy (PPTT) using gold nanoparticles.” Lasers Med. Sci.23: 217-228.

Ito, Y, Kennan, R.P., Watanabe, E., and Koizumi H. (2000). "Assessment of heating effects in skin during continuous wave near infrared spectroscopy." J. Biomed Opt. 5:383-390.

Jain, S., Hirst, D., and O’Sullivan, J.M. (2012). "Gold nanoparticles as novel agents for cancer therapy." The British Journal of Radiology 85: 101-113.

Klar, T., Perner, M., Grosse, S., von Plessen, G., Spirkl, W., and Feldmann, J. (1998). "Surface-Plasmon Resonances in Single Metallic Nanoparticles." Physical Review Letters 80: 4249-4252.

Link, S. and El-Sayed, M.A. (1999a). "Spectral Properties and Relaxation Dynamics of Surface Plasmon Electronic Oscillations in Gold and Silver Nanodots and Nanorods." J. Phys. Chem. B 103: 8410-8426.

Link, S. and El-Sayed, M.A. (1999b). "Size and Temperature Dependence of the Plasmon Absorption of Colloidal Gold Nanoparticles." Journal of Physical Chemistry 103: 4212-4217.

Liu, X., Atwater, M., Wang, J., and Huo, Q. (2006). "Extinction coefficient of gold nanoparticles with different sizes and different capping ligands" Colloids and Surfaces B: Biointerfaces 58: 3-7.

Loo, C., Lin, A., Hirsch, L., Lee, M., Barton, J., Halas, N., West, J., Drezek, R. (2004). "Nanoshell-Enabled Photonics-Based Imaging and Therapy of Cancer." Technology in Cancer Research \& Treatment 3: 33-40.

Mie, G. (1908). "Contributions to the optics of turbid media, particularly of colloidal metal solutions." Ann. Phys. 25,: 377-445. 
Morris, T., Copeland, H., and Szulczewski, G. (2002). "Synthesis and Characterization of Gold Sulfide Nanoparticles." Langmuir 18: 535-539.

Millstone, J., Hurst, S., Me'traux, G., Cutler, J., and Mirkin, C. (2009). “Colloidal Gold and Silver Triangular Nanoprisms.” Small 5: 646-664.

Nikoobakht, B. and El-Sayed, M. A. (2003). "Preparation and Growth Mechanism of Gold Nanorods (NRs) Using Seed-Mediated Growth Method." Chem. Mater. 15: 1957-1962

Oldenburg, S.J., Averitt, R.D., Westcott, S.L., Halas, N.J. (1999). "Nanoengineering of optical resonances." Chemical Physics Letters 288: 243-247.

Patel, Dhruvinkumar. 2012. A Novel High Yield Process For Gold Sulfide Nanoparticle Synthesis Via Shifting Equilibrium of Self-Assembling Reaction. Master of Engineering thesis, University of Louisville.

Pinto, R. and Neves, M. (2012). Composites of Cellulose and Metal Nanoparticles. In Nanocomposites - New Trends and Development (pp. 73-96). InTech

Schwartzberg, A.M., Grant, C.D., van Buuren, T., and Zhang, J.Z. (2007).

"Reduction of $\mathrm{HAuCl}_{4}$ by $\mathrm{Na}_{2} \mathrm{~S}$ Revisited: The Case for Au Nanoparticle Aggregates and Against $\mathrm{Au}_{2} \mathrm{~S} / \mathrm{Au}$ Core/Shell Particles." J. Phys. Chem. C 111: 8892-8901.

Thompson, D.(2007). "Using gold nanoparticles for catalysis” NanoToday 2: 40-43.

Tréguer-Delapierre, M., Majimel, J., Mornet, S., Duguet, E., Ravaine, S. (2008). "Synthesis of non-spherical gold nanoparticles." Gold Bulletin 41: 195-207.

Weissleder, R. (2001). “ A clearer vision for in vivo imaging.” Nature Biotechnology 19: $316-317$.

Willets, K. and Van Duyne, R. (2007). "Localized Surface Plasmon Resonance Spectroscopy and Sensing." Annu. Rev. Phys. Chem. 58: 267-97.

Young, J., Figueroa, E., and Drezek, R. (2012). "Tunable Nanostructures as Photothermal Theranostic Agents." Annals of Biomedical Engineering 40: 438-459.

Young, K., Jones, M., Zhanga, J. Macfarlanea, J., Esquivel-Sirventa, R., Nape, R., Wuc, J., Schatza, G., Leef, B., and Mirkin, C. (2012). “Assembly of reconfigurable one-dimensional colloidal superlattices due to a synergy of fundamental nanoscale forces." PNAS 109: 2240-2245.

Yu, Y., Chang, S., Lee, C., and Wang, C. (1997). "Gold Nanorods: Electrochemical Synthesis and Optical Properties." J. Phys. Chem. B 101: 6661-6664 
Zharov, V.P., Mercer, K.E., Galitovskaya, E.N., Smeltzer, M.S. (2006).

"Photothermal Nanotherapeutics and Nanodiagnostics for Selective Killing of

Bacteria Targeted with Gold Nanoparticles." Biophysical Journal 90: 619-627.

Zhang, G., Jasinski, J., Howell, J., Patel, D., Stephens, D., and Gobin, A.M. (2012). Tunability and stability of gold nanoparticles obtained from chloroauric acid and sodium thiosulfate reaction." Nanoscale Res Lett. 7: 337.

Zhou, H.S., Honma, I., and Komiyama, H. (1994). "Controlled synthesis and quantum-size effect in gold-coated nanoparticles." Physical Review B 50: 1205212056. 